$$
\begin{gathered}
\text { UNIVERSIDADE DE SÃO PAULO } \\
\text { FFCLRP - DEPARTAMENTO DE FÍSICA } \\
\text { PÓS-GRADUAÇÃO EM FÍSICA APLICADA A } \\
\text { MEDICINA E BIOLOGIA }
\end{gathered}
$$

Dosimetria gel no controle de qualidade tridimensional para Radioterapia de Intensidade modulada (IMRT) de Próstata

Matheus Antonio da Silveira

$$
\text { Ribeirão Preto - SP }
$$

2014 
Matheus Antonio da Silveira

\section{Dosimetria gel no controle de qualidade tridimensional para Radioterapia de Intensidade modulada (IMRT) de Próstata}

Dissertação de mestrado apresentado ao Departamento de Física da Faculdade de Filosofia Ciências e Letras de Ribeirão Preto da Universidade de São Paulo como parte das exigências para obtenção do título de Mestre em ciências.

Área de concentração: Física aplicada à medicina e biologia.

Orientador: Prof. Dr. Oswaldo Baffa Filho.

Ribeirão Preto 
Autorizo a divulgação parcial ou total para fins de estudo e pesquisa, por qualquer meio convencional ou eletrônico, desde que citada à fonte.

\section{Catalogação da publicação \\ Departamento de Física \\ Faculdade Filosofia Ciências e Letras de Ribeirão Preto da \\ Universidade de São Paulo}

Silveira, Matheus Antonio.

Dosimetria gel no controle de qualidade tridimensional para Radioterapia de Intensidade modulada (IMRT) de Próstata.

Ribeirão Preto, 2014.

109 p il. $30 \mathrm{~cm}$.

Dissertação de mestrado apresentado ao Departamento de Física da Faculdade de Filosofia Ciências e Letras de Ribeirão Preto da Universidade de São Paulo - Área de concentração: Física aplicada à medicina e biologia.

Orientador: Prof. Dr. Oswaldo Baffa Filho

1. Dosimetria gel. 2. Gel Magic-f. 3. IMRT 4. Controle de qualidade em IMRT. 5. Imagens por Ressonância Magnética Nuclear. 
Dedico esse trabalho a minha familia, e em memória da minha avó Iracema de Oliveira. 


\section{Agradecimentos}

Ao meu orientador Prof. Dr, Oswaldo Baffa Filho, pela oportunidade, sabedoria em sua orientação, apoio, incentivo, paciência e amizade, no decorrer do desenvolvimento do trabalho.

À Professora Dr. Juliana Fernandes pelos seus ensinamentos em radioterapia e nas irradiações necessárias para esse trabalho, a professora Dr. Patrícia Nicolucci pelo conhecimento transmitido em dosimetria e física da radioterapia, ao professor Dr. Carlos Garrido que pelos ensinamentos em Ressonância magnética e todos os Professores do Departamento de Física.

Aos funcionários do Departamento de Física, Nilza, Ricardo, Sonia Loureço, Serginho, Aziane e Carlão, por toda ajuda que necessitei.

Aos meus pais, meu irmão e avós que sempre me incentivaram, apoiaram e estão comigo em todos os momentos da minha vida, tanto nos momentos de alegria como de tribulações.

À minha namorada Natália Malta, que está sempre ao meu lado, me apoiando em cada etapa da minha vida com seu amor, companheirismo, carinho e compreensão.

Ao Centro de Radioterapia de São Carlos que proporcionou as irradiações desse trabalho.

Ao Hospital das Clínicas de Ribeirão Preto, pessoal da radioterapia pelas tomografias computadorizadas necessárias e ao pessoal da ressonância magnética, pela ajuda nas aquisições das imagens.

Agradeço a todos os meus colegas de pós-graduação, por caminharem junto a mim durante esse período de crescimento.

À CNPq pelo apoio financeiro.

À USP pelo local de trabalho e toda sua infraestrutura.

À Nossa Senhora das Graças, minha padroeira por sua intercessão nessa etapa da minha vida.

E finalmente a Deus por ter proporcionado esse momento de crescimento e santificação, pois sem Ele não existiria sentido em minha vida.

Muito Obrigado. 


\section{Resumo}

Silveira, M. A. Dosimetria gel no controle de qualidade tridimensional para Radioterapia de Intensidade modulada (IMRT) de Próstata. 2014. 105f. Dissertação de Mestrado - Departamento de Física, Faculdade de Filosofia Ciências e Letras de Ribeirão Preto, Universidade de São Paulo, Ribeirão Preto, 2014.

A radioterapia de intensidade modulada (IMRT) é uma das mais modernas técnicas radioterapêuticas que permite a entrega de elevadas e complexas doses ao volume tumoral, que necessita de novos métodos para o controle de qualidade dos procedimentos efetuados. Nos serviços de radioterapia costuma-se usar para o controle de qualidade do sistema de planejamento, a câmara de ionização para verificação pontual da dose e um dispositivo com diodos semicondutores (MapCHECK2) para a verificação bidimensional em um plano da fluência planejada, entretanto para a verificação tridimensional dessas distribuições de doses ainda não há um dosímetro consolidado na rotina clínica. Nesse contexto, para a dosimetria tridimensional se destacam os géis poliméricos. Neste trabalho foram feitas a dosimetria convencional, pontual e bidimensional como se faz na rotina clínica, e a dosimetria tridimensional utilizando o gel polimérico Magic-f, que apresenta a distribuição de dose volumétrica. Para este trabalho foi escolhido o tratamento de câncer de próstata, pois na atualidade é um dos tipos de cânceres mais comuns entre os homens. No contexto da dosimetria gel, para se obter a informação volumétrica é necessária uma técnica de imagem, no presente caso foram utilizadas imagens por ressonância magnética (magnetic resonance imaging, MRI), que demonstraram ser uma poderosa técnica na aquisição de imagens. A partir dessas imagens é possível determinar as distribuições de doses processando-as em um software desenvolvido pelo grupo que determina as taxas de relaxação R2 associada à dose absorvida e posteriormente comparar as imagens obtidas com as imagens do sistema de planejamento. Para isso se obteve dez fatias ao longo de cada simulador físico ou fantom em que sua comparação foi feita com a respectiva fatia do sistema de planejamento, na posição correspondente. Para uma avaliação quantitativa foi utilizado o conceito de índice gama, no critério padrão da radioterapia, $3 \%$ da dose e $3 \mathrm{~mm}$ de distância de concordância. Os resultados obtidos com a dosimetria gel se mostram de acordo com os controles de qualidade convencionais e oferecem uma visão global da distribuição de dose no volume alvo. 
Palavras chave: Dosimetria gel. Gel Magic-f. Radioterapia de Intensidade modulada. Controle de qualidade em IMRT. Imagens por Ressonância Magnética Nuclear. 


\begin{abstract}
Silveira, M. A. Gel dosimetry in three-dimensional quality control for Intensity Modulated Radiation Therapy (IMRT) for Prostate. 2014. 106f. Master Thesis Department of Physics, Faculty of Philosophy, Sciences and Letters of Ribeirão Preto, University of São Paulo, Ribeirão Preto , 2014.
\end{abstract}

The intensity modulated radiotherapy (IMRT) is one of the most modern radiotherapeutic technique that enables the delivery of high and complexes conformational doses to the tumor volume, that requires new methods for the quality assurance of the procedures performed. Radiotherapy services usually perform quality assurance of the planning system with the ionization chamber for spot-checking and an array of semiconductor diodes (MapCHECK2) to check on a two-dimensional plane, however for tridimensional dose verification does not exist an established dosimeter in the clinical routine. In this context, for three-dimensional dosimetry the polymeric gels were used. In This work the conventional one and two-dimensional dosimetry as employed in the clinical routine, and the three-dimensional dosimetry using polymer gel MAGIC- $\mathrm{f}$, which provide the volumetric dose distribution were compared. Prostate cancer clinical cases were chosen for this work because this kind of tumor is one of the most common cases in male individuals. In the context of dosimetry gel to obtain volumetric information an imaging technique is necessary, in this case the magnetic resonance imaging (MRI), was used to measure the dose, which revealed to be a powerful technique for image acquisition. From these images it is possible to determine the distributions of doses processing them in a software developed by our research group that determines $\mathrm{R} 2$ relaxation rates associated with the absorbed dose and subsequently compare the images obtained with the images of the planning system. For this, ten slices were obtained along each phantom, and comparisons were made with the respective slice of the treatment planning system, in the corresponding position. For a quantitative evaluation the concept index range, the standard criterion in radiotherapy, 3 $\%$ dose and $3 \mathrm{~mm}$ distance to agreement was used. The results obtained shown that gel dosimetry agrees with the conventional quality controls and provide an overview of dose distribution in the target volume. 
Keywords: Gel dosimetry . Gel Magic - f . Intensity -modulated radiotherapy . Quality control in IMRT . Nuclear Magnetic Resonance Imaging. 


\section{$\underline{\text { Sumário }}$}

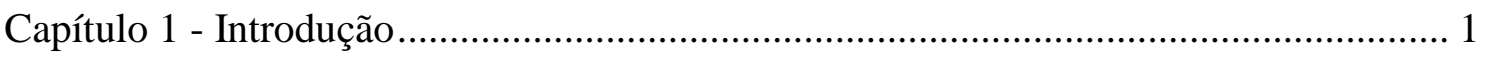

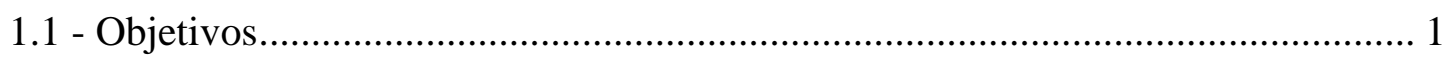

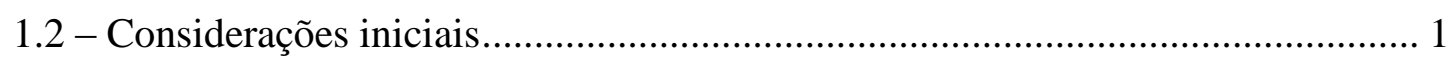

Capítulo 2 - Controle de qualidade em Radioterapia................................................ 4

2.1- Câmaras de ionização (CI) .......................................................................... 4

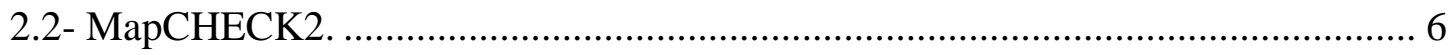

2.3 - Diferença percentual de dose $(\mathrm{D} \%)$.......................................................... 7

2.4 - Distância de concordância (DTA) ………...................................................... 8

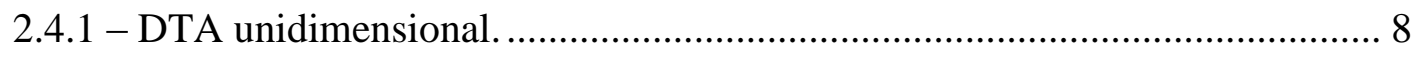

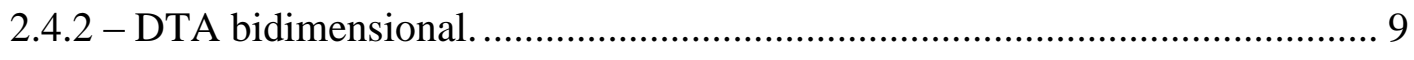

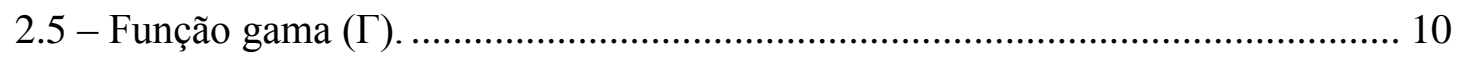

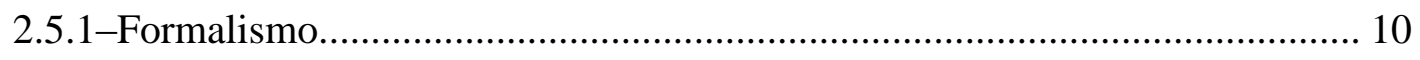

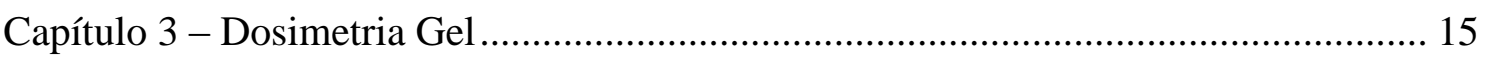

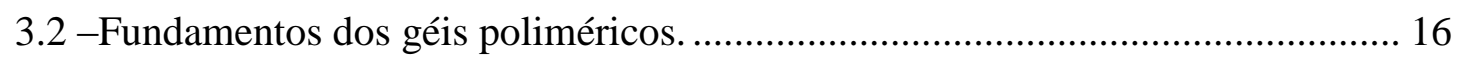

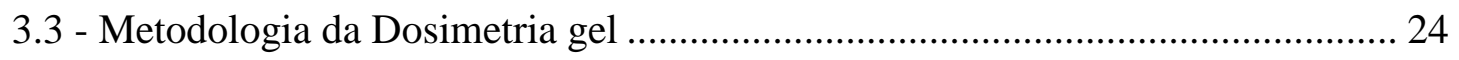

3.4 - Imagens por ressonância magnética nuclear ................................................... 18

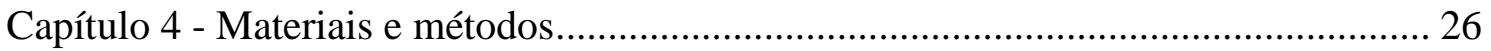

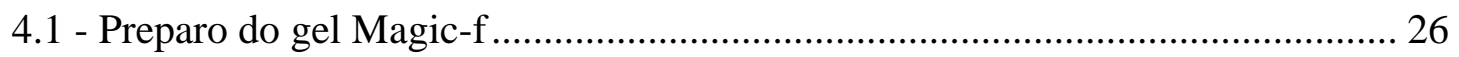

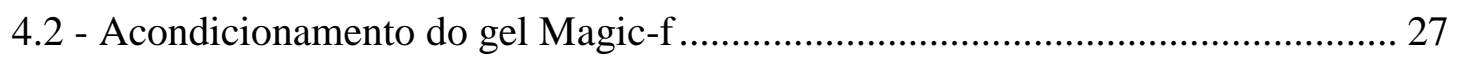

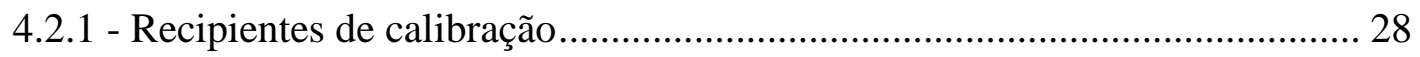

6.2.2 - Recipientes usados para simular o tratamento de radioterapia. .................. 28

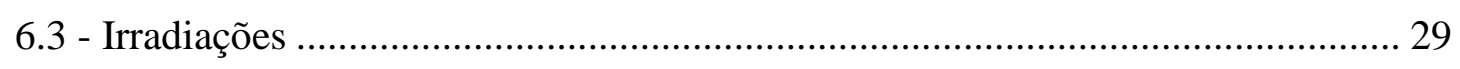

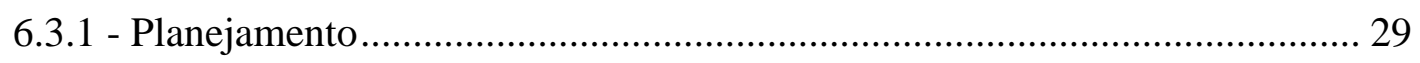

4.3.2 - Irradiações com a Câmara de ionização................................................... 32

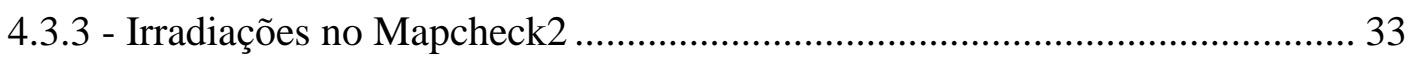


4.3.4 - Irradiação de calibração - gel Magic-f. ....................................................... 34

4.3.5 - Irradiação dos objetos simuladores - Gel Magic-f...................................... 35

4.4 - Aquisições das imagens por ressonância magnética ......................................... 35

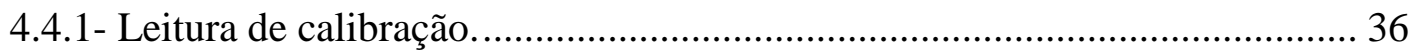

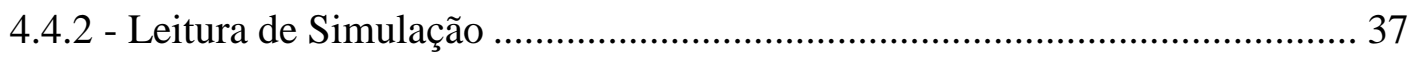

4.5 - Análise das imagens de ressonância magnética................................................ 39

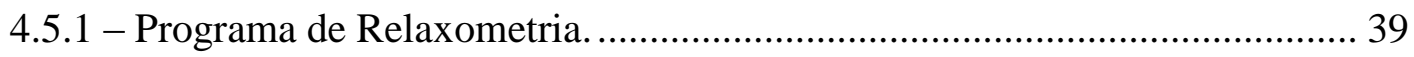

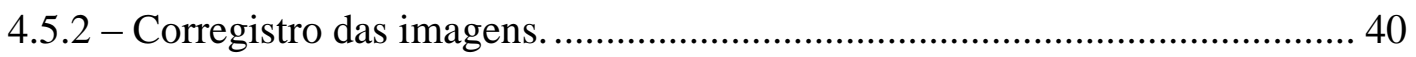

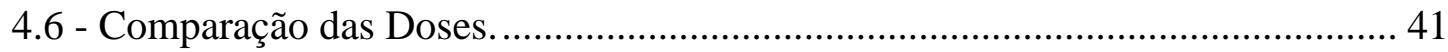

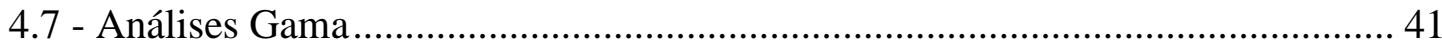

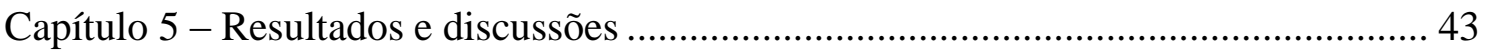

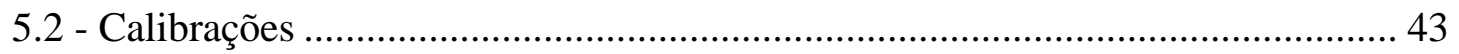

5.2.1 - Checagem de calibração do $\mathrm{Al}$.................................................................. 43

5.2.2 - Curvas de calibração - Magic-f ................................................................ 44

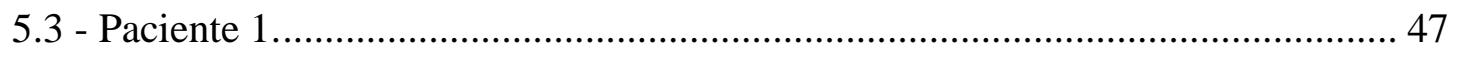

5.3.1 - Controle de qualidade pontual - Câmara de ionização .............................. 47

5.3.2 - Controle de qualidade bidimensional - MapCHECK2 ........................... 48

5.3.3 Controle de qualidade Tridimensional - Resultados com Gel Magic-f.......... 49

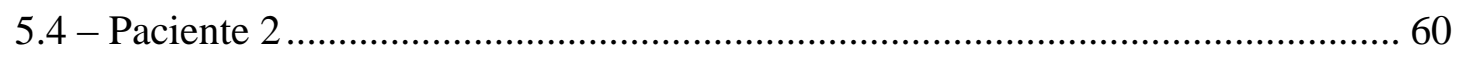

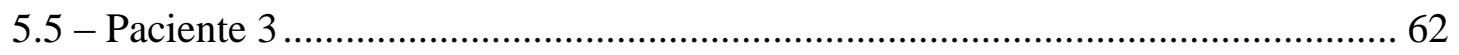

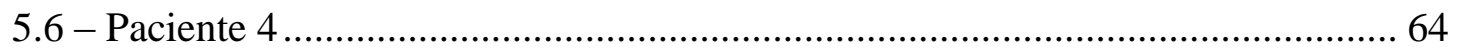

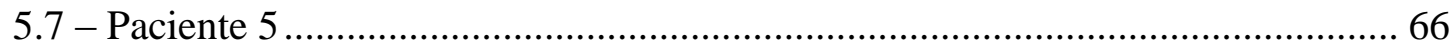

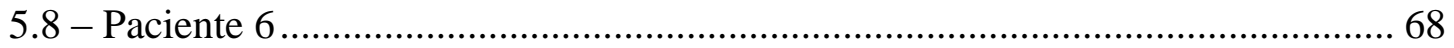

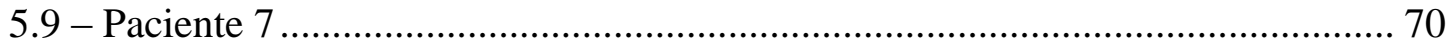

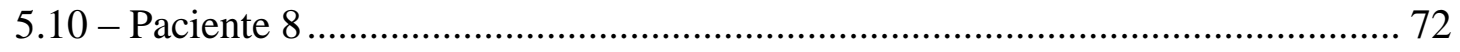

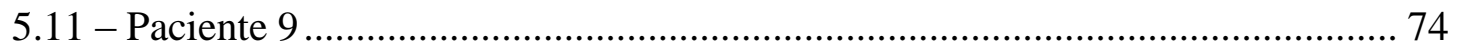

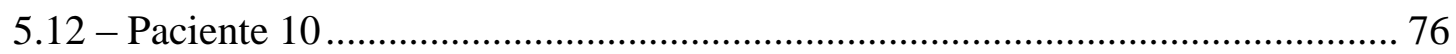




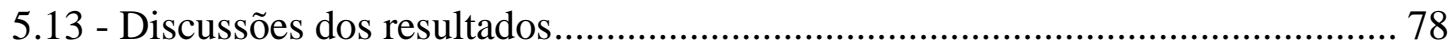

5.13.1 - Considerações gerais dos resultados. .................................................. 78

5.13.2 - Análise dos resultados em cada paciente dos resultados.......................... 79

5.13.3 - Considerações com os trabalhos apresentados na literatura...................... 81

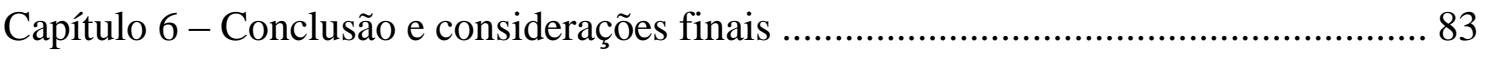

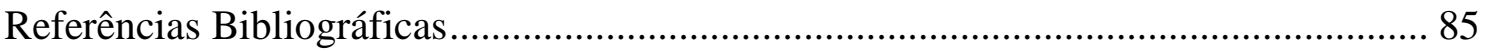




\section{Lista de figuras}

Figura 1.1: Componentes principais de um acelerador linear mostrando o gantry ou suporte, o foco de radiação, o sistema de posicionamento do paciente com lasers e a mesa para o paciente (figura extraída e modificada do site http://www.centraldecomunicacao.jor.br)... 3

Figura 2.1: Câmara de ionização tradicionais, cilíndricas e esférica de modelos diferentes ...6

Figura 2.2: Câmara de ionização cilíndrica de cavidade pequena 7

Figura 2.3: Representação de um objeto simulador sendo irradiado com cinco campos de radiação. CI é a localização da câmara de ionização. .7

Figura 2.4: MapCHECK2 fabricado pela Sun Nuclear Corporation. .8

Figura 2.5: Representação para a distância de concordância unidimensional .9

Figura 2.6: Representação esquemática para DTA bidimensional. .10

Figura 2.7: Representação no eixo de coordenadas para a diferença percentual de dose e o DTA e ainda a representação do vetor da função gama .12

Figura 2.8: Representação Geométrica tridimensional para a diferença percentual de dose e o DTA e a representação do vetor da função gama. .14

Figura 3.1: Inicio do processo de polimerização com a formação do primeiro monômero radical. .18

Figura 3.2: Polimerização a partir do monômero radical inicial formado, formando um polímero radical. .18

Figura 3.3: Esquema do movimento de precessão do vetor magnetização sobre o $\mathrm{B}_{0}$ 
Figura 3.4: Comportamento da Magnetização longitudinal após um pulso de $90^{\circ}$. (a)magnetização no eixo $\mathrm{z}$ com magnetização $\mathrm{M}_{\mathrm{z}}=\mathrm{M}_{0}$. (b) Magnetização deslocada para o plano z-y pelo pulso de $90^{\circ}$. (c) Após o tempo de relaxação T1 a magnetização $\mathrm{M}_{\mathrm{z}}$ possui $63 \%$ de $\mathrm{M}_{0}$. (d) Restabelecimento do equilíbrio na condição inicial. .21

Figura 3.5: Comportamento da magnetização transversal após um pulso de $90^{\circ}$.(a) magnetização no eixo $\mathrm{z}$ com magnetização $\mathrm{M}_{\mathrm{z}}=\mathrm{M}_{0}$. (b) Magnetização deslocada para $\mathrm{o}$ plano z-y pelo pulso de $90^{\circ}$. (c) Inicio da defasagem diminuindo $\mathrm{M}_{\mathrm{xy}}$. (d) defasagem completa resultando em $\mathrm{M}_{\mathrm{xy}}=0$ .22

Figura 3.6: Sequência multi spin eco com pulsos de $90^{\circ}$ sucedidos por pulsos de $180^{\circ} \mathrm{e}$ emitindo o sinal de eco

Figura 3.7: Sinal FID, decaimento de $\mathrm{T} 2 *$ e $\mathrm{T} 2$, sendo que o decaimento de $\mathrm{T} 2$ predomina na sequência multi spin eco. Figura retirada do site http://www.nmr.uniduesseldorf.de e modificada. .24

Figura 3.8: Aquisição das imagens de ressonância Magnética para determinação de R2 e das distribuições de dose. Figura retirada do De Deene et al, 2002 e modificada.......25

Figura 3.9: Metodologia da dosimetria gel passo a passo, fabricação, irradiação, leitura pela técnica de imagem e determinação das distribuições de dose 26

Figura 4.1: Confecção do Gel Magic-f usando agitador magnético. 28

Figura 4.2: tubos BD Vacutainer® com $5 \mathrm{ml}$ de volume e $12 \mathrm{~mm}$ de diâmetro .29

Figura 4.3: (a) Tupperware usado para acondicionar o gel. (b) Tupperware no suporte confeccionado para o CT de planejamento, irradiação no AL, e leitura no tomógrafo de ressonância magnética .30

Figura 4.4: Tomografo PHILIPS Hospital das clinicas de Ribeirão Preto 31 
Figura 4.5: Imagem de CT no isocento localizado pelo bibs no circulo de cor cinza, o retangulo cinza abaixo do circulo é o suporte de acrilico

Figura 4.6: Planejamento em um paciente real a ser tratado no centro de radioterapia de São Carlos..... .33

Figura 4.7: Planejamento exportado de um paciente para o objeto simulador. .33

Figura 4.8: Irradiação com a Câmara de ionização posiciona no isocentro do acelerador linear CLINAC 600CD/ Varian da Santa Casa de Misericórdia de São Carlos. .34

Figura 4.9: Placa de diodos MapCHECK $2^{\mathrm{TM}}$ da Sun Nuclear Corporation. 35

Figura 4.10: Interface do software Mapcheck2. Imagem própria do fabricante no site http://www.sunnuclear.com/medPhys/patientqa/mapcheck2/mapcheck2.asp 35

Figura 4.11: Posicionamento do objeto simulador para a irradiação mostrando o feixe de lasers e o suporte de acrílico

Figura 4.11: Tomógrafo de Ressonância Magnética Philips Achieva 3T. Foto retirada do site www.philips.com .38

Figura 4.12: À esquerda os tubos de calibração no suporte para a leitura. À direita o recipiente preenchido com a solução de calibração.

Figura 4.13: Posicionamento do objeto simulador na bobina de cabeça, no tomógrafo de ressonância magnética Philips Achieva 3T para a aquisição das imagens

Figura 4.14: Interface do programa de relaxometria, mostrando as informações das imagens, data de aquisição, sequencia, tempos de eco, tempo de repetição, números de fatias e as funções disponíveis.

Figura 4.15: Interface do CERR para visualização do planejamento, apresentando os perfis, axial, sagital e coronal. 
Figura 5.1: Curva de calibração referente aos pacientes de 1 a 5 . .47

Figura 5.2: Curva de calibração referente aos pacientes de 6 a 10 .48

Figura 5.3: Curvas de calibração para os experimentos realizados. .49

Figura 5.4: Resultados apresentados pelo MapCHeck2 para o Paciente 1 .51

Figura 5.5: Primeira coluna apresenta as distribuições de dose obtidas com Gel Magicf. Na segunda coluna apresenta as distribuições calculadas pelo planejamento. 55

Figura 5.6: Sobreposição dos perfis de dose. Em azul mostra o perfil de dose do sistema de planejamento e em vermelho o perfil de dose medida pelo gel Magicf.. .58

Figura 5.7: Na primeira coluna mapas de distribuições dos índices gama em cada fatia. $\mathrm{Na}$ segunda coluna Histograma de pixel apresentando a porcentagem de pixels com gama $\leq 1$.

Figura 5.8: Distribuições de dose medida, planejada, sobreposição das isodose e histograma de Pixels com índice gama para o paciente 2 . .63

Figura 5.9: Distribuições de dose para os cortes no isocentro, medida e planejada.

Figura 5.10: Mapa de índices gama e seu respectivo histograma de pixels para o isocentro, apresentando $97,2 \%$ dos pixels $\operatorname{com} \gamma \leq 1$ .64

Figura 5.11: Distribuições de dose medida, planejada, sobreposição das isodose e histograma de Pixels com índice gama para o paciente 3

Figura 5.12: Distribuições de dose para os cortes no isocentro, medida e planejada. .66 
Figura 5.13: Mapa de índices gama e seu respectivo histograma de pixels para o isocentro, apresentando $96,2 \%$ dos pixels com $\gamma \leq 1$.

Figura 5.14: Distribuições de dose medida, planejada, sobreposição das isodose e histograma de Pixels com índice gama para o paciente 4.

Figura 5.15: Distribuições de dose para os cortes no isocentro, medida e planejada. .68

Figura 5.16 Mapa de índices gama e seu respectivo histograma de pixels para o isocentro, apresentando $96,1 \%$ dos pixels com $\gamma \leq 1$ .68

Figura 5.17: Distribuições de dose medida, planejada, sobreposição das isodose e histograma de Pixels com índice gama para o paciente 5 .69

Figura 5.18: Distribuições de dose para os cortes no isocentro, medida e planejada. .70

Figura 5.19: Mapa de índices gama e seu respectivo histograma de pixels para o isocentro, apresentando $96,5 \%$ dos pixels com $\gamma \leq 1$ .70

Figura 5.20: Distribuições de dose medida, planejada, sobreposição das isodose e histograma de Pixels com índice gama para o paciente 6. .71

Figura 5.21: Distribuições de dose para os cortes no isocentro, medida e planejada. .72

Figura 5.22: Mapa de índices gama e seu respectivo histograma de pixels para o isocentro, apresentando $97,4 \%$ dos pixels com $\gamma \leq 1$. .72

Figura 5.23: Distribuições de dose medida, planejada, sobreposição das isodose e histograma de Pixels com índice gama para o paciente 7. 
Figura 5.24: Distribuições de dose para os cortes no isocentro, medida e planejada.

Figura 5.25: Mapa de índices gama e seu respectivo histograma de pixels para o isocentro, apresentando $94,5 \%$ dos pixels com $\gamma \leq 1$ .74

Figura 5.26: Distribuições de dose medida, planejada, sobreposição das isodose e histograma de Pixels com índice gama para o paciente 8 . .75

Figura 5.27: Distribuições de dose para os cortes no isocentro, medida e planejada. .76

Figura 5.28: Mapa de índices gama e seu respectivo histograma de pixels para o isocentro, apresentando $94,5 \%$ dos pixels com $\gamma \leq 1$ .76

Figura 5.29: Distribuições de dose medida, planejada, sobreposição das isodose e histograma de Pixels com índice gama para o paciente 9 .77

Figura 5.30: Distribuições de dose para os cortes no isocentro, medida e planejada. .78

Figura 5.31: Mapa de índices gama e seu respectivo histograma de pixels para o isocentro, apresentando $97,1 \%$ dos pixels com $\gamma \leq 1$ .78

Figura 5.32: Distribuições de dose medida, planejada, sobreposição das isodose e histograma de Pixels com índice gama para o paciente 10 .79

Figura 5.33: Distribuições de dose para os cortes no isocentro, medida e planejada. .80

Figura 5.34: Mapa de índices gama e seu respectivo histograma de pixels para o isocentro, apresentando $98,5 \%$ dos pixels com $\gamma \leq 1$

Figura 5.35: Médias da porcentagem de índices gama em cada paciente. .82 
Figura 5.36: Média da porcentagem de índices gama índices gamas em relação a cada paciente. 


\section{Lista de Tabelas}

Tabela 4.1: Composição em Massa do gel MAGIC-f.....................................................27

Tabela 4.2- Porcentagem em massa dos componentes da solução de calibração...........39

Tabela 5.1: Checagem da calibração para irradiação dos Pacientes de 1 a 5.................46

Tabela 5.2: Checagem da calibração para irradiação dos Pacientes de 6 a 10...............47

Tabela 5.3: Comparação entre as calibrações nas medidas de R2 ................................49

Tabela 5.3: Leitura da câmara de ionização para o Paciente 1......................................50

Tabela 5.6: Porcentagem de índices gama na posição de cada corte.............................62

Tabela 5.7: Leituras usando CI para o Paciente 2 .........................................................63

Tabela 5.8: Apresenta os índices gama para cada corte na posição respectiva.............64

Tabela 5.9: Leituras usando CI para o Paciente 3 ........................................................65

Tabela 5.10: Apresenta os índices gama para cada corte na posição respectiva...........66

Tabela 5.11: Leituras usando CI para o Paciente 4.....................................................67

Tabela 5.12: Apresenta os índices gama para cada corte na posição respectiva...........68

Tabela 5.13: Leituras usando CI para o Paciente 5.......................................................69

Tabela 5.14: Apresenta os índices gama para cada corte na posição respectiva.............70

Tabela 5.15: Leituras usando CI para o Paciente 6........................................................ 71

Tabela 5.16: Apresenta os índices gama para cada corte na posição respectiva.............72

Tabela 5.17: Leituras usando CI para o Paciente 7 ..................................................... 73

Tabela 5.18: Apresenta os índices gama para cada corte na posição respectiva............74

Tabela 5.19 Leituras usando CI para o Paciente 8 …....................................................75

Tabela 5.20: Apresenta os índices gama para cada corte na posição respectiva............76

Tabela 5.21: Leituras usando CI para o Paciente 9...................................................77

Tabela 5.22: Apresenta os índices gama para cada corte na posição respectiva.............78

Tabela 5.23: Leituras usando CI para o Paciente 10..................................................79

Tabela 5.24: Apresenta os índices gama para cada corte na posição respectiva............80

Tabela 5.25: Índices Gama para o Paciente 1 com limiares de $20 \%$ a $85 \%$....................85 


\section{Capítulo 1 - Introducão}

\section{1 - Objetivos}

Neste trabalho vamos aplicar a dosimetria gel com o gel Magic-f no controle de qualidade tridimensional em radioterapia. Para isso, em dez planejamentos de radioterapia de intensidade modulada (IMRT) de pacientes reais para tratamento de câncer de próstata, realizaremos os controles de qualidade convencionais usando a câmara de ionização e o MapCHECK2, bem como o controle de qualidade tridimensional utilizando o gel polimérico Magic-f associado a imagens de ressonância magnética nuclear para determinar as distribuições de dose.

\section{2 - Considerações iniciais}

O câncer é uma doença degenerativa que tem como característica a divisão desenfreada das células de um tecido. Uma das maneiras encontradas de tratar essa doença é a radioterapia através do uso da radiação ionizante para combater o crescimento desordenado das células. Nos indivíduos do sexo masculino a próstata é uma das regiões mais afetadas por essa doença. De acordo com o Instituto Nacional do Câncer em 2014 há uma estimativa de 68.800 novos casos só no Brasil.

A radiação ionizante é capaz de destruir, através de danos produzidos no núcleo celular, tanto células tumorais quanto sadias. Então, seu uso de maneira adequada é um benefício quando respeitados os limites de dose absorvida para cada célula. Para ter esse conhecimento, devem-se quantificar a radiação utilizada no tratamento, através das grandezas radiométricas e dosimétricas. A pesquisa desenvolvida nessa dissertação irá visar à grandeza dosimétrica dose absorvida(D) na radioterapia de intensidade modulada.

A dose absorvida (D), é uma grandeza dosimétrica que quantifica a energia absorvida $(\mathrm{dE})$ por unidade de massa $(\mathrm{dm})$, proveniente tanto da radiação eletromagnética quanto corpuscular:

$$
D=\frac{d E}{d m}
$$

a unidade no sistema internacional é o Gray (Gy) que corresponde a $1 \mathrm{~J} / \mathrm{Kg}$. 
Nos tratamentos radioterapêuticos podem ser utilizados dois tipos de fontes de radiação. Uma com elemento químico de núcleo instável, por exemplo, o cobalto-60 (Co-60) que emite radiação gama com energia de 1,25 MV, outra possibilidade no tratamento é a utilização de um gerador de radiações, como um acelerador linear (Figura 1.1), que gera radiação ionizante pelo princípio de Bremsstralung, emitindo raios- $x$ através da desaceleração dos elétrons em um alvo. Atualmente os aceleradores lineares têm substituídos às unidades de Cobalto nos serviços de radioterapia e deverão ser os equipamentos predominantes como fonte de fótons para teleterapia. Uma técnica moderna de radioterapia conformacional que se destaca é a radioterapia de intensidade modulada (intesity-modulated radiation therapy), que se caracteriza por conformar e variar a intensidade do feixe de radiação ao volume alvo planejado (Planning target volume - PTV).

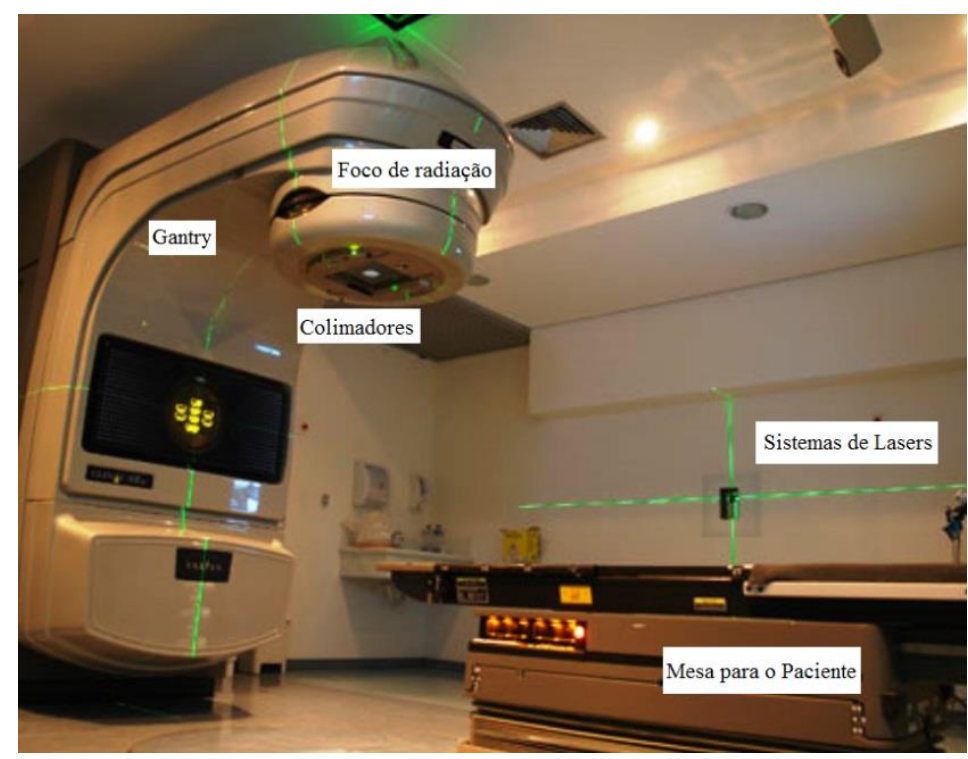

Figura 1..1: Componentes principais de um acelerador linear mostrando o gantry ou suporte, o foco de radiação, o sistema de posicionamento do paciente com lasers e a mesa para o paciente (figura extraída e modificada do site http://www.centraldecomunicacao.jor.br)

A Radioterapia de intensidade Modulada é uma das técnicas mais modernas utilizadas nos tratamentos radioterapêuticos, possui os mesmo componentes de um acelerador linear comum: fonte de radiação (alvo com alto número atômico), gantry ou suporte (braço de movimentação), colimadores, mesa para o paciente e o sistema de posicionamento (laser na sala), conforme mostra a figura 1.1. A grande diferença da IMRT está nos colimadores, que são um sistema de multi-folhas (multileaf). Estes, durante o tratamento se conformam proporcionando campos de radiação com diferentes intensidades e formatos. Essa conformação dos campos de radiação pode ser feita de 
maneira estática ou dinâmica, através de técnicas nomeadas de "step and shoot" ou "slide window", respectivamente. A grande vantagem das técnicas de IMRT é a deposição de doses mais elevadas e complexas no volume alvo, ao mesmo tempo em que há a proteção dos tecidos sadios.

Conforme as técnicas de tratamento evoluem também surge à necessidade do controle de qualidade dessas técnicas. Atualmente já existem dosímetros consolidados para verificação pontual, como as câmaras de ionização (CI) e os dosímetros termoluminescentes, e bidimensional como placas de diodos semicondutores ou filmes radiográficos. Mas para a dosimetria tridimensional, ainda não há um dosímetro aplicado na rotina clínica. Nesse contexto vem se destacando a dosimetria gel combinada com técnicas de imagens de alta resolução, como a ressonância magnética nuclear.

O gel Magic-f elaborado pelo nosso grupo em 2008 (Fernandes et al, 2008), tem se destacado com resultados bem sucedidos na dosimetria tridimensional, como em braquiterapia, radiocirurgia, tomoterapia entre outras aplicações.(Marques et al, 2009, Alva et al, 2009, Pavoni et al, 2010, Fernandes et al 2012). 


\section{Capítulo 2 - Controle de qualidade em radioterapia}

A evolução das técnicas de radioterapia com a deposição e conformação de doses como em IMRT, implica na utilização de sistemas de planejamentos mais complexos. Por essa razão no controle de qualidade do sistema de planejamento são necessários métodos de grande precisão e acurácia para tal verificação.

Atualmente nas clínicas se utilizam vários tipos de detectores de radiação como: câmaras de ionização, matrizes com diodos semicondutores, portais eletrônicos (EPIDs), filmes radiocrômicos dentre outros. Primeiramente nesse capítulo vamos nos concentrar em descrever, de maneira geral, os dosímetros tradicionais que foram utilizados nesse trabalho, a câmara de ionização e uma matriz com diodos semicondutores cujo nome comercial é MapCHECK2, que fornecem medidas de dose pontuais e a bidimensionais respectivamente.

Para validar de maneira quantitativa se um planejamento de radioterapia está qualificado ou não para o tratamento a ser realizado, é necessário definir que parâmetros fornecerá essa informação. O parâmetro mais utilizado atualmente para tal comparação é o índice gama (Low et al,1998), calculado pixel a pixel entre imagens. O índice gama relaciona dois parâmetros que já se usavam para comparação de duas distribuições: a diferença percentual de dose (D\%) e a distância de concordância, em inglês distance-toagreement (DTA) (Harms et al,1998).

Também nesse capítulo, para fins didáticos, será apresentada a aplicação da diferença percentual de dose, a DTA e depois o índice gama, que é o parâmetro utilizado para validação dos nossos resultados.

\section{1- Câmaras de ionização (CI)}

As câmaras de ionização (figura 2.1) são os dosímetros mais tradicionais e amplamente usados. O princípio da CI consiste em ser um objeto geométrico com volume sensível definido (cavidade) preenchido com um gás que detecta a quantidade de carga criada pela ionização direta no gás, para isso se aplica um campo elétrico adequado a esse volume. 


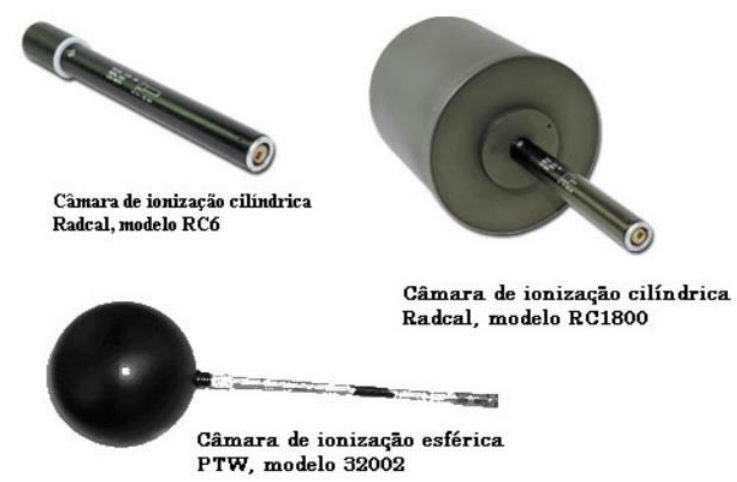

Figura 2.1:Câmaras de ionização tradicionais, cilíndricas e esférica de modelos diferentes.

Existem dois tipos de câmaras de ionização, as seladas e as câmaras não seladas. Nas câmaras seladas o ar contido no volume sensível não se comunica com o ar atmosférico. Nas câmaras não seladas o ar contido no volume se comunica livremente com a atmosfera. Para que essa câmara apresente o valor correto da leitura é necessário fazer a correção por um fator de temperatura e pressão $\mathrm{K}_{\mathrm{tp}}$ dado pela equação 2.1.

$$
K_{t p}=\frac{760 \cdot(273,15+T)}{(293,15) \times P}
$$

Onde a média da temperatura $(\mathrm{T})$ está em ${ }^{\circ} \mathrm{C}$ e a pressão(P) em mmHg. Então para determinar a dose absorvida na câmara de ionização temos a seguinte equação:

$$
D_{a b}=L \cdot K_{t p} \cdot N_{W, Q}
$$

Onde $\mathrm{N}_{\mathrm{W}, \mathrm{Q}}$ é o fator de calibração da câmara de ionização, calibrada de acordo com o TRS-358 (technical report series-358) da IAEA(International Atomic Energy Agency) para dosimetria, e L é a leitura realizada pelo eletrômetro que mede a carga gerada pela exposição a radiação.

O eletrômetro é acoplado por um cabo especifico à câmara de ionização que funcionam como um amperímetro medindo a corrente $(\mathrm{mA})$ ou a carga(nC) gerada pela câmara de ionização.

No controle de qualidade na clínica, as câmaras de ionização cilíndricas de cavidade pequena como exemplificado na figura 2.2, são colocadas em uma região de 
alta gradiente de dose, e cada campo de irradiação é irradiado para se determinar a dose pontual nessa região. Por exemplo, na figura 2.3 onde temos a representação de um objeto simulador sendo irradiado com cinco campos de radiação e a câmara de ionização é posicionada na região de alto gradiente de dose, onde há PTV.

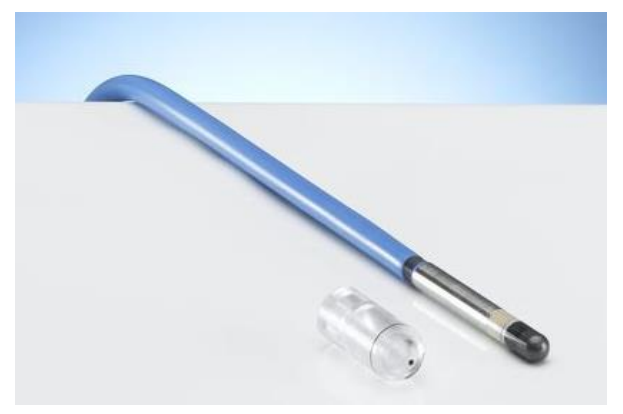

Figura 2.2: Câmara de ionização cilíndrica de cavidade pequena.

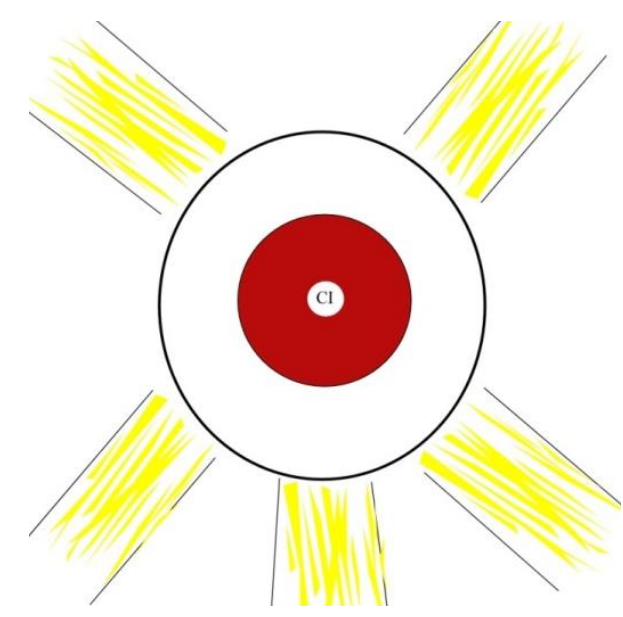

Figura 2.3: Representação de um objeto simulador sendo irradiado com cinco campos de radiação. O ponto indicado como CI mostra a localização da câmara de ionização.

\section{2- MapCHECK2}

O MapCHECK2 (figura 2.3), fabricado pela Sun Nuclear Corporation, é um sistema dosimétrico para o controle de qualidade bidimensional em radioterapia. Esse sistema testa as habilidades do acelerador linear para depositar um mapa de dose planejada em um objeto simulador. Para isso o cálculo da distribuição de dose planejada que o objeto simulador irá receber é feito a partir da sobreposição de todos os campos 
planejados para o tratamento e pôr fim a comparação entre as distribuições bidimensionais planejadas e medida é comparada qualitativamente e quantitativamente usando o índice gama.

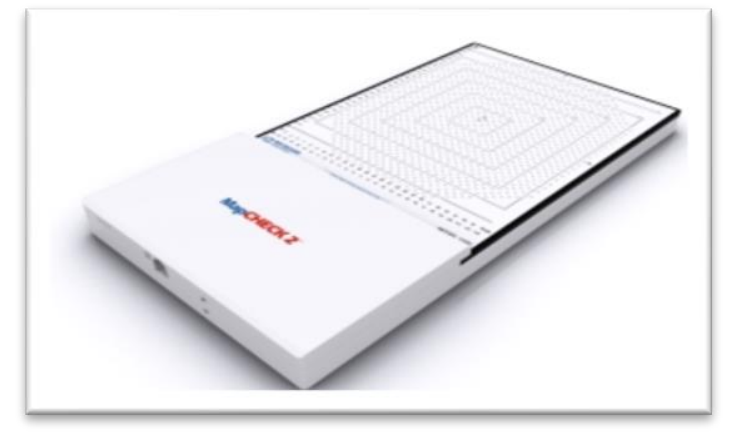

Figura 2.4: MapCHECK2 fabricado pela Sun Nuclear Corporation

A detecção do mapcheck2 baseia-se em uma placa contendo 1527 diodos semicondutores cada um com área sensível de $0,64 \mathrm{~cm}^{2}$, com espaçamento de $7,07 \mathrm{~mm}$ entre cada diodo, podendo ser irradiado com campo máximo de $32 \times 26 \mathrm{~cm}$.

\section{3 - Diferença percentual de dose $(\mathrm{D} \%)$}

O conceito da diferença percentual de dose (Van Dyk et al,1993), consiste na diferença numérica ponto a ponto e é expressada em porcentagem. Por exemplo: temos duas distribuições de dose, na primeira, em um determinado ponto, se tem a dose calculada pelo planejamento $\left(\mathrm{D}_{\mathrm{c}}\right)$ de 10,65 cGy, na segunda, na mesma posição, temos a dose medida $\left(\mathrm{D}_{\mathrm{m}}\right)$ de 10,50 cGy, obtida pelo método experimental. A diferença numérica é feita pela equação:

$$
\Delta \mathrm{D}=\mathrm{D}_{\mathrm{c}}-\mathrm{D}_{\mathrm{m}}
$$

$\mathrm{O}$ resultado de $\Delta \mathrm{D}$ é $0,15 \mathrm{cGy}$, sendo a diferença percentual de $1,4 \%$. Caso o critério escolhido para a diferença for o padrão da radioterapia e radiocirurgia, com D\% $=3 \%$ e $\mathrm{D} \%=2 \%$ respectivamente, esse resultado passaria no teste.

A diferença percentual avalia apenas uma diferença numérica de dose, e não a tolerância espacial, em que está localizado o mesmo valor. 


\section{4 - Distância de concordância (DTA)}

O conceito da distância de concordância (Harms et al,1998) consiste em calcular a menor distância em que um ponto, em uma primeira distribuição, possui o mesmo valor na segunda. O DTA pode ser avaliado na dimensão que for conveniente às distribuições. Para entender seu conceito matemático, vamos ilustrar o conceito unidimensional e em seguida bidimensional.

\subsection{1 - DTA unidimensional}

A distância de concordância avaliada em uma dimensão consiste em considerar apenas um eixo de coordenadas que chamaremos de $\mathrm{X}$, nesse eixo a diferença da distância entre o ponto medido $\mathrm{X}_{\mathrm{m}}$, que colocaremos na origem, e o calculado $\mathrm{X}_{\mathrm{c}}$, que estamos avaliando, deve estar dentro o critério de aceitação $\Delta \mathrm{d}_{\mathrm{m}}$, que varia no eixo $\mathrm{x}$, tanto no sentido positivo quanto negativo.

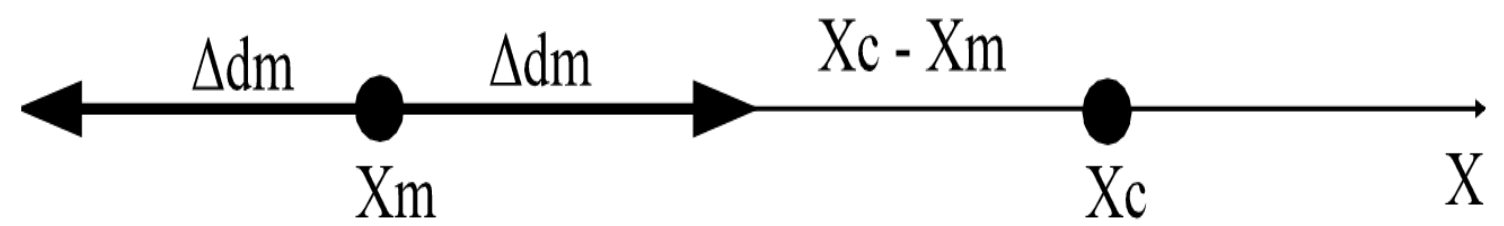

Figura 2.5: Representação para a distância de concordância unidimensional.

Como mostrado na figura 2.5, a distância de concordância unidimensional $\Delta \mathrm{x}$ é representada pela equação:

$$
\Delta \mathrm{X}=\mathrm{X}_{\mathrm{c}}-\mathrm{X}_{\mathrm{m}}
$$

Para que $\Delta \mathrm{x}$ seja validado no critério de aceitação, deve estar de acordo com a seguinte condição:

$$
|\Delta \mathrm{X}| \leq \Delta \mathrm{d}_{m}
$$

Vamos exemplificar considerando duas distribuições unidimensionais a serem comparadas, o ponto $\mathrm{X}_{\mathrm{m}}$ na posição $2 \mathrm{~mm}$, obtido pelo método experimental, e o ponto 
$\mathrm{X}_{\mathrm{c}}$ na posição $5 \mathrm{~mm}$, que corresponde a mesma dose na distribuição que será avaliada. Fazendo a diferença correspondente à equação 5.2, temos o DTA com $\Delta \mathrm{X}=3 \mathrm{~mm}$.

Se o critério de aceitação fosse $\Delta \mathrm{d}_{\mathrm{m}}=3 \mathrm{~mm}$, que é o padrão em radioterapia, esse ponto passaria no teste, no caso de uma radiocirurgia com $\Delta \mathrm{d}_{\mathrm{m}}=2 \mathrm{~mm}$, o mesmo falharia.

\subsection{2 - DTA bidimensional}

Para explicar o formalismo matemático para o DTA bidimensional, vamos ilustrar na figura 2.6 as variáveis envolvidas.

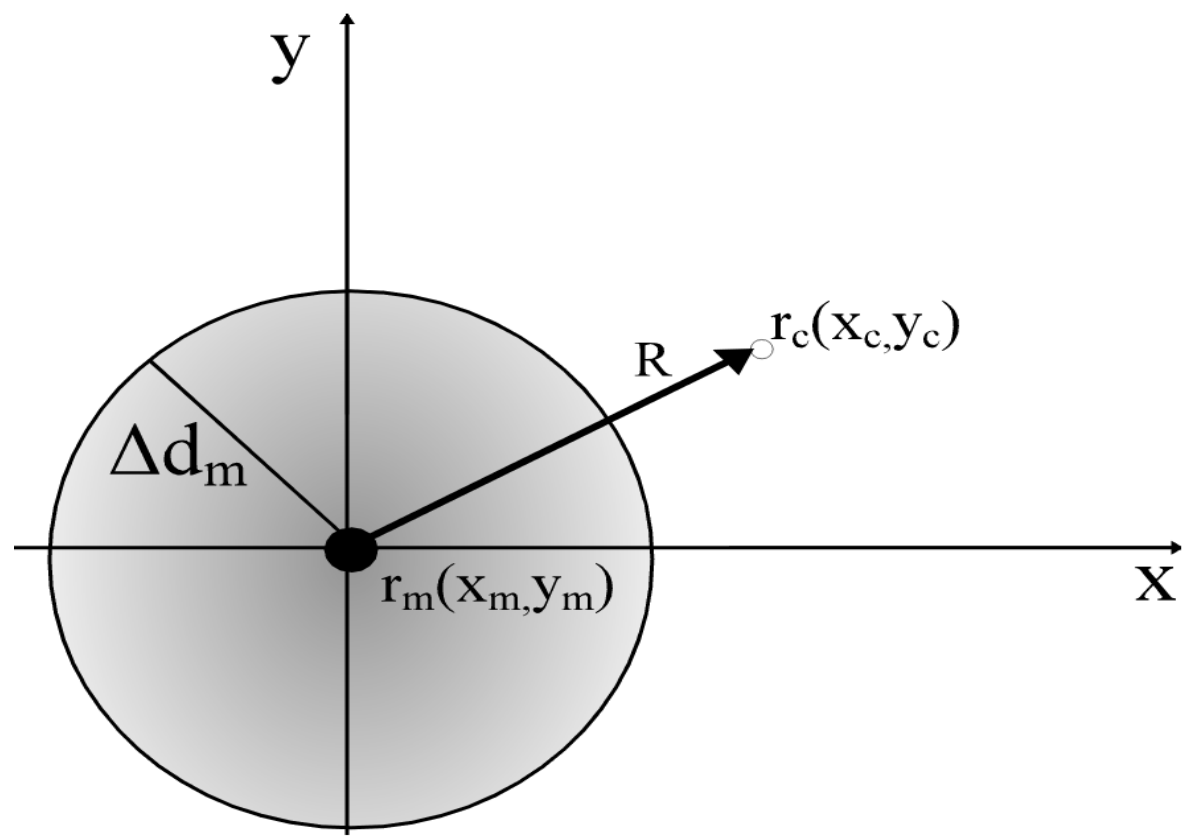

Figura 2.6: Representação esquemática para DTA bidimensional.

Considerando dois pontos, o $\mathbf{r}_{\mathbf{m}}$ obtido pelo método experimental, e o $\mathbf{r}_{\mathbf{c}}$ que será avaliado, cada um com coordenadas no plano cartesiano $\left(\mathrm{x}_{\mathrm{m}}, \mathrm{y}_{\mathrm{m}}\right)$ e $\left(\mathrm{x}_{\mathrm{c}}, \mathrm{y}_{\mathrm{c}}\right)$, a distância entre esses dois pontos é o modulo do vetor $\mathbf{R}$, onde:

$$
|\mathbf{R}|=\left(\left(\mathrm{x}_{\mathrm{c}}-\mathrm{x}_{\mathrm{m}}\right)^{2}+\left(\mathrm{y}_{\mathrm{c}}-\mathrm{y}_{\mathrm{m}}\right)^{2}\right)^{\frac{1}{2}}
$$

O cálculo do módulo de $\mathbf{R}$ na equação 2.4 corresponde ao DTA entre os pontos no plano cartesiano $\left(\mathrm{x}_{\mathrm{m}}, \mathrm{y}_{\mathrm{m}}\right)$ e $\left(\mathrm{x}_{\mathrm{c}}, \mathrm{yc}\right)$. $\mathrm{O}$ critério de aceitação $\Delta \mathrm{d}_{\mathrm{m}}$, varia no sentido positivo e negativo nas duas coordenadas, descrevendo assim uma circunferência de raio $\Delta \mathrm{d}_{\mathrm{m}}$, esse valor impõe a condição para que $\mathrm{R}$ seja validado, sendo assim: 


$$
|\mathbf{R}| \leq \Delta \mathrm{dm}
$$

Com o intuído de exemplificar o Cálculo para o DTA bidimensional, vamos considerar o ponto de dose medido $\mathbf{r}_{\mathbf{m}}$, na origem do plano cartesiano $(0,0)$, e o ponto de mesma dose a ser avaliado, $\mathbf{r}_{\mathbf{c}}$, nas coordenadas $(2,2)$, e a unidade de medida para a distância em milímetros, utilizando a equação 2.5 , tem - se o cálculo:

$$
|\mathbf{R}|=\left((2-0)^{2}+(2-0)^{2}\right)^{\frac{1}{2}}=2 \sqrt{2}=2,8 \mathrm{~mm}
$$

Se o critério de aceitação $\Delta \mathrm{d}_{\mathrm{m}}$ for de $3 \mathrm{~mm}$ como em radioterapia, esse ponto é passa no teste, no caso de uma radiocirurgia com $\Delta \mathrm{d}_{\mathrm{m}}$ de $2 \mathrm{~mm}$, esse ponto falharia no teste de DTA (Harms et al, 1998).

\section{5 - Função gama $(\Gamma)$}

Os métodos quantitativos apresentados anteriormente possuem suas limitações, a alternativa desenvolvida foi a função gama (Low et al, 1998), que se caracteriza por avaliar de maneira simultânea a diferença percentual de dose, e o DTA, encontrando o índice gama $\gamma$, entre duas distribuições de dose.

\subsection{1-Formalismo}

Primeiramente o caso unidimensional para o formalismo matemático da função gama, se considera duas distribuições, exemplificando primeiramente o caso unidimensional, no eixo horizontal, chamamos de $\mathrm{x}$, avaliaremos a o DTA unidimensional, como estaremos avaliando outro parâmetro, no eixo vertical avaliaremos a diferença percentual de dose, que denominaremos pela letra $\delta$. Os valores a serem comparados são: a dose e a posição medida $\mathrm{D}_{\mathrm{m}}\left(\mathrm{x}_{\mathrm{m}}\right), \mathrm{x}_{\mathrm{m}}$ respectivamente, com a dose e a posição calculada $D_{c}\left(x_{c}\right), x_{c}$ respectivamente, e os critérios de tolerância $\Delta d_{m} e$ $\Delta \mathrm{D}_{\mathrm{M}}$ foram os limites da elipse, ou circunferência se no caso de $\Delta \mathrm{d}_{\mathrm{m}}=\Delta \mathrm{DM}$, em que valor de $|\boldsymbol{\Gamma}|$ deve obedecer esses limites para ser validado . A figura 2.7 mostra um modelo esquemático para a interpretação geométrica com os dois eixos de coordenadas, e os pontos a serem analisados e os critérios de tolerância. 


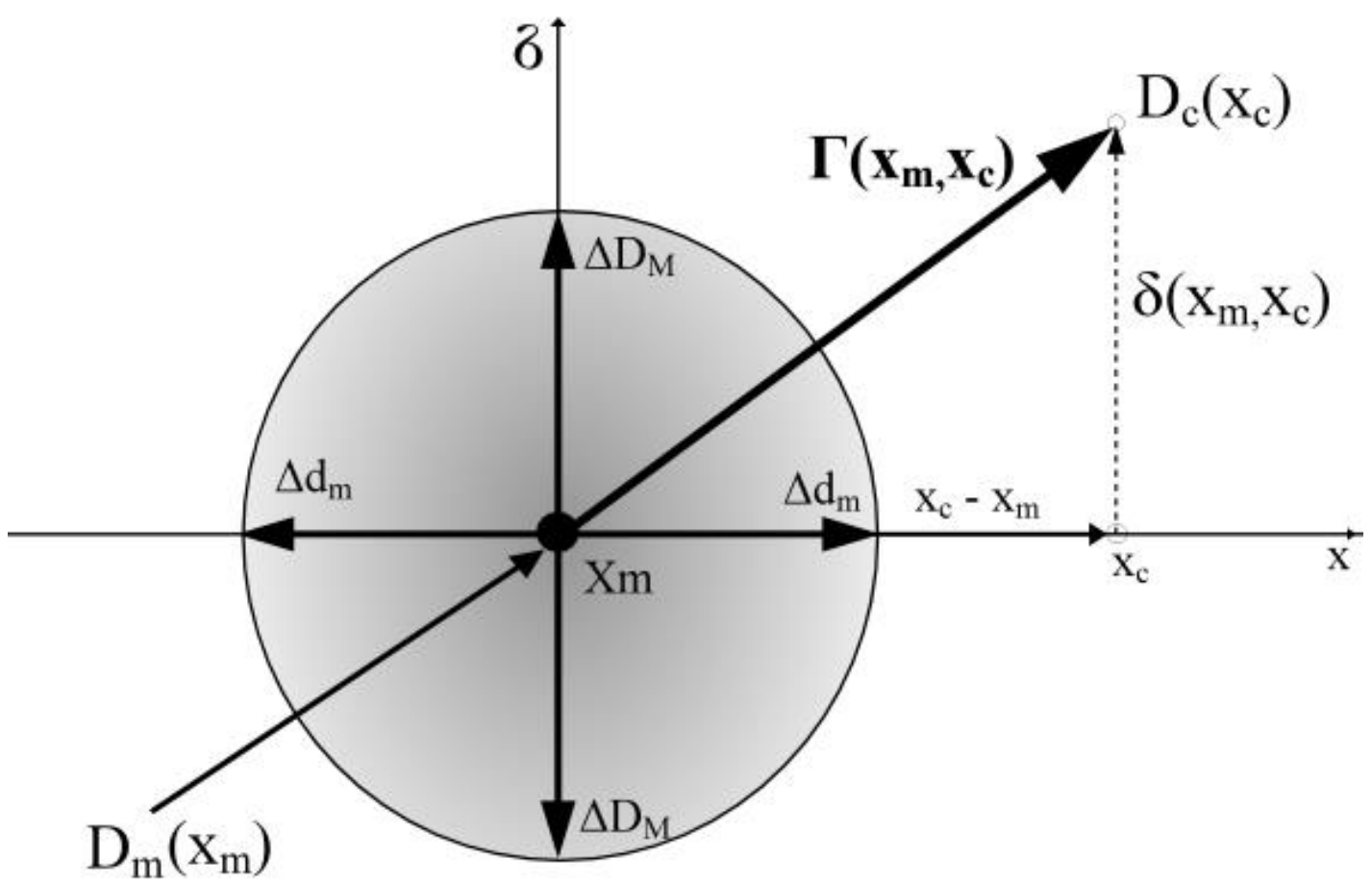

Figura 2.7: Representação no eixo de coordenadas para a diferença percentual de dose e o DTA e ainda a representação do vetor da função gama.

O mesmo conceito geométrico se aplica quando se tem o DTA em duas dimensões, nesse caso utilizando três coordenadas, $\mathrm{x}$ e y para as coordenadas do DTA e a coordenada $\delta$ para a diferença do valor de dose, portando temos o ponto $r_{m}\left(x_{m}, y_{m}\right)$ as coordenadas do ponto de referência, nesse mesmo ponto tem- se a terceira coordenada referente a dose $D_{m}\left(r_{m}\right)$, e o ponto a ser avaliado denotado por $r_{c}\left(x_{c}, y_{c}\right)$ sendo nesse ponto a dose calculada $D_{c}\left(r_{c}\right)$. Os critérios de tolerância $\Delta d_{m}$, para o DTA e $\Delta D M$, para a dose, formam uma superfície elipsoidal, descrita pela equação:

$$
1=\sqrt{\frac{\Delta D\left(\mathbf{r}, \mathbf{r}_{\mathbf{m}}\right)^{2}}{\Delta \mathrm{D}_{M}^{2}}+\frac{\Delta \mathrm{r}\left(\mathbf{r}, \mathbf{r}_{\mathbf{m}}\right)^{2}}{\Delta \mathrm{d}_{m}^{2}}}
$$

onde

$$
\Delta r\left(\mathbf{r}, \mathbf{r}_{\mathbf{m}}\right)=\left|\mathbf{r}-\mathbf{r}_{\mathbf{m}}\right|
$$

$\mathrm{e}$

$$
\Delta \mathrm{D}\left(\mathbf{r}, \mathbf{r}_{\mathbf{m}}\right)=\mathrm{D}(\mathbf{r})-\mathrm{D}_{m}\left(\boldsymbol{r}_{\boldsymbol{m}}\right)
$$


Sendo $\mathbf{r}$ o ponto calculado na superfície elipsoidal.

A função que calcula a distância entre os pontos de referência e a serem avaliados, levando em consideração a três coordenadas mencionadas é chamada função gama, mostrada na figura 2.8 e descrita por:

$$
\Gamma\left(\mathbf{r}_{c}, \mathbf{r}_{\mathbf{m}}\right)=\sqrt{\frac{\Delta D\left(\mathbf{r}_{c}, \mathbf{r}_{\mathbf{m}}\right)^{2}}{\Delta \mathrm{D}_{M}^{2}}+\frac{\Delta \mathrm{r}\left(\mathbf{r}_{c}, \mathbf{r}_{\mathbf{m}}\right)^{2}}{\Delta \mathrm{d}_{m}^{2}}}
$$

onde

$$
\Delta \mathrm{r}\left(\mathbf{r}_{c}, \mathbf{r}_{\mathbf{m}}\right)=\left|\mathbf{r}_{c}-\mathbf{r}_{\mathbf{m}}\right|
$$

e

$$
\Delta \mathrm{D}\left(\mathbf{r}_{\boldsymbol{c}}, \mathbf{r}_{\mathbf{m}}\right)=\mathrm{D}_{c}\left(\mathbf{r}_{\boldsymbol{c}}\right)-\mathrm{D}_{m}\left(\boldsymbol{r}_{\boldsymbol{m}}\right)
$$




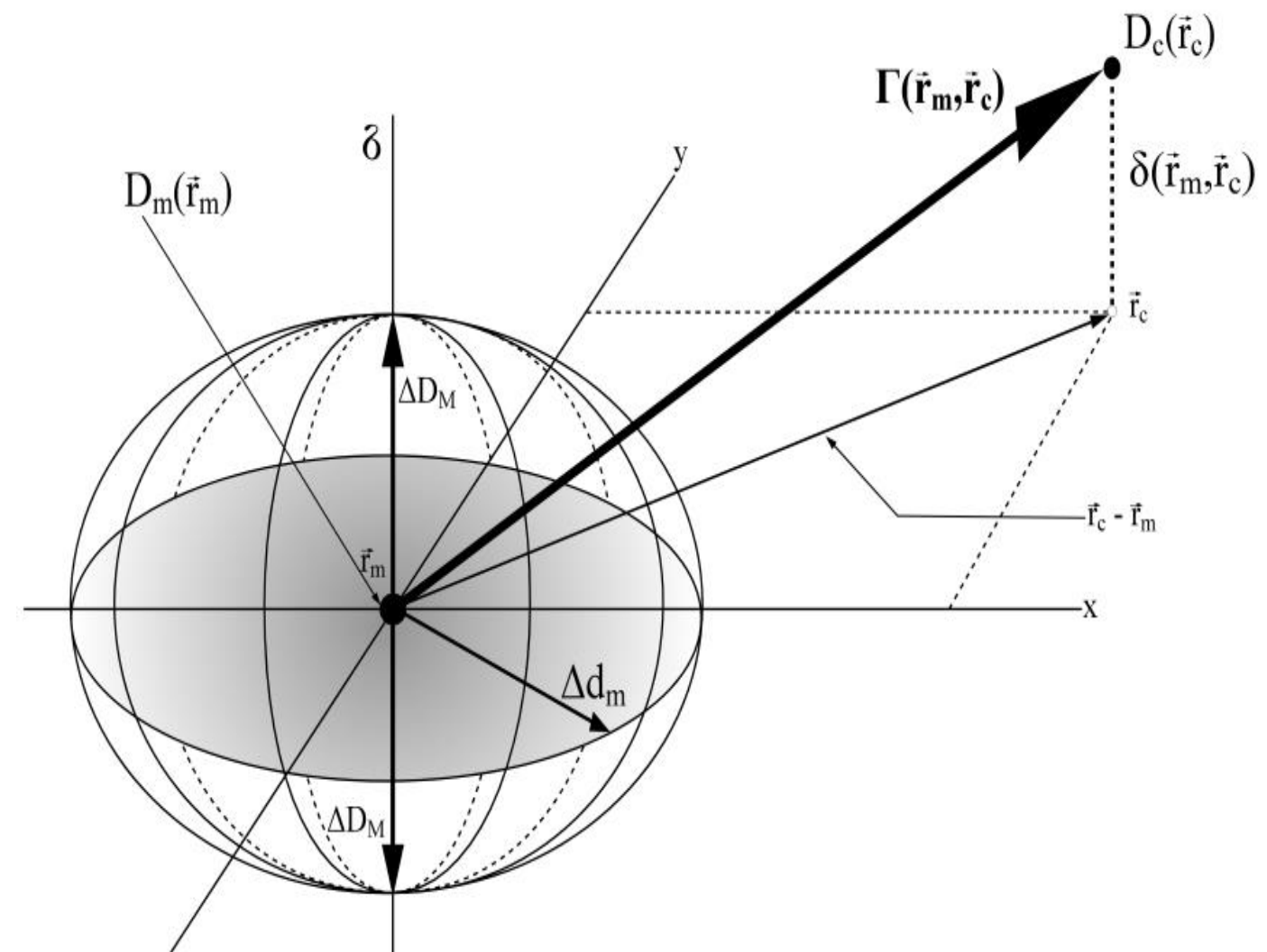

Figura 2.8: Representação Geométrica tridimensional para a diferença percentual de dose e o DTA e a representação do vetor da função gama.

O Cálculo da função gama é feito em todos os pontos, e o índice gama $\gamma$ é o menor valor encontrado para cada cálculo da função, ou seja:

$$
\gamma\left(\mathbf{r}_{\mathbf{m}}\right)=\min \left\{\boldsymbol{\Gamma}\left(\mathbf{r}_{\mathbf{c}}, \mathbf{r}_{\mathbf{m}}\right)\right\} \forall\left\{\mathbf{r}_{\mathbf{c}}\right\}
$$

Os índices gama passam no critério escolhido pela seguinte condição:

$\gamma\left(\mathbf{r}_{\mathbf{m}}\right) \leq 1$ - passa nos critérios de aceitação.

$\gamma\left(\mathbf{r}_{\mathbf{m}}\right)>1$ - falha nos critérios de aceitação.

Para ilustrar o cálculo com a função gama, comparado dois pixels calculados a um mesmo ponto de referência temos o primeiro com $+4 \%$ de $\Delta \mathrm{D}\left(\mathbf{r}_{c}, \mathbf{r}_{\mathbf{m}}\right)$ e o DTA $\left(\Delta \mathrm{r}\left(\mathbf{r}_{c}, \mathbf{r}_{\mathbf{m}}\right)\right)$ de $1 \mathrm{~mm}$, o segundo pixel com $+1,5 \%$ e $\Delta \mathrm{D}\left(\mathbf{r}_{\boldsymbol{c}}, \mathbf{r}_{\mathbf{m}}\right)$ e DTA de $1,5 \mathrm{~mm}$. Considerando o cálculo da função gama com os critérios de tolerância 3\%/3mm tem-se a seguinte avaliação:

Para o primeiro pixel comparado

$$
\sqrt{\frac{(4 \%)^{2}}{(3 \%)^{2}}+\frac{(1 m m)^{2}}{(3 m m)^{2}}}=1,3
$$


Para o segundo pixel comparado

$$
\sqrt{\frac{(1,5 \%)^{2}}{(3 \%)^{2}}+\frac{(1,5 m m)^{2}}{(3 m m)^{2}}}=0,7
$$

Então tomando a condição 5.11 temos o índice gama com

$$
\gamma=0,7
$$

e seu valor correspondente à $\gamma \leq 1$ seria um pixel aprovado no critério $3 \% / 3 \mathrm{~mm}$. Contudo a função gama, que calcula o índice gama, permite combinar os dois critérios descritos nesse capítulo, a diferença percentual de dose e a distância de concordância, avaliando-os simultaneamente, o que a torna um método confiável para o aceite e recusa das distribuições de doses planejadas. Para esse cálculo em empresas e grupos de pesquisas vêm desenvolvendo softwares com algoritmos rápidos, por exemplo, o Doselab $^{\circledR}$ e o Image-Pro ${ }^{\circledR}$ para a rotina clínica. Detectores como MapCHECK ${ }^{\circledR}$ acompanham um software próprio para o cálculo do índice gama. Esses softwares normalmente fornecem um mapa de índice gama com o valor do índice em cada pixel, e também um histograma da porcentagem de pixels com gama $\leq 1$ para assim verificar o aceite e recusa da distribuição planejada. 


\section{Capítulo 3-Dosimetria Gel}

Nesse capítulo será apresentada a dosimetria gel visando o gel polimérico Magic-f, seus princípios e sua aplicação. Também nesse capítulo vamos descrever imagens por ressonância magnética aplicada a dosimetria gel para quantificação das distribuições de dose.

\section{1- Dosímetros gel polimérico e o Gel Magic-f}

Inicialmente os primeiros dosímetros gel polimérico foram os géis tipo BANANA (Bis Acrylamide Nitrous oxide And Agarose) (Maryanski et al, 1993), BANG $^{\circledR}$ (Bis Acrylamide Nitrous oxide Gel) (Maryanski et al, 1994), e PAG(Polymer acrylamide Gelatine) (Baldock,1998), semelhantes na polimerização da acrilamida (AAm) e monômeros de Bis nos dois primeiros, diferindo apenas nas formulações, sendo o gel $\mathrm{BANG}^{\circledR}$ utilizando matriz de gelatina e não agarose, e os géis tipo PAG para outras formulações desse mesmo tipo de gel. As desvantagens desses géis para o uso na rotina clínica estão na alta toxicidade e na necessidade de um meio inerte para evitar a supressão de oxigênio, o que leva a alteração na reposta, linearidade e reprodutibilidade do dosímetro.

$\mathrm{Na}$ busca de gel em que a resposta à radiação não é inibida pela confecção na presença de oxigênio (Venning et al, 2005) e baixa toxicidade o surge o gel Magic (Fong et al, 2001), na sua formulação há monômeros de ácido metacrílico gelatina, um metal bivalente(sulfato de cobre) e um antioxidante (ácido ascórbico), esses dois últimos se ligam formando um complexo, assim o ácido ascórbico captura o oxigênio molecular e permite que o radical livre inicie a polimerização. Essa supressão do oxigênio pelo ácido ascórbico é a principal diferença entre o gel Magic dos outros tipos de géis.

Para aumentar a sensibilidade e ponto de fusão do gel Magic em 2008 nosso grupo adicionou na formulação desses dosímetro gel o formaldeído, seguindo o mesmo método de preparo que os trabalhos de Gustavsson (Gustavsson et al, 2003). Com isso o gel foi nomeado Magic-f pelo nosso grupo, tendo então um gel com ponto de fusão suficientemente alto $\left(69^{\circ} \mathrm{C}\right)$ para reter a informação tridimensional evitando o derretimento da gelatina, além de aumentar a sensibilidade do gel sem alterar as reações 
importantes para a polimerização e captura de oxigênio pelo ácido ascórbico (Fernandez et al, 2008).

\section{2 - Fundamentos dos géis poliméricos}

O principal fundamento dos dosímetros géis está na composição de uma matriz gelatinosa, em que os monômeros estão dissolvidos nesse meio. Ao serem irradiados ocorre o processo de radiólise da água (equação 3.1), tendo como produtos, elétrons aquosos, também chamados hidratados $\left(e_{a q}^{-}\right)$, radicais hidroxila $\left(\mathrm{OH}^{\bullet}\right)$ e íons hidroxônio $\left(\mathrm{H}_{3} \mathrm{O}^{+}\right)$.

$$
\mathrm{H}_{2} \mathrm{O} \stackrel{k_{d}}{\rightarrow} H^{\bullet}+{ }^{\bullet} \mathrm{OH}=2 R^{\bullet}
$$

As reações mais importantes a partir da radiólise são as de inicialização da polimerização (equação 3.2), a de crescimento da cadeia (equação 3.2) polimérica e as reações de terminação (equação 3.4, 3.5, 3.6)(Mano e Mendes, 1999).

$$
\begin{aligned}
& R^{\bullet}+M_{n} \stackrel{k_{1}(n)}{\longrightarrow} R M_{n}^{\bullet} \\
& R M_{n}^{\cdot}+M_{m} \stackrel{k_{p}(n, m)}{\longrightarrow} R M_{n+m}^{\cdot} \\
& R^{\bullet}+R^{\bullet} \stackrel{k_{t}}{\longrightarrow} R R=I \\
& R^{\bullet}+R M_{n}^{\cdot} \stackrel{k_{t 1}(n)}{\longrightarrow} I+M_{n} \\
& R M_{n}^{\cdot}+R M_{m}^{\bullet} \stackrel{k_{t 2}(n+m)}{\longrightarrow} I+M_{n+m}
\end{aligned}
$$

Nas equações $\mathrm{R}$ representa os radicais que reagem com os monômeros, os coeficientes k correspondem à taxa de reação proporcional a dose absorvida.

Os radicais produzidos iniciam a polimerização dos monômeros na ligação dupla do monômero, no caso do gel MAGIC-f, o ácido metacrílico apresenta apenas uma dupla ligação, onde o radical resultante da radiólise ira se ligar (figura 3.2.1) enfraquecendo a ligação $\pi$, a mais fraca das duplas ligações. 


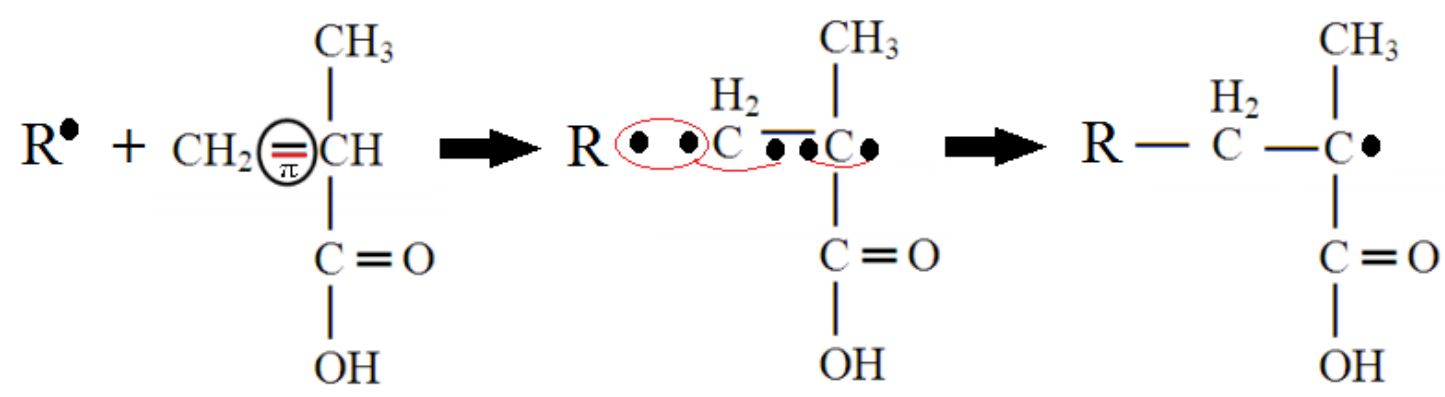

Radical + Ácido metacrilico

RM1

Figura 3.1: Inicio do processo de polimerização com a formação do primeiro monômero radical.

A figura 3.2.3 apresenta o mecanismo de reação da continuidade da polimerização

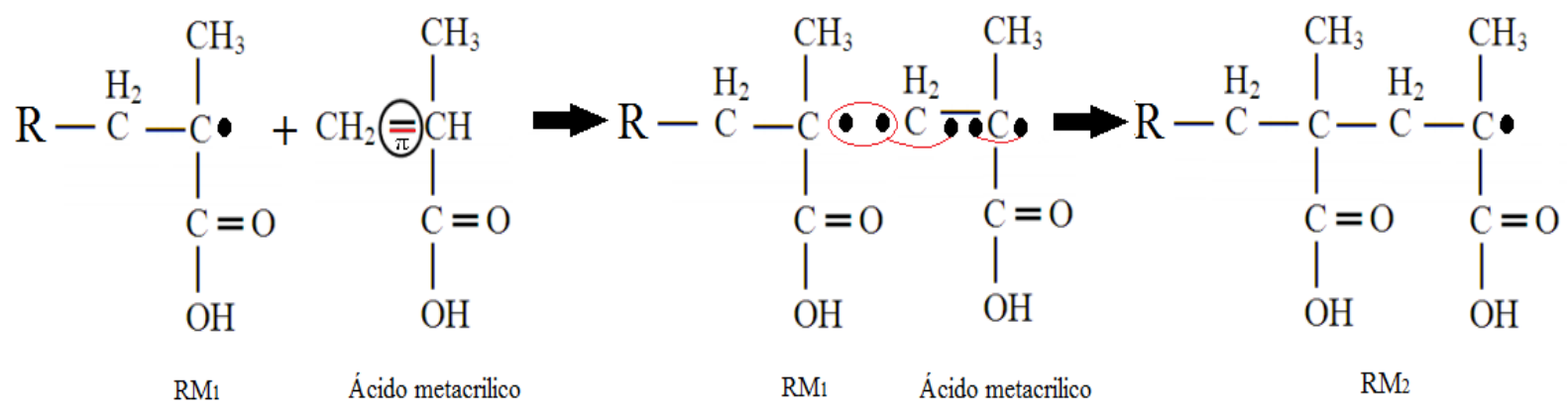

Figura 3.2: Polimerização a partir do monômero radical inicial formado, formando um polímero radical.

Como já citado o gel Magic foi o primeiro gel a ser confeccionado na presença do oxigênio, isso se deve ao sulfato de cobre e ao acido ascórbico que foram um complexo para suprimir o oxigênio presente no gel. A adição de formaldeído para aumentar o ponto de fusão do gel, isso acontece, pois o formaldeído reage com as terminações aminas primária da lisina e da arginina, que são aminoácidos presente na gelatina, formando assim ligações cruzadas entre os resíduos de gelatina (equação 3.8). O ponto de fusão aumenta, pois as ligações duplas cruzadas necessitam de mais energia para serem quebradas.

$$
\text { Gelatina }-\mathrm{NH}_{2}+\mathrm{CH}_{2} \mathrm{O} \rightarrow \mathrm{Gel}-\mathrm{N}=\mathrm{CH}_{2}+\mathrm{H}_{2} \mathrm{O}
$$

Ainda com a adição do formaldeído o dosímetro gel MAGIC-f continuou com a equivalência do tecidual com número atômico $Z_{\text {eff }}=7,045$ (Fernandez et al, 2008). 


\section{3 - Imagens por ressonância magnética nuclear}

As imagens por ressonância magnética nuclear é uma poderosa técnica de que medem de maneira não invasiva e não destrutiva a magnetização dos átomos de hidrogênio em moléculas de água com grande resolução espacial podendo ser em até três dimensões.

O fenômeno da ressonância magnética nuclear acontece quando temos uma amostra e a colocamos em um campo magnético uniforme, com isso os prótons de spins $1 / 2$ "quebram" a sua degenerescência pelo efeito Zeeman, assumindo dois estados diferentes de energia, um em que spins apresentam seu momento magnético paralelo, de menor energia, e outro antiparalelo ao campo magnético, sendo este de maior energia. Os dois níveis de energia são separados pela equação 3.9:

$$
\Delta E=\gamma B_{0}
$$

onde $\gamma$ é a razão giromagnética e $\mathrm{B}_{0}$ é o campo magnético aplicado.

Quando um sistema macroscópico está em equilíbrio a distribuição dos elementos paralelos e antiparalelos segue a distribuição de Boltzmann:

$$
\frac{N_{\text {paralelo }}}{N_{\text {antiparalelo }}}=e^{\frac{\Delta E}{k T}}
$$

Onde $\Delta \mathrm{E}$ é a diferença de energia entre os dois níveis de energia, $\mathrm{K}$ a constante de Boltzmann, $\mathrm{T}$ a temperatura, $\mathrm{N}_{\text {paralelo }} \mathrm{O}$ número de elementos orientado no sentido

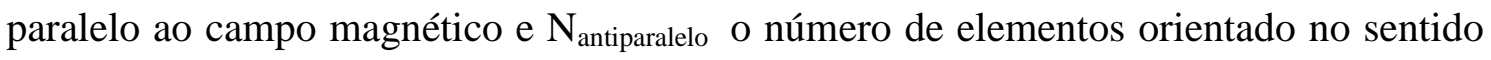
antiparalelo ao campo magnético. Quando temos a distribuição de prótons paralelos e antiparalelos podemos definir um verto de magnetização $(\vec{M})$, sendo esse o somatórios de todos os momentos magnéticos da amostra por unidade de volume (equação 3.11)

$$
\vec{M}=\frac{1}{V} \sum_{i}^{n} \vec{\mu}
$$

sendo $\mathrm{n}=\mathrm{N}_{\text {paralelo }}+\mathrm{N}_{\text {antiparalelo }}$ e $\mathrm{V}$ o volume infinitesimal da amostra submetida ao campo $\mathrm{B}_{0}$. 
O comportamento do vetor magnetização é de precessão ao redor do campo magnético aplicado com frequência angular $\omega_{0}$ (figura3.3), proporcional a intensidade do campo (equação 3.12).

$$
\omega_{0}=\gamma B_{0}
$$

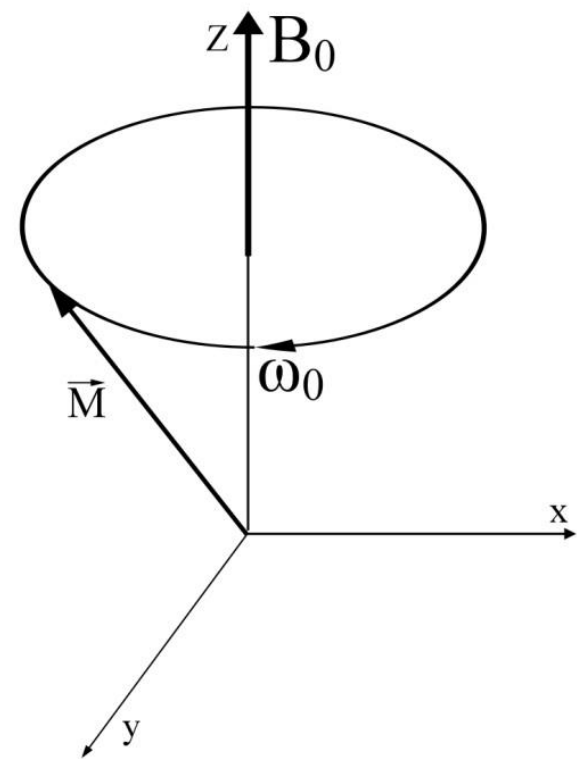

Figura 3.3: Esquema do movimento de precessão do vetor magnetização sobre o $B_{0}$.

A relação entre a frequência angular expressa em $\mathrm{rad} / \mathrm{s}$ e a frequência de precessão $\mathrm{f}_{0}$ expressa em $\operatorname{Hertz}(\mathrm{Hz})$ é dada pela seguinte relação:

$$
\omega_{0}=2 \pi f_{0}
$$

Sendo assim a frequência de precessão ou também chamada de frequência de ressonância temos combinado as equações 3.12 e 3.13 dada por:

$$
f_{0}=\frac{\gamma}{2 \pi} B_{0}
$$

No caso de um campo $\mathrm{B}_{0}$ de $1 \mathrm{~T}$ e $\gamma / 2 \pi=42,6 \mathrm{MHz}$, assim a frequência de ressonância será $\mathrm{f}_{0}=42,6 \mathrm{MHz}$. 
Quando aplicamos um pulso de radiofrequência os prótons no estado de menor energia transitam para o estado de maior energia, provocando a mudança no vetor magnetização, ao retornar ao estado inicial ocorre indução de corrente na bobina receptora gerando o sinal de RMN.

O tempo de retorno da magnetização ao estado inicial é chamado de tempo de relaxação que acontece em duas modalidades simultaneamente: Relaxação longitudinal e transversal.

Relaxação longitudinal ou spin-rede (T1): Inicialmente no eixo z a magnetização $\mathrm{M}_{\mathrm{z}}$ é igual a $\mathrm{M}_{0}$, ao aplicar o pulso de radiofrequência é deslocada para o plano x-y, assim a magnetização no plano x-y $\left(\mathrm{M}_{\mathrm{xy}}\right)$ é igual a $\mathrm{M}_{0}$ e o processo de relaxação inicia conforme a equação (3.15)

$$
M_{z}=M_{0}\left(1-e^{-\frac{t}{T 1}}\right)
$$

Após o tempo $\mathrm{T} 163 \%$ da magnetização $\mathrm{M}_{0}$ é restabelecida. A figura 3.4 ilustra o comportamento da magnetização longitudinal (Tofts, 1999).

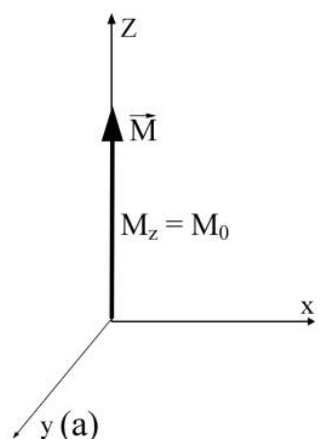

Figura 3.4: Comportamento da Magnetização longitudinal após um pulso de $90^{\circ}$. (a) magnetização no eixo $\mathrm{z}$ com magnetização $\mathrm{M}_{\mathrm{z}}=\mathrm{M}_{0}$. (b) Magnetização deslocada para o plano z-y pelo pulso de $90^{\circ}$. (c) Após o tempo de relaxação $\mathrm{T} 1$ a magnetização $\mathrm{M}_{\mathrm{z}}$ possui $63 \%$ de $\mathrm{M}_{0}$. (d) Restabelecimento do equilíbrio na condição inicial.

Relaxação transversal ou spin-spin(T2): Quando o pulso de radiofrequência deslocar a magnetização para o plano $\mathrm{x}-\mathrm{y}$, a rotação dos spins em torno do eixo z possui a mesma frequência que a frequência de Larmor. No processo de relaxação transversal, descrita pela equação 3.5, a magnetização total entra em defasagem devido aos diferentes campos magnéticos dos spins interagindo, girando com sua própria frequência, assim a 
magnetização no plano x-y $M_{x y}$ vai diminuindo pela sobreposição desses diferentes vetores de magnetização (figura 3.4.3) (Tofts, 1999).

$$
M_{x y}=M_{0} e^{-\frac{t}{T 2}}
$$

O tempo T2 é sempre menor que T1, refere-se ao tempo para diminuir a magnetização no plano $\mathrm{x}-\mathrm{y}$ a $37 \%$ do seu valor inicial ao mesmo tempo em que a magnetização longitudinal cresce novamente no eixo $\mathrm{z}$.
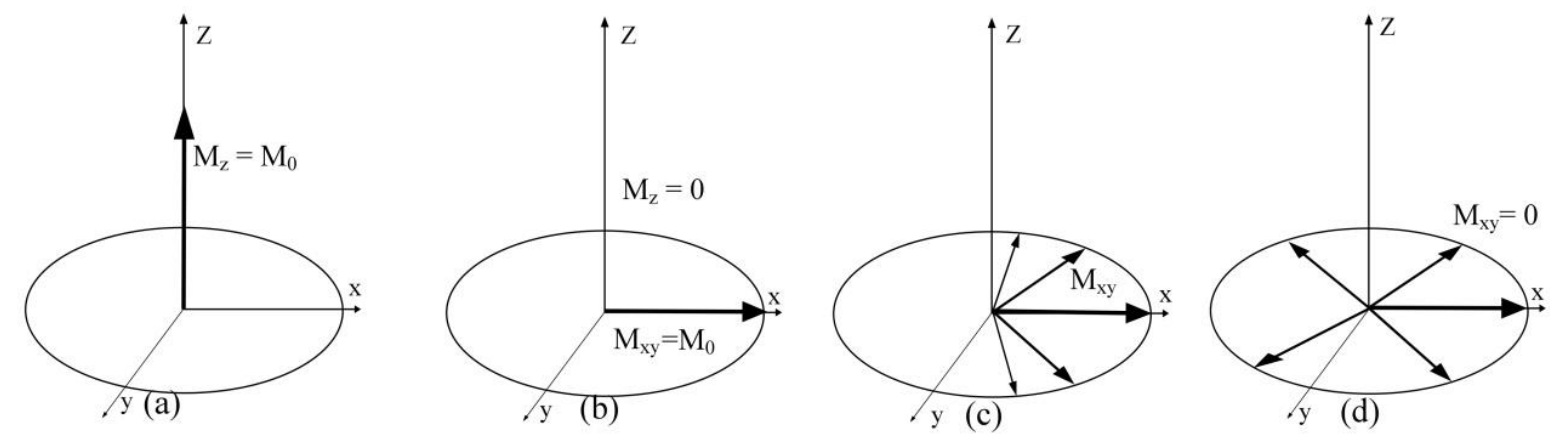

Figura 3.5: Comportamento da magnetização transversal após um pulso de $90^{\circ}$.(a) magnetização no eixo z com magnetização $M_{z}=M_{0}$. (b) Magnetização deslocada para o plano z-y pelo pulso de $90^{\circ}$. (c) Inicio da defasagem diminuindo $M_{x y}$. (d) defasagem completa resultando em $M_{x y}=0$.

A relaxação transversal é influenciada por dois fatores, as interações moleculares e ao efeito da não homogeneidade do campo magnético $\mathrm{B}_{0}$. A combinação desses dois efeitos é chamada de $\mathrm{T} 2{ }^{*}$ dado pela equação:

$$
\frac{1}{T 2^{*}}=\frac{1}{T 2}+\frac{1}{T 2_{\text {inomogeniedades }}}
$$

Quando o dosímetro gel é irradiado o monômero é convertido em polímero, o que provoca alterações nas taxas de relaxação longitudinal $(\mathrm{R} 1=1 / \mathrm{T} 1)$ e transversal $(\mathrm{R} 2=1 / \mathrm{T} 2)$ que são associadas às doses absorvidas. Em dosimetria com géis poliméricos as taxas de relaxação R2 são melhores visualizadas que R1, o que faz que com R2 seja medido nas IRMN. (Baldock et al, 2010).

A sequência de ressonância magnética preferida para a dosimetria com géis poliméricos é a sequência Multi spin eco (MSE) (Baldock et al, 2010). Nessa sequência 
é aplicado primeiramente um pulso de $90^{\circ}$ seguido de sucessivos pulsos de $180^{\circ}$ (figura 3.4.4). Após a aplicação do pulso de $90^{\circ}$ a magnetização $\mathrm{M}_{\mathrm{xy}}$ possui seu valor máximo o que gera uma corrente na bobina de RMN chamada FID (Free induction decay) (figura3.4.5). Quando se inicia a defasagem o FID diminui devido ao processo de relaxação. Após um tempo se aplica o pulso de $180^{\circ}$ que faz com que os spins entrem novamente em fase por um tempo até que entrem novamente em defasagem e gerem o sinal nas bobinas de detecção. Este sinal é chamado sinal de eco e o tempo que se aplica o pulso ao tempo que o sinal de eco possui maior intensidade são chamados de tempo de eco (TE). A cada pulso de $180^{\circ}$ aplicado o sinal diminui exponencialmente devido à relaxação $\mathrm{T} 2$.

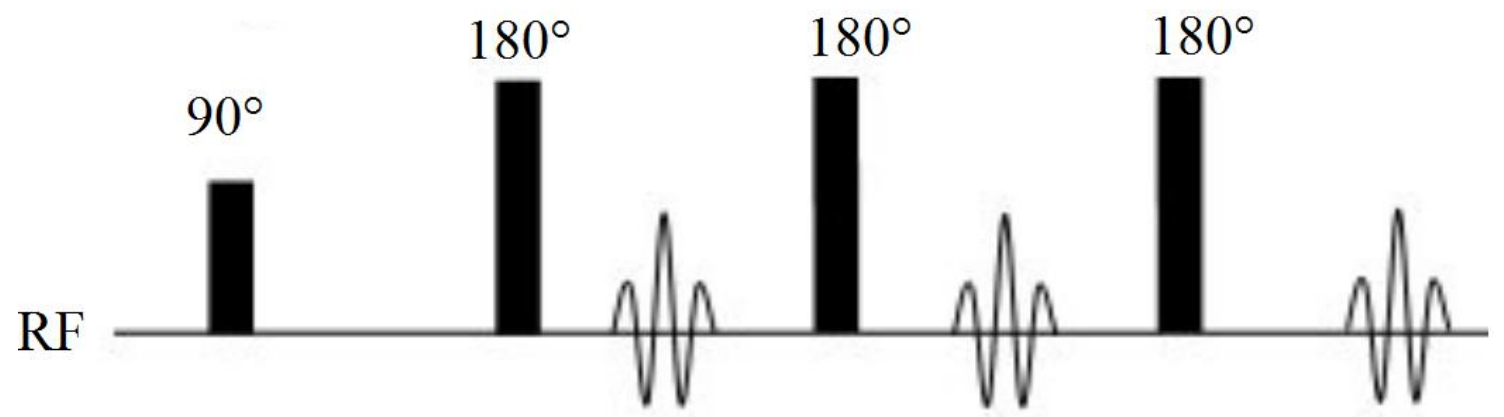

Figura 3.6: Sequência multi spin eco com pulsos de $90^{\circ}$ sucedidos por pulsos de $180^{\circ}$ e emitindo o sinal de eco.

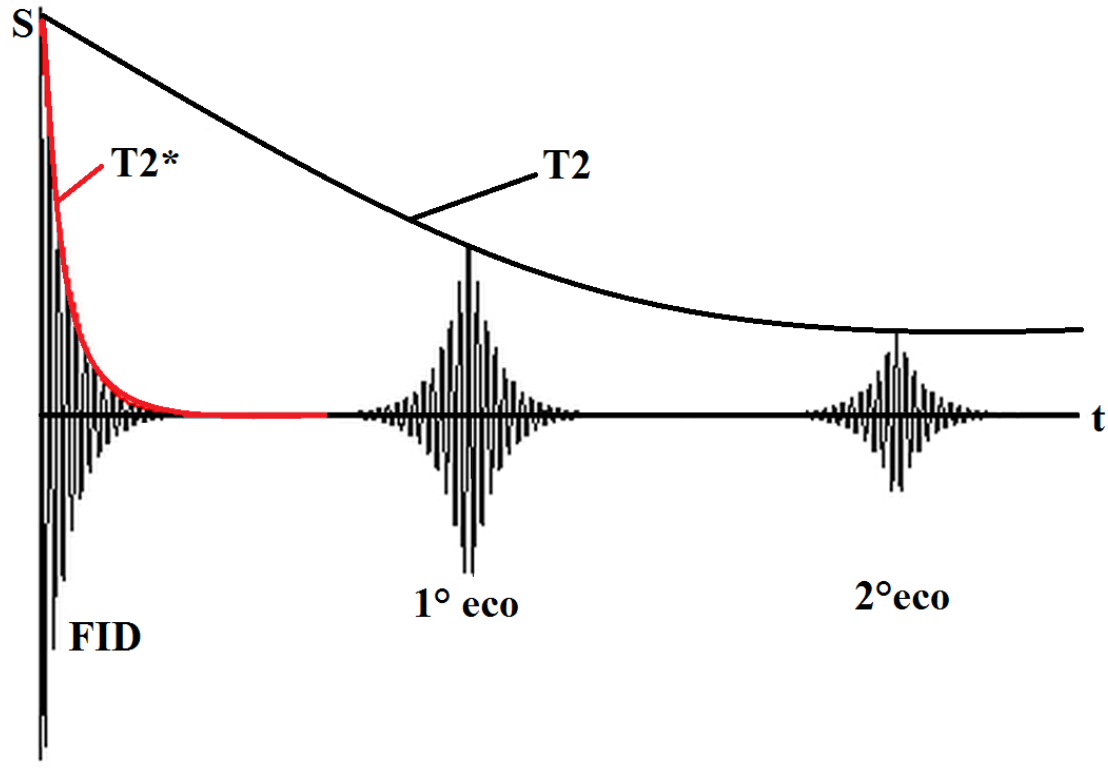

Figura 3.7: Sinal FID, decaimento de $\mathrm{T} 2 *$ e $\mathrm{T} 2$, sendo que o decaimento de $\mathrm{T} 2$ predomina na sequência multi spin eco. Figura retirada do site http://www.nmr.uni-duesseldorf.de e modificada. 
Nas sequencias MSE outro parâmetro importante é o tempo de repetição TR , que dever ser longo com tempos de eco TE curtos para obter as imagens ponderadas em T2, e assim o sinal de eco é descrito pela equação:

$$
\mathrm{SE}=S_{0} e^{-\frac{T E}{T 2}}
$$

Para se determinar a dose absorvida em uma região anatômica escolhida no objeto simulador é necessário pelo menos dois ecos para determinar a taxa de relaxação $\mathrm{R} 2$, pois na equação temos duas incógnitas, o sinal SE e o tempo de relaxação. Determinado a taxa se associa a dose absorvida.

Na figura 3.8 mostra os passos para se determinar a distribuição de dose a partir de uma sequência multi spin eco. Primeiro adquirindo vários ecos, em seguida determinando o mapa de R2 a partir da regressão linear dos logaritmos naturais das intensidades do sinal, e por fim determinado as distribuições de dose. 


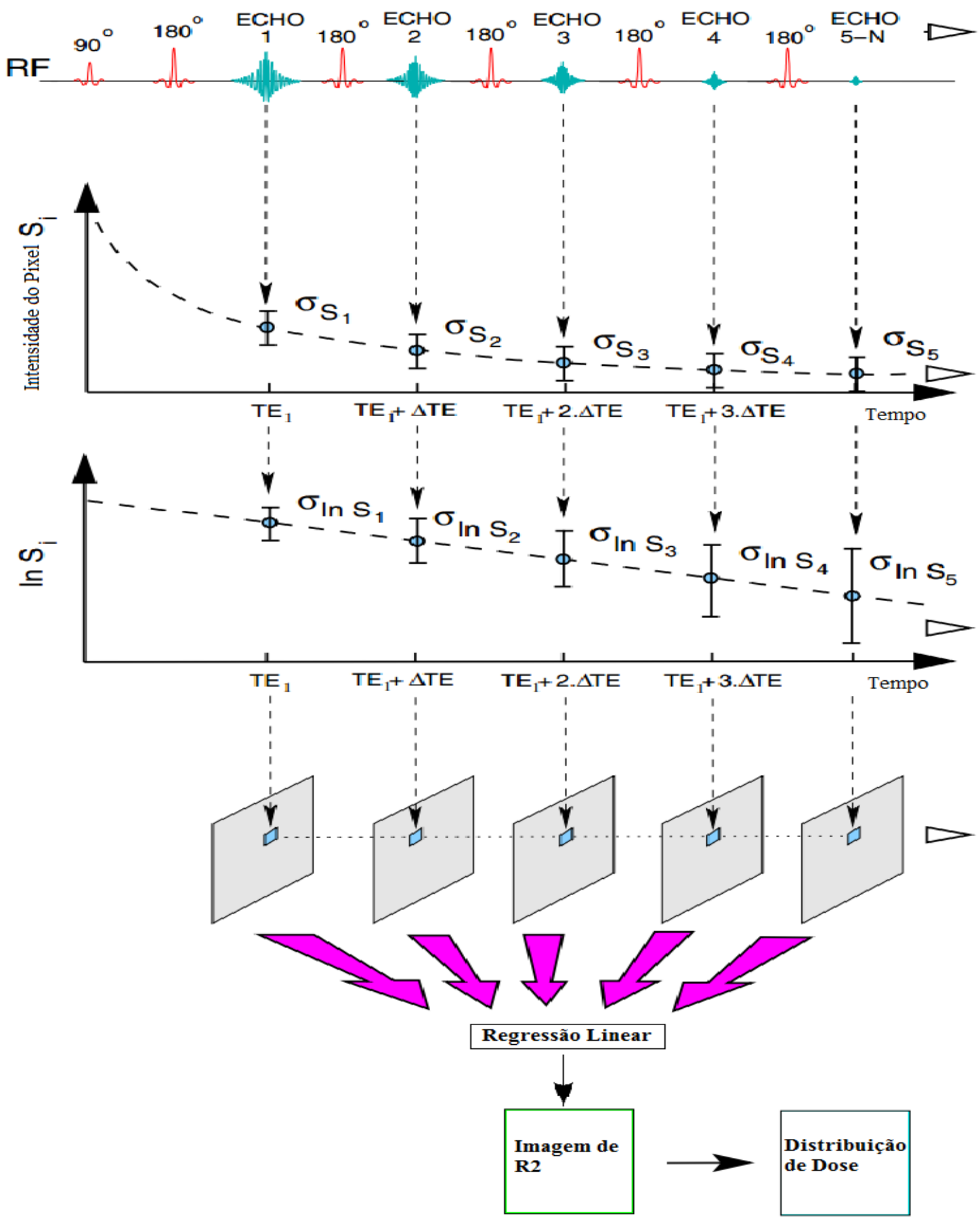

Figura 3.8: Aquisição das imagens de ressonância Magnética para determinação de R2 e das distribuições de dose. Figura retirada do De Deene et al, 2002 e modificada.

\section{4 - Metodologia da Dosimetria gel}

A dosimetria com géis poliméricos possui quatro etapas (figura 3.9): Primeiramente o gel é fabricado e acondicionado nos objetos simuladores e tubos de calibração. A segunda etapa os objetos simuladores são irradiados com o tipo de tratamento que faz uso da radiação ionizante, nesse trabalho IMRT para dez tratamentos 
de câncer de próstata. Também na segunda etapa são irradiados os tubos de calibração, onde cada tubo é irradiado com doses conhecidas para se determinas a taxa de relaxação R2 associada a cada dose. Na terceira etapa após o processo de polimerização estabilizar os objetos simuladores são submetidos à leitura por uma técnica de imagem, no caso desse trabalho Imagens por ressonância magnética (IRM). E por fim as imagens são processadas para se determinar as distribuições de dose tridimensionais.

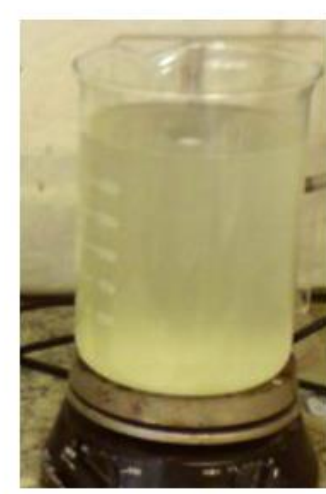

Fabricação

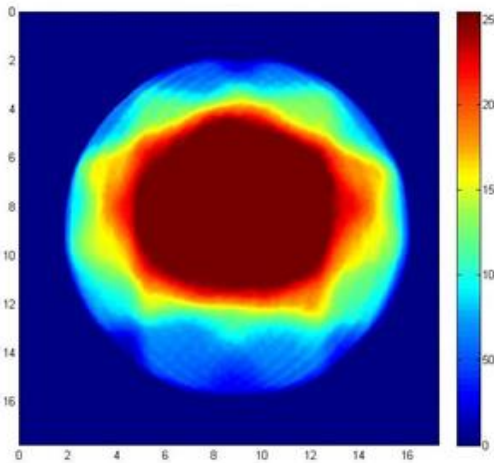

Determinação das distribuições de dose

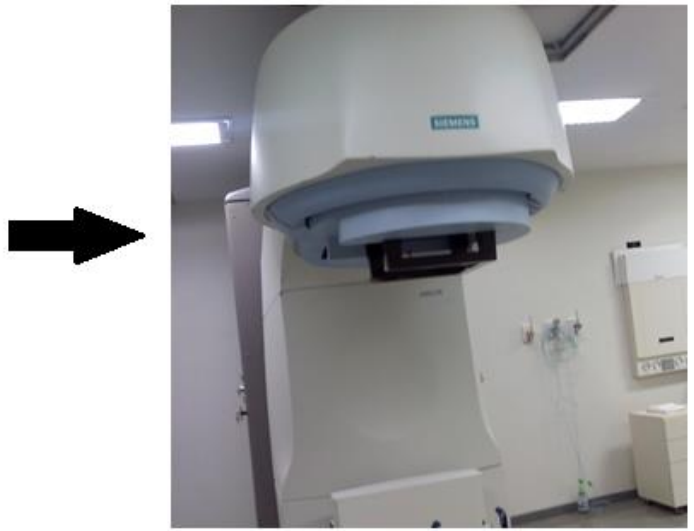

Irradiacão

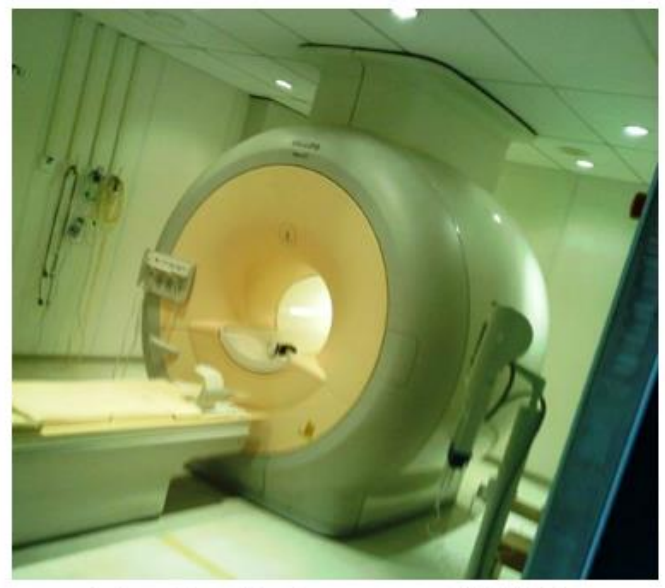

Técnica de Imagem:IRMN

Figura 3.9: Metodologia da dosimetria gel passo a passo, fabricação, irradiação, leitura pela técnica de imagem e determinação das distribuições de dose. 


\section{Capítulo 4 - Materiais e métodos}

Nesse capítulo serão apresentados os seguintes passos: Manufatura do gel Magic-f, acondicionamento do gel nos objetos simuladores, planejamento da radioterapia, as irradiações, as aquisições das imagens de ressonância magnética e o procedimento de processamento das imagens para obter os resultados desse trabalho.

\section{1 - Preparo do gel Magic-f}

O preparo do gel MAGIC-f necessita de uma minuciosa atenção em pesar, medir, adicionar os reagentes e também na estabilidade da temperatura durante o processo de fabricação, pois de acordo com a literatura, a história térmica do gel pode influenciar na sensibilidade. A composição do gel Magic-f que foi desenvolvido em nosso grupo é apresentada na tabela1.

Tabela 4.1: Composição em Massa do gel MAGIC-f

\begin{tabular}{|c|c|}
\hline Reagente & Porcentagem em Massa \\
\hline Água Mili-Q & $82,70 \%$ \\
\hline Gelatina-300Bloom & $8,25 \%$ \\
\hline Ácido Metacrílico & $6,00 \%$ \\
\hline Formoldeído & $3,00 \%$ \\
\hline Ácido ascórbico & $0,03 \%$ \\
\hline Sulfato de cobre & $0,02 \%$ \\
\hline
\end{tabular}

O processo de manufatura do gel se inicia utilizando um agitador magnético (figura 4.1), que aquece a água até $50^{\circ} \mathrm{C}$ em constante agitação. Mantendo essa temperatura, a gelatina é adicionada ao poucos, para que seja dissolvida uniformemente e não forme crostas ou bolhas dentro da matriz gelatinosa, essa etapa tem duração em média de 45 minutos. Quando toda gelatina é dissolvida tem-se uma solução transparente e homogênea. Em seguida a solução é resfriada até $35^{\circ} \mathrm{C}$, e se adiciona o ácido ascórbico e o sulfato de cobre. Após uma homogeneização de 5 minutos é adicionado o formaldeído e o ácido metacrílico e a solução é deixada em agitação por mais 10 minutos. Assim o gel é acondicionado nos recipientes usados para calibração e simulação do tratamento. Os recipientes com gel são colocados na geladeira a uma 
temperatura em média de $12^{\circ} \mathrm{C}$, onde foram mantidos para gelatinização por pelo menos 12 horas.

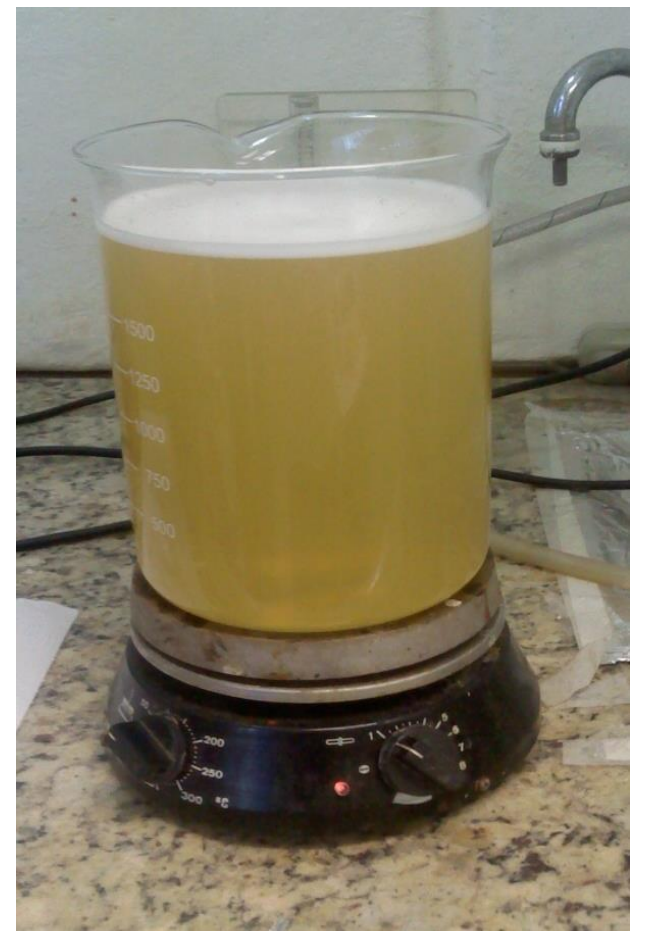

Figura 4.1: Confecção do Gel Magic-f usando agitador magnético.

A sensibilidade e a reprodutibilidade do gel dependem de diversos fatores, dentre eles, a efetividade química dos reagentes e a histórica térmica da preparação do gel. Por isso a cada processo da dosimetria com gel polimérico é necessário fazer a calibração.

\section{2 - Acondicionamento do gel Magic-f}

Para acondicionar o gel é fundamental que se escolha recipientes que protejam o lote de gel da influência do oxigênio, pois o mesmo pode interferir ou até mesmo inibir o processo de polimerização, e assim a informação da dose absorvida ser comprometida devido a esse efeito. 


\subsection{1 - Recipientes de calibração}

Nesse estudo, a calibração foi feita usando vários tubos de mesmo volume passando por um único feixe de radiação ionizante de mesma característica.

Os tubos de calibração devem possuir um volume pequeno, pois assim evita-se o efeito do decaimento da radiação com a profundidade, levando a menos variações de dose absorvida em seu interior, contribuindo para uma medida de R2 confiável. O tubo para calibração escolhido foi do tipo BD Vacutainer® com $5 \mathrm{ml}$ de volume e $12 \mathrm{~mm}$ de diâmetro, utilizado para colher sangue em exames. O tamanho desses tubos nos permite uma análise estatística adequada da dose absorvida em seu interior, se assim assumirmos que a dose depositada no seu interior é homogênea, como feito nesse trabalho. Esses tubos são feitos de vidro para evitar a difusão do oxigênio externo para o meio interno e ainda por possuir vácuo tem a vantagem de não deixar a amostra interna em contato com o oxigênio.

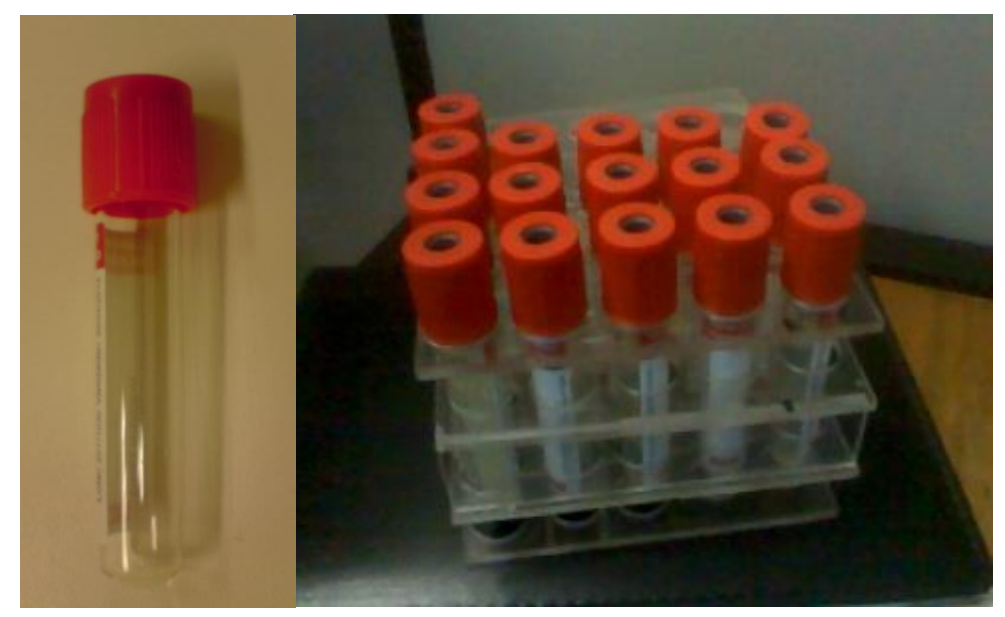

Figura 4.2: tubos BD Vacutainer® com $5 \mathrm{ml}$ de volume e $12 \mathrm{~mm}$ de diâmetro.

\subsection{2 - Recipientes usados para simular o tratamento de radioterapia}

Nesses recipientes serão simulados os tratamentos de câncer de próstata, então sua escolha exige os seguintes requisitos: volume adequado para simular a região da próstata e sua vizinhança, além de isolar o ar exterior do lote de gel no interior do recipiente. 
Os acondicionamentos do gel foram feitos em recipientes Tupperware ${ }^{\circledR}$, de formato cilíndrico com $10 \mathrm{~cm}$ de altura, 14,5 cm de diâmetro e volume de 1,65 litros, sendo este um tamanho razoável para simular a região a ser irradiada, além disso, esses recipientes possuem um sistema hermético na tampa, o que possibilita vedar bem o recipiente e assim diminuir a ação do oxigênio externo no lote de gel acondicionado. $O$ recipiente utilizado é mostrado na figura 4.3:

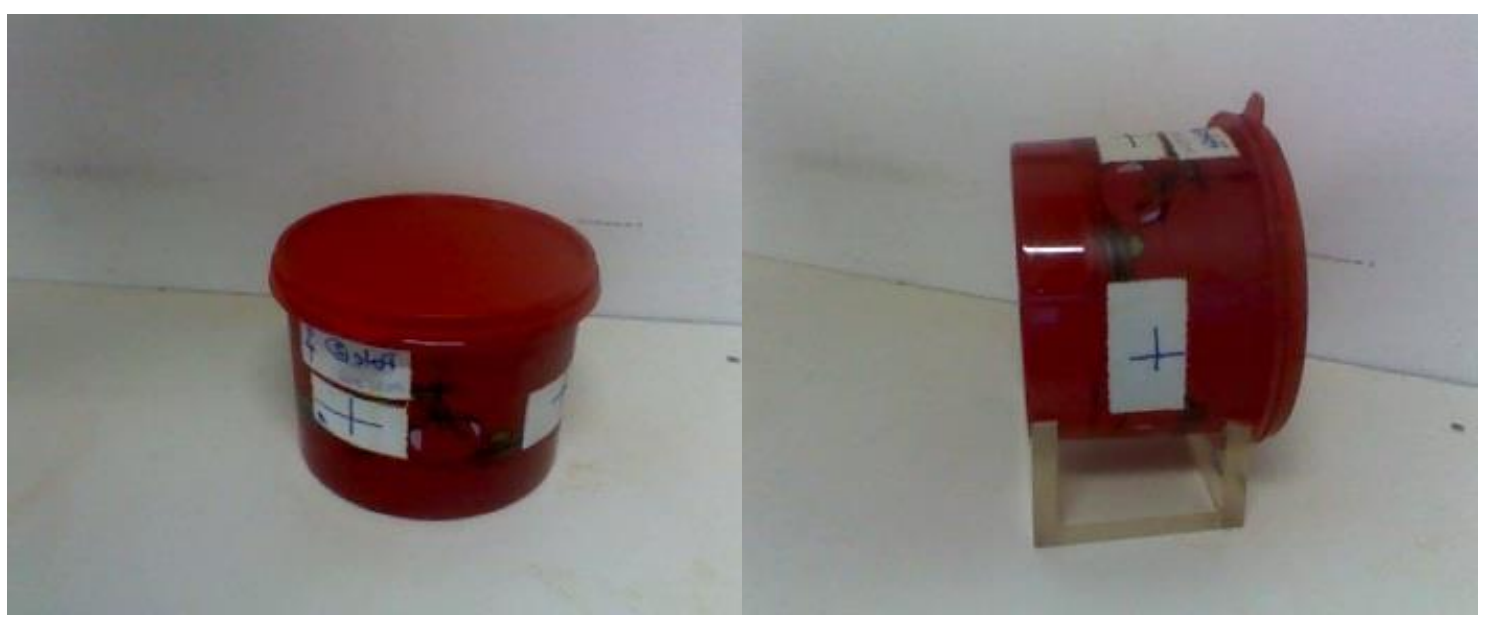

Figura 4.3: (a) Tupperware usado para acondicionar o gel. (b) Tupperware no suporte confeccionado para o CT de planejamento, irradiação no AL, e leitura no tomógrafo de ressonância magnética.

\section{3 - Irradiações}

As irradiações nesse trabalho foram feitas no centro de radioterapia de São Carlos no Hospital Santa Casa da Misericórdia usando um acelerador linear de 6MV (CLINAC 600CD/ Varian).

\subsection{1 - Planejamento}

A tomografia computadorizada de planejamento das irradiações foi realizada no Hospital das Clínicas em Ribeirão Preto, em um tomógrafo PHILLIPS (figura 4.4) utilizando o mesmo objeto simulador preenchido com água para facilitar o procedimento e evitar o consumo de gel. Nesse procedimento se adquiri as imagens para serem exportadas para o sistema de planejamento Eclipse ${ }^{\circledR}$ na Santa Casa da Misericórdia em São Carlos. Para a localização do isocentro, na marcação com o laser foram colocados objetos radiopacos chamados de "bibs", que na imagem adquirida revela a posição do isocentro, como mostrado na figura 4.5 . 


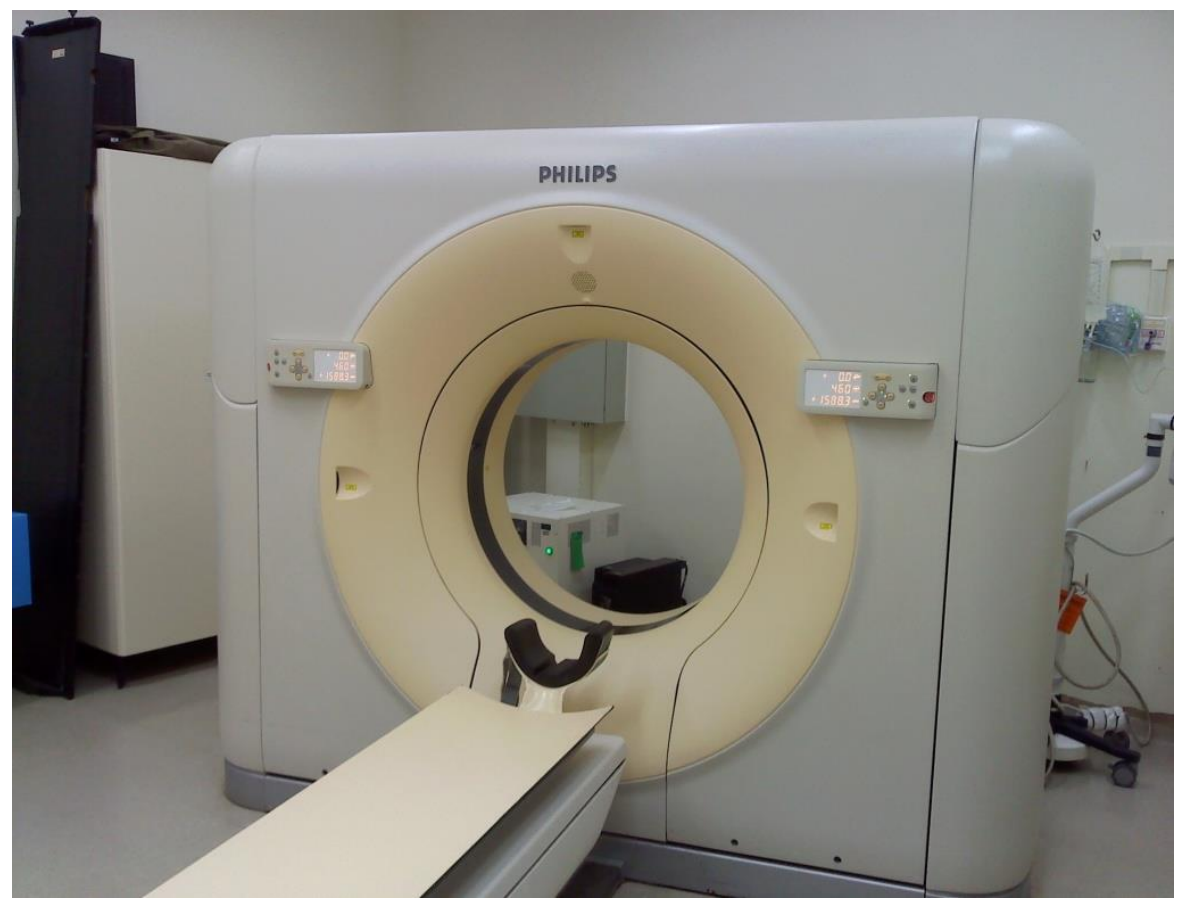

Figura 4.4: Tomografo PHILIPS Hospital das clínicas de Ribeirão Preto.

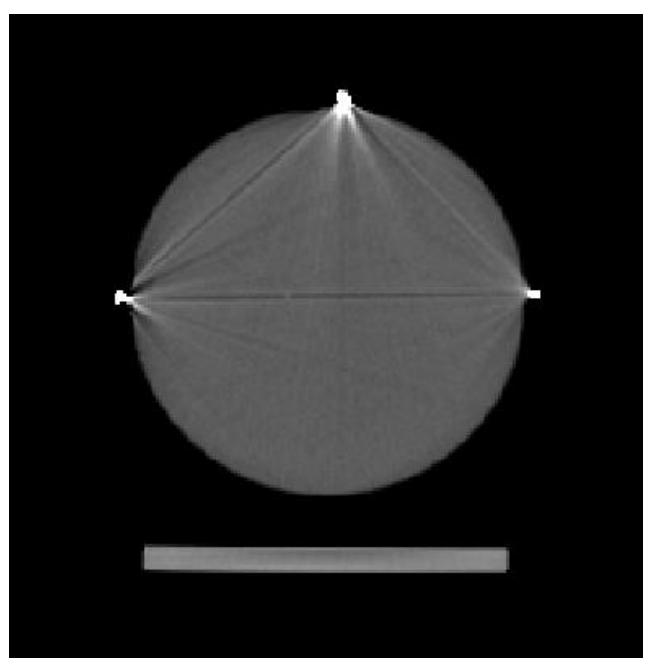

Figura 4.5: Imagem de CT no isocento localizado pelo bibs no circulo de cor cinza, o retangulo cinza abaixo do circulo é o suporte de acrilico.

O Protocolo utilizado foi o padrão para a pelve, já salvo no sistema computacional do tomografo, e foram adquiridas 52 imagens no formato DICOM de $512 \times 512$ pixels de $0,97 \times 0,97 \mathrm{~mm}$ com espesurra de $3 \mathrm{~mm}$ e espaçamento de $3 \mathrm{~mm}$ entre elas.

Os planejamentos utilizados nesse trabalho pertenciam a 10 pacientes já tratados no ano de 2011 e 2012, então utilizando o sistema de planejamento Eclipse ${ }^{\circledR}$ da Santa 
Casa de Misericordia os planejamentos desses pacientes foram exportados para as imagens de CT do objeto simulador. Como mostram as figuras 4.6 e 4.7 a seguir.

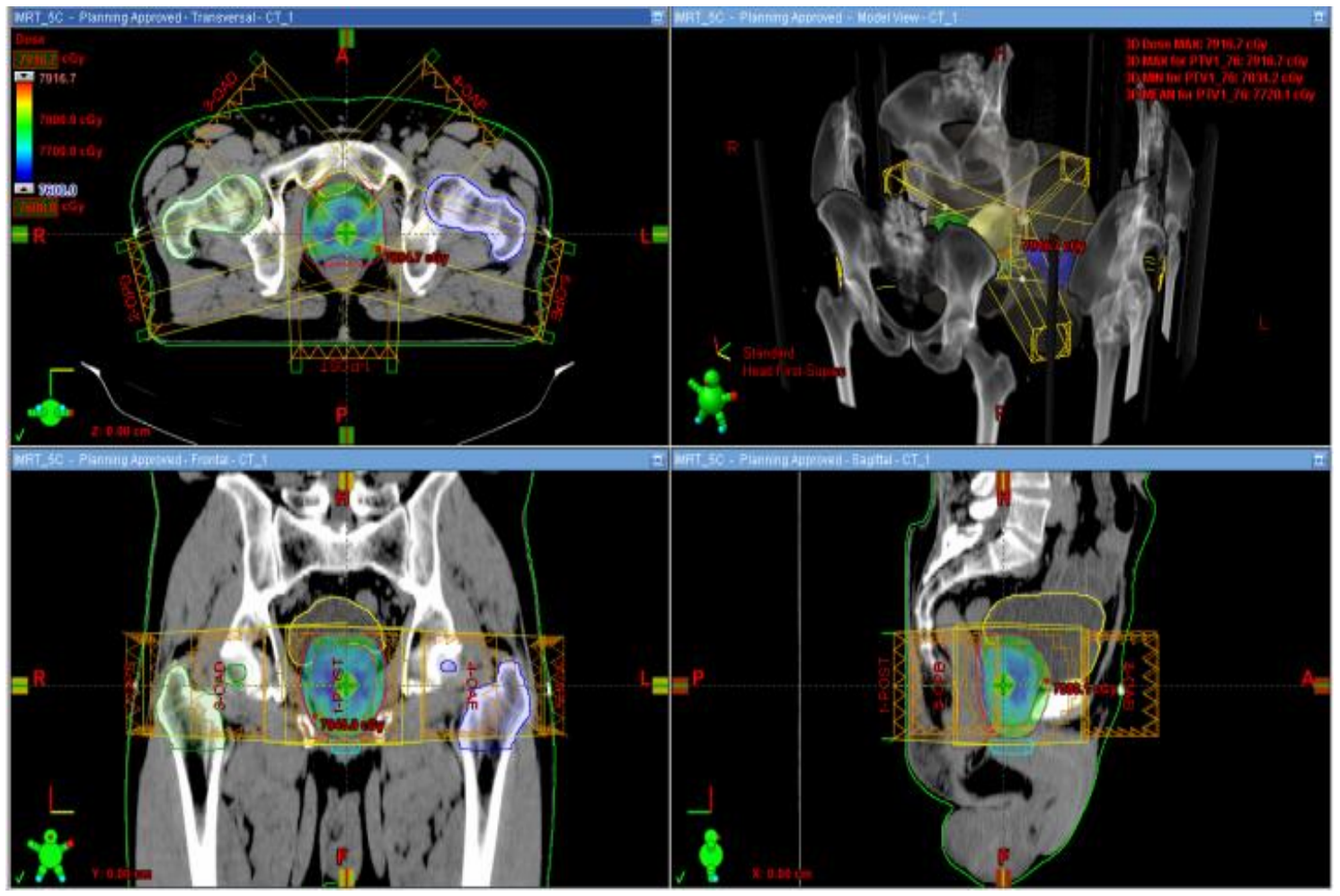

Figura 4.6: Planejamento em um paciente real a ser tratado no centro de radioterapia de São Carlos.

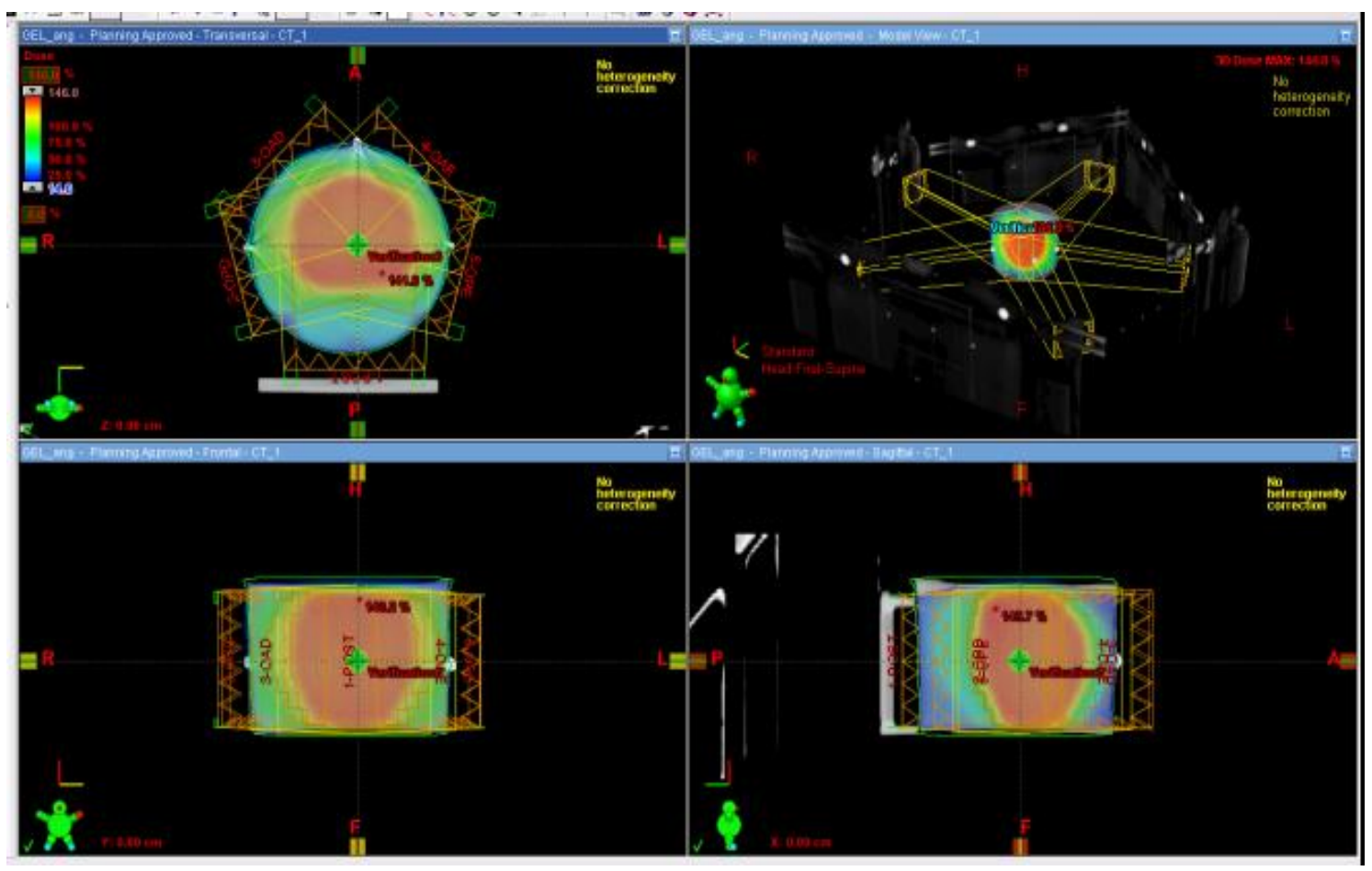

Figura 4.7: Planejamento exportado de um paciente para o objeto simulador 


\subsection{2 - Irradiações com a Câmara de ionização}

As irradiações com a câmara de ionização fazem parte do procedimento convencional do controle de qualidade em IMRT no centro de radioterapia de São Carlos. Essa irradiação consiste em utilizar um cilindro feito de polimetil metacrilato, em que no isocentro é colocada a câmara de ionização Iba 0.13 MAX4001 de fator de calibração $\mathrm{N}_{\mathrm{W}, \mathrm{Q}}$ de 26,575 cGy/nC.

Para a verificação da calibração do acelerador linear é medida a temperatura e a pressão da sala de tratamento, a fim de determinar o fator de temperatura e pressão $\mathrm{F}(\mathrm{P}, \mathrm{T})$ e feita uma leitura na câmara de ionização com a exposição de um campo $10 \mathrm{x}$ $10 \mathrm{~cm}$ com unidades monitoras de 100.

As irradiações para o controle de qualidade pontual são feitas de duas maneiras no Centro de Radioterapia de São Carlos: A primeira cada campo é irradiado no seu respectivo ângulo do gantry, e a segunda todos os campos com o ângulo na posição inicial $\left(180^{\circ}\right.$ na marcação no acelerador).

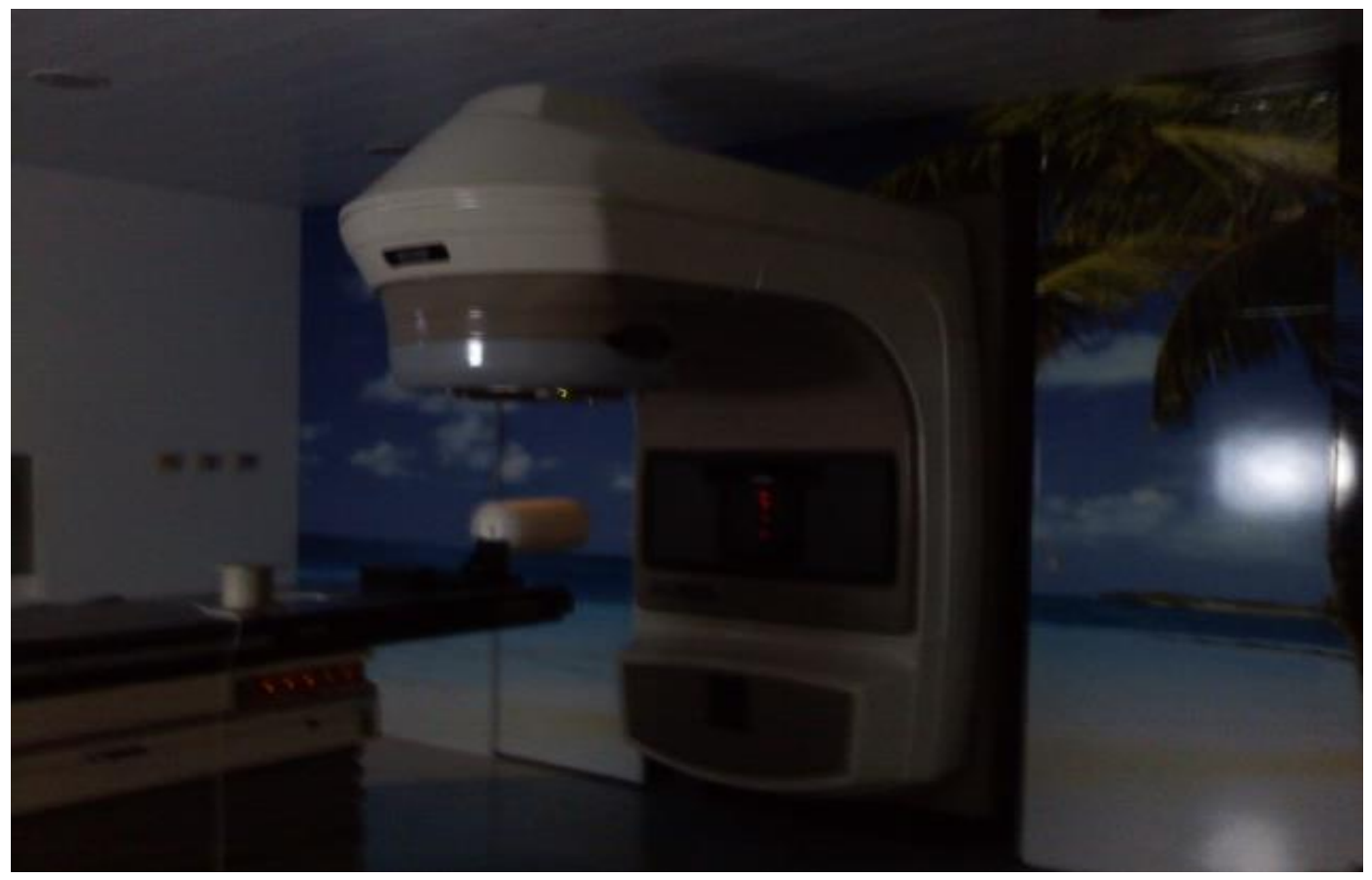

Figura 4.8: Irradiação com a Câmara de ionização posiciona no isocentro do acelerador linear CLINAC 600CD/ Varian da Santa Casa Misericórdia de São de Carlos. 


\subsection{3 - Irradiações no Mapcheck2}

O controle de qualidade bidimensional no Centro de radioterapia de São Carlos é feito utilizando uma placa com diodos chamado MapCHECK2 ${ }^{\mathrm{TM}}$ da SunNuclear Corporation. Como já citado esse detector possui 1527 diodos com área sensível de $0,64 \mathrm{~cm}^{2}$, com espaçamento de 7,07mm entre cada diodo, podendo ser irradiado com campo máximo de $32 \times 26 \mathrm{~cm}$.

As irradiações no Mapchek2 são feitas apenas com o gantry na posição inicial, sobrepondo todos os campos planejados, e o resultado adquirido, é visualizado no software próprio do produto mostrado na figura 4.10 .

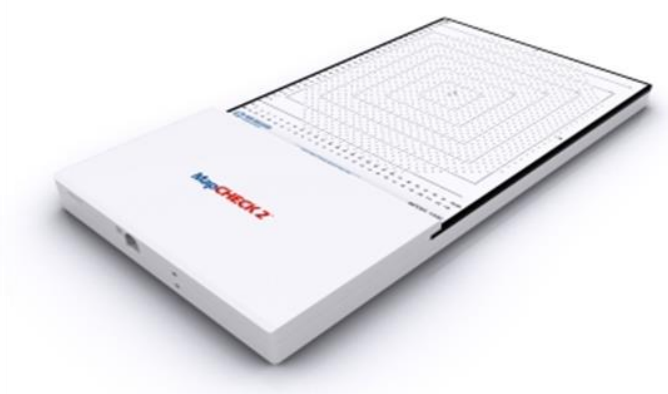

Figura 4.9: Placa de diodos MapCHECK $2^{\mathrm{TM}}$ da Sun Nuclear Corporation.

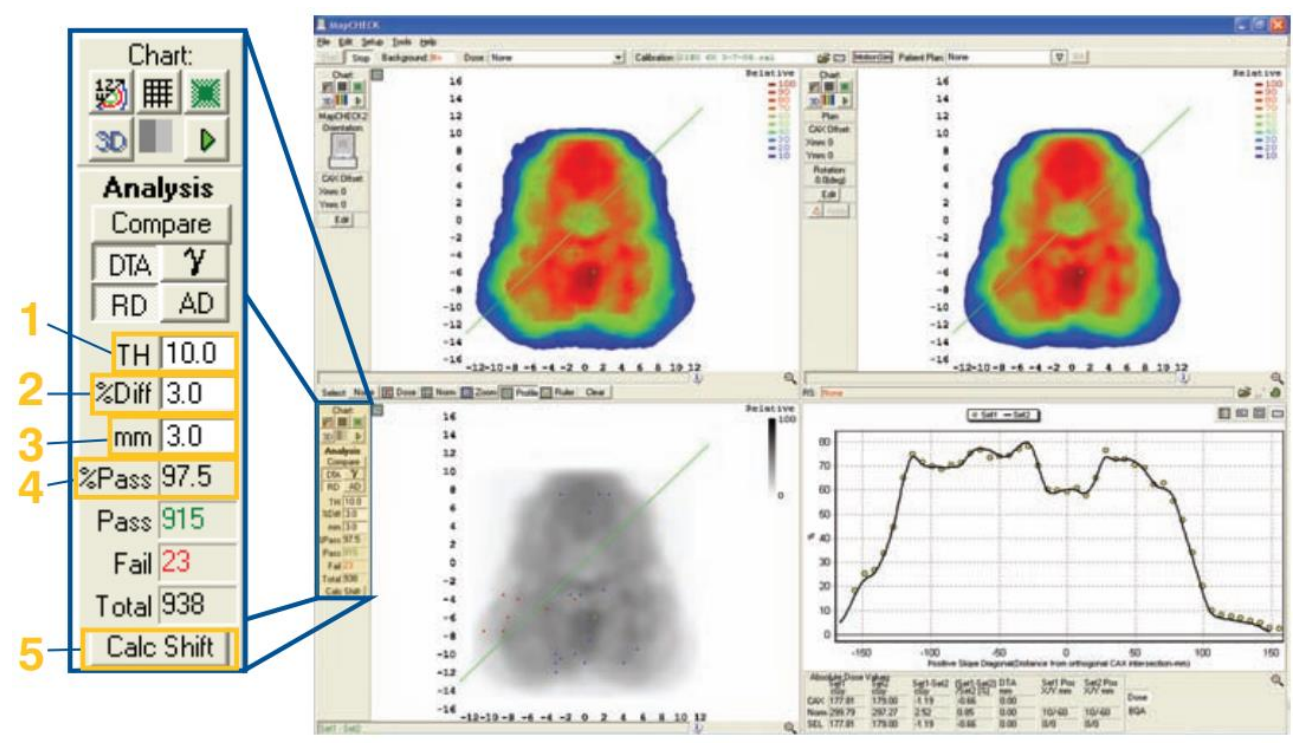

Figura 4.10: Interface do software Mapcheck2. Imagem própria do fabricante no site http://www.sunnuclear.com/medPhys/patientqa/mapcheck2/mapcheck2.asp 
$\mathrm{Na}$ sua interface mostrada na figura 4.10, o software permite escolher os critérios para a comparação da imagem planejada com a imagem adquirida, o limiar da isodose para ser analisada em 1, critério de aceitação de porcentagem de dose em 2, critério de distância de concordância em 3, o software ainda calcula o índice gama em cada ponto e mostra a porcentagem que passa nos critérios de aceitação em 4 e determina se há algum desalinhamento entre a imagem calculada e planejada no botão 5, caso necessite de alguma correção no corregistro.

Para a comparação entre a imagem medida pelo Mapcheck2 e a imagem planejada e foram usados os parâmetros da rotina clínica do Centro de Radioterapia de São Carlos: Limiar de dose (Threshold) de 5\%, DTA $3 \mathrm{~mm}$ e porcentagem de dose de $3 \%$.

\subsection{4 - Irradiação de calibração - gel Magic-f}

No procedimento da dosimetria gel é necessário fazer uma calibração, como já citado anteriormente, isso significa que os tubos de $5 \mathrm{ml}$ serão irradiados com doses conhecidas e assim determinar a taxa de relaxação equivalente a dose absorvida pela pequena quantidade de gel nos tubos.

A irradiação de calibração foi feita com um feixe único, com seu eixo paralelo ao diâmetro dos tubos, que são de formato cilíndrico. Para esse procedimento foi considerada a dose em toda região central do tubo e seu diâmetro aproximado para o valor de $1 \mathrm{~cm}$. Os tubos de calibração foram colocados sobre a superfície de $5 \mathrm{~cm}$ de acrílico, e abaixo de $4 \mathrm{~cm}$ de acrílico, para garantir que a dose seja depositada nos frascos. A distância fonte superfície para essa irradiação foi a padrão para o acelerador linear de $6 \mathrm{MV}$, com $100 \mathrm{~cm}$.

As irradiações dos objetos simuladores foram feitas em duas etapas. Na primeira etapa a irradiação de cinco planejamentos, na segunda etapa a irradiação dos outros cinco planejamentos. As doses para a primeira calibração foram entre valores de 0,2 a 2,2Gy em passos de 0,2 Gy e de 2,6 a 3,4 Gy em passos de 0,4 Gy, para os pacientes de 1 a 5 . Na segunda calibração para os pacientes de 6 a 10 as doses utilizadas foram de 0,2 a 2,0Gy em passos de 0,2 Gy e de 2,4 a 4 Gy em passos de 0,4 Gy. 


\subsection{5 - Irradiação dos objetos simuladores - Gel Magic-f}

As irradiações dos objetos simuladores contendo o gel Magic-f, foram feitas com os campos planejados pelo sistema de Planejamento Eclipse® de acordo com o respectivo paciente. Para alinhar o objeto simulador aos lasers de posicionamento, foi colocado sobre um suporte de acrílico confeccionado para o CT de planejamento, as irradiações e para a ressonância Magnética, assim a posição do eixo central se mantem sempre paralela a mesa, minimizando os erros de posicionamento.

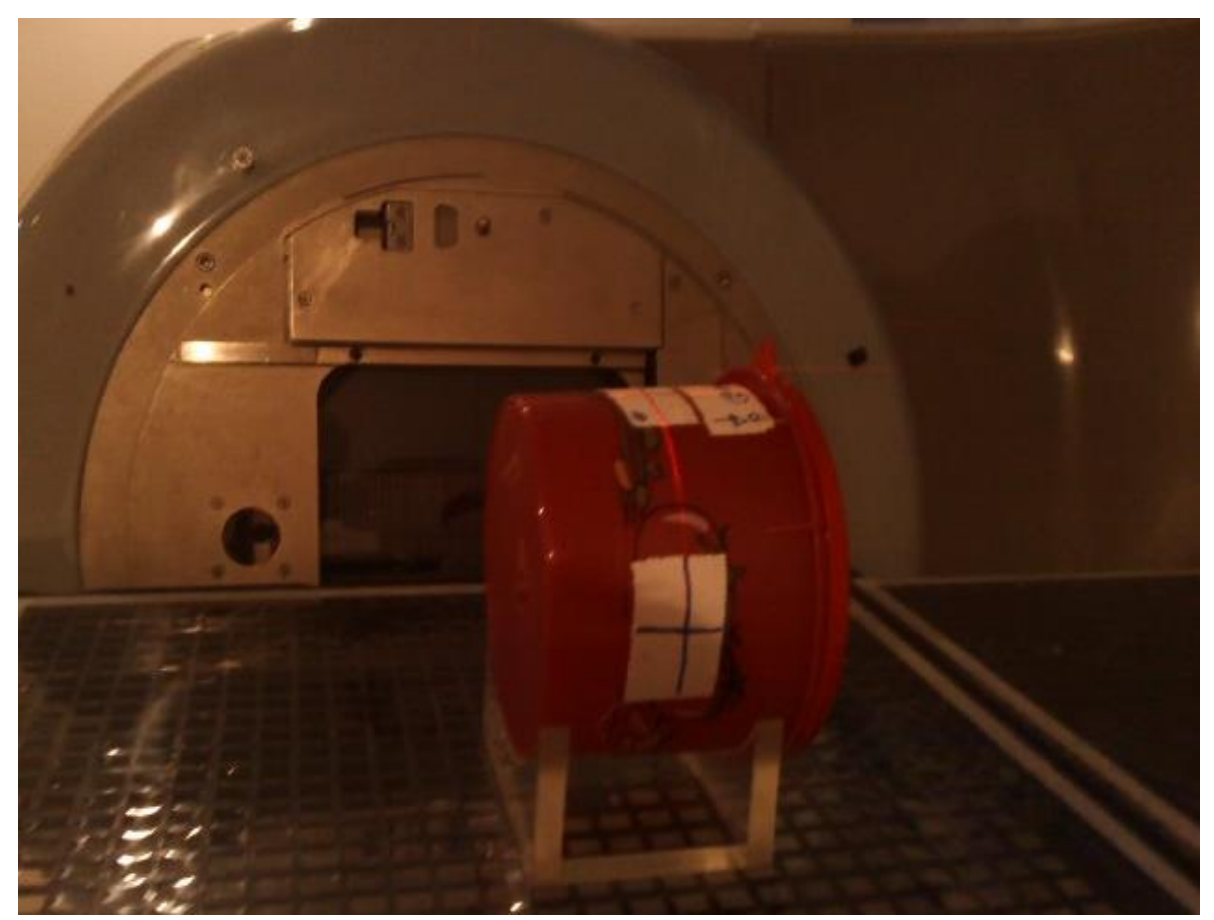

Figura 4.11: Posicionamento do objeto simulador para a irradiação mostrando o feixe de lasers e o suporte de acrílico.

\section{4 - Aquisições das imagens por ressonância magnética}

As aquisições das imagens por ressonância magnética foram feitas no Hospital das Clínicas de Ribeirão Preto, utilizando um tomógrafo Philips Achieva 3T mostrado na figura 4.11. Para evitar variações na determinação das taxas de relaxação $R 2$, os objetos simuladores e de calibração foram colocados no local de aquisição uma hora antes da leitura a fim de entrar em equilíbrio térmico com o meio. 


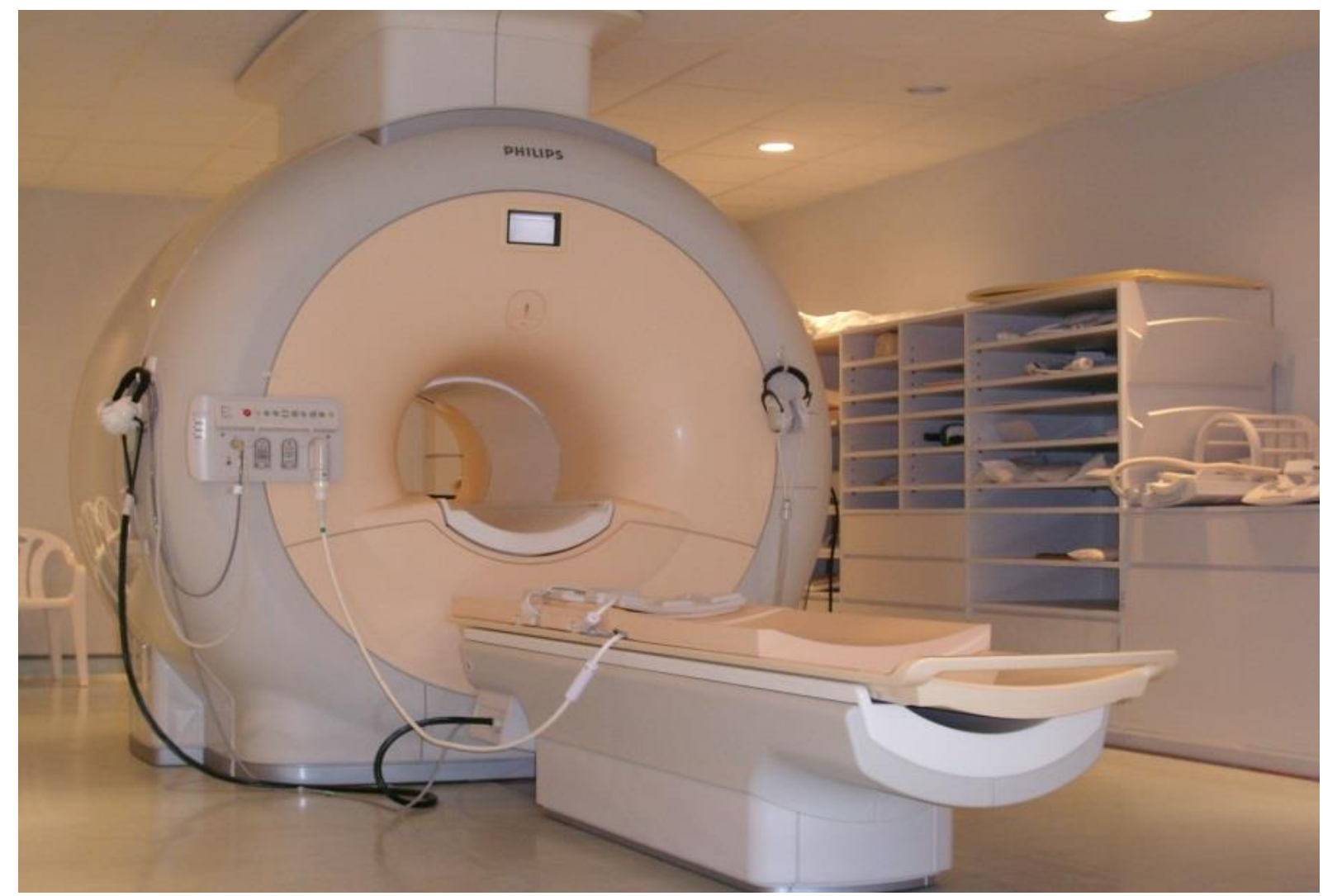

Figura 4.11: Tomógrafo de Ressonância Magnética Philips Achieva 3T. Foto retirada do site www.philips.com.

\subsection{1- Leitura de calibração}

Para a leitura de calibração os tubos foram inseridos no suporte, e o mesmo colocado em um recipiente de tamanho apropriado. Esse recipiente foi preenchido com uma solução de agua mili-Q, cloreto de sódio e cloreto de manganês, a razão de se usar essa solução é para evitar artefatos na borda dos tubos de calibração e estabelecer o contraste entre o tubo e o meio. A proporção dos reagentes da solução é apresentada na tabela 4.2.

Tabela 4.2- Porcentagem em massa dos componentes da solução de calibração

\begin{tabular}{|c|c|}
\hline Reagente & Porcentagem em massa(\%) \\
\hline Agua mili-Q & 99,5 \\
\hline Cloreto de sódio & 0,2 \\
\hline Cloreto de manganês & 0,3 \\
\hline
\end{tabular}




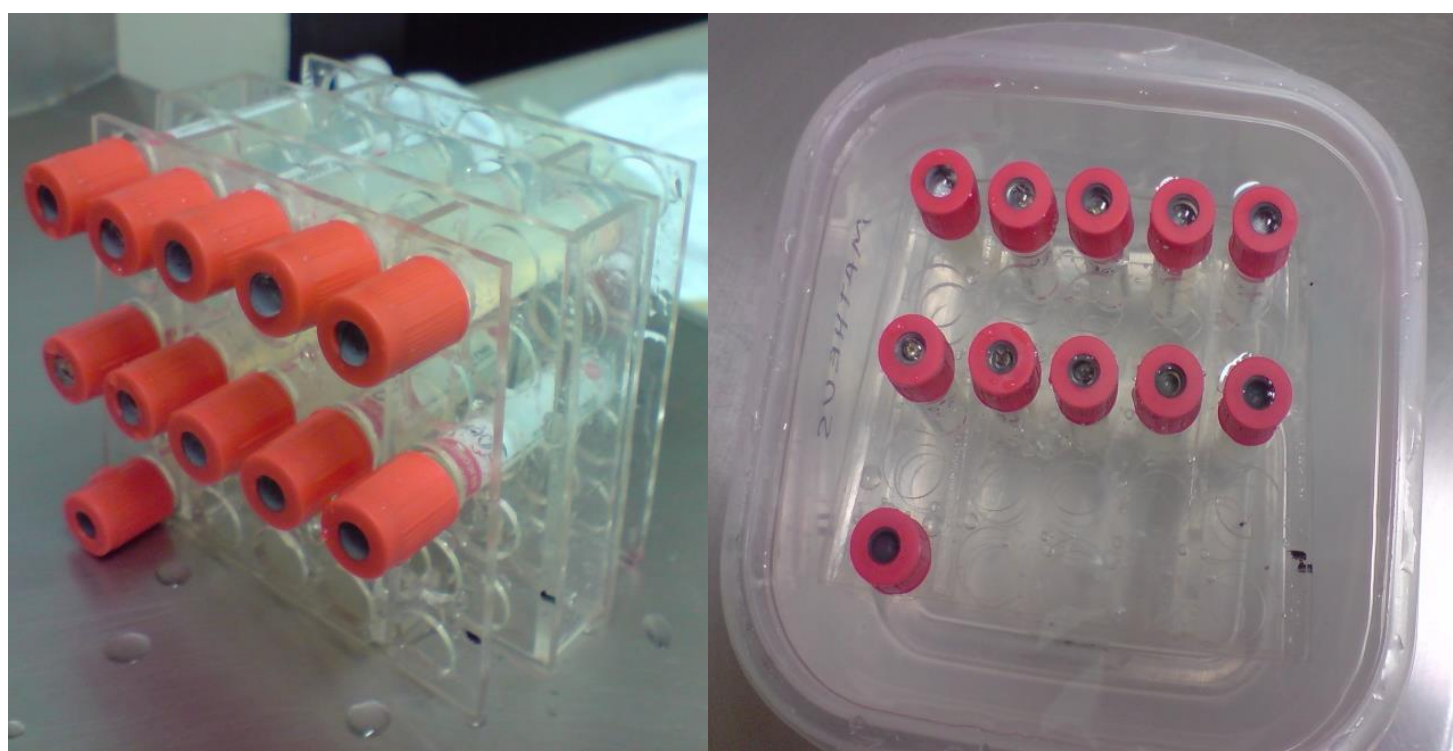

Figura 4.12: À esquerda os tubos de calibração no suporte para a leitura. À direita o recipiente preenchido com a solução de calibração.

O protocolo para a leitura para a calibração: Sequencia Multi spin eco com 16 ecos múltiplos de 20, ou seja, TE = 20 - $320 \mathrm{~ms}$; TR=2000 ms; Número de fatias = 5(axial e Sagital); espaçamento entre as fatias $=5 \mathrm{~mm}$; Espessura da fatia $=5 \mathrm{~mm}$; FOV $=148 \mathrm{~mm} ;$ matriz $=288 \times 288$; tamanho do pixel efetivo $=0.47 \mathrm{~mm}$; relação sinalruído $=1,36$.

\subsection{2 - Leitura de Simulação}

Para a leitura com os objetos de simulação, o mesmo foi posicionado na bobina de cabeça, localizado com os lasers, e mantendo o mesmo posicionamento que o CT de planejamento e a irradiação no Acelerador linear. $O$ isocentro foi marcado com capsulas de vitamina E para posteriormente identifica-lo etapa de corregistro das imagens. 


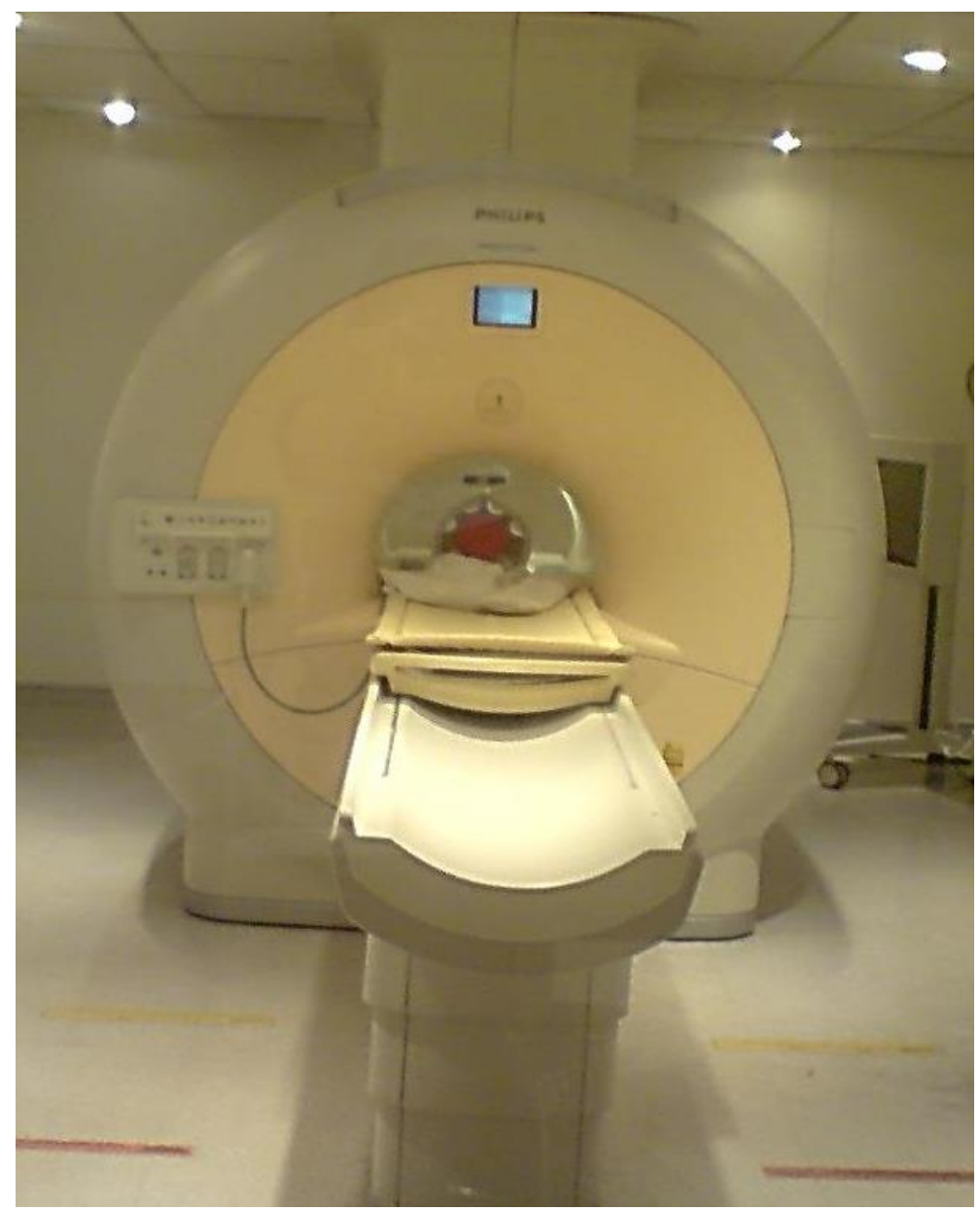

Figura 4.13: Posicionamento do objeto simulador na bobina de cabeça, no tomógrafo de ressonância magnética Philips Achieva 3T para a aquisição das imagens.

Protocolo para a leitura dos objetos simuladores com gel Magic-f: Sequencia Multi spin eco com 16 ecos múltiplos de 20, ou seja, TE = 20 - 320 ms; TR=2000 ms; Número de fatias $=5($ axial e Sagital); espaçamento entre as fatias $=5 \mathrm{~mm}$; Espessura da fatia $=5 \mathrm{~mm} ; \mathrm{FOV}=148 \mathrm{~mm} ;$ matriz $=288 \times 288 ;$ tamanho do pixel efetivo $=0.47$ $\mathrm{mm}$;

O protocolo utilizado foi o mesmo para os fantons de referência, ou seja, o mesmo objeto simulador contendo gel não irradiado nomeado de imagens de referência, com o objetivo de mapear o campo magnético e posteriormente fazer a razão entre as imagens obtidas com as imagens de referência, e assim eliminar a influência da não homogeneidade do campo magnético. 


\section{5 - Análise das imagens de ressonância magnética}

\subsection{1 - Programa de Relaxometria}

Para fazer a comparação entre os resultados obtidos com o gel e o calculado pelo sistema de planejamento é necessário determinar as taxas de relaxação $\mathrm{R} 2$, essa determinação foi feita usando software de relaxometria (figura 6.14) desenvolvido pelo nosso grupo em ambiente Matlab® 6.5. O programa visualiza as imagens de ressonância magnética em formato DICOM, calcula a taxa de relaxação R2 resolvendo a equação 3.9 (capítulo 3). Como já dito o programa foi desenvolvido anteriormente, mas nesse trabalho foi alterado para criar as variáveis de cada imagem a serem comparadas e fazer o corregistro com as imagens do sistema de planejamento, e a adaptação para todos os ecos usados na razão entre as imagens com gel irradiado e a imagem de referência, pois em seu desenvolvimento o trabalho em questão utilizava a sequência spin eco, e nesse trabalho faz uso da sequência multi-spin eco.

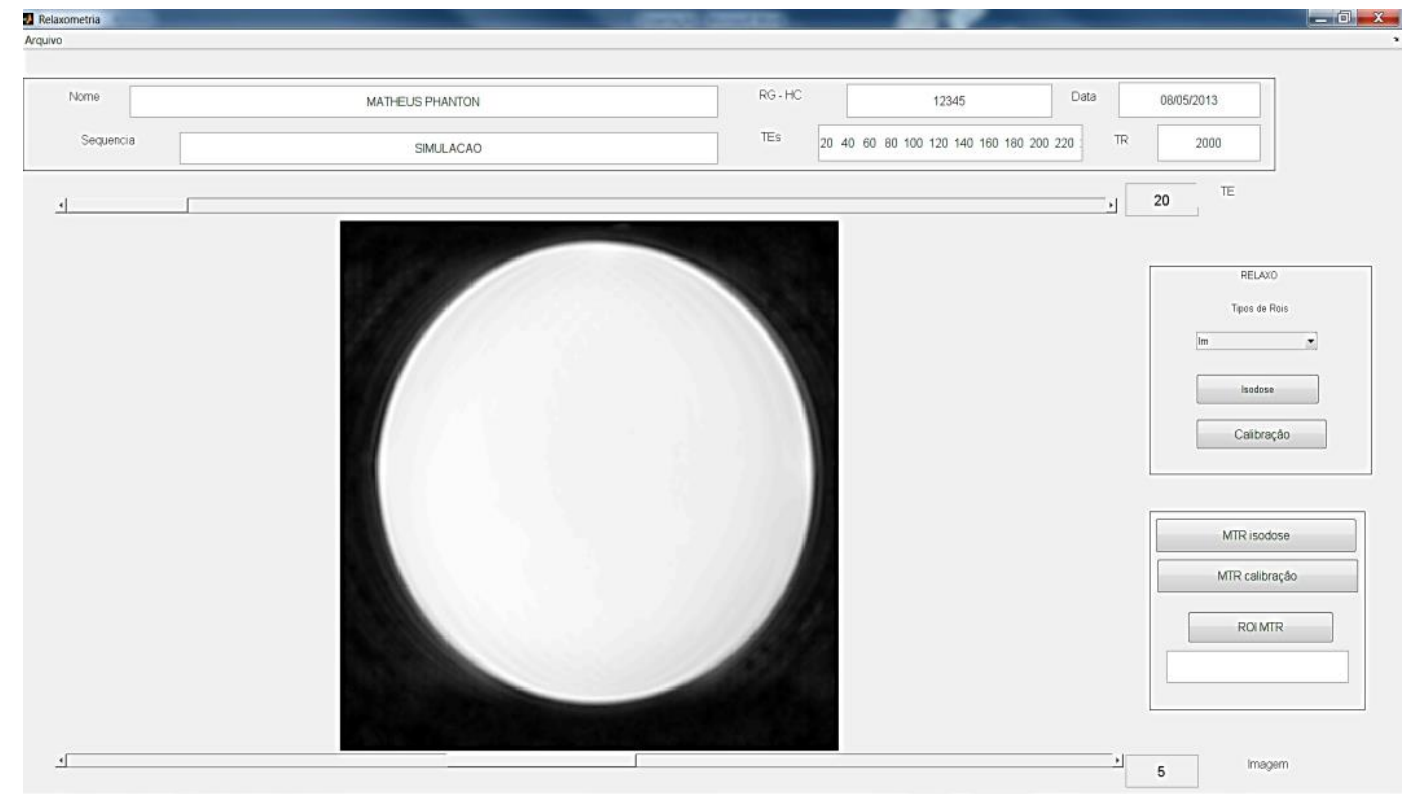

Figura 4.14: Interface do programa de relaxometria, mostrando as informações das imagens, data de aquisição, sequência, tempos de eco, tempo de repetição, números de fatias e as funções disponíveis. 


\subsection{2 - Corregistro das imagens}

As imagens do sistema de planejamento Eclipse ${ }^{\circledR}$ foram exportadas em DICOM-RT, protocolo DICOM para imagens em radioterapia. Os dados importados pelo programa CERR - Computational Environment for Radiotherapy Research, que permite a visualização do planejamento feito (figura 6.15), sendo possível extrair as matrizes das doses planejadas como variáveis bem como a posição das fatias e serem analisadas em Matlab®.

As resoluções das imagens variaram em cada planejamento exportado, sendo a maior resolução encontrada no paciente 1 com 64x64 pixels, então a comparação das imagens com esses paciente foi colocando as imagens extraídas do sistema de planejamento na resolução das imagens de ressonância magnética, conservando a informação obtida pelo gel Magic-f.

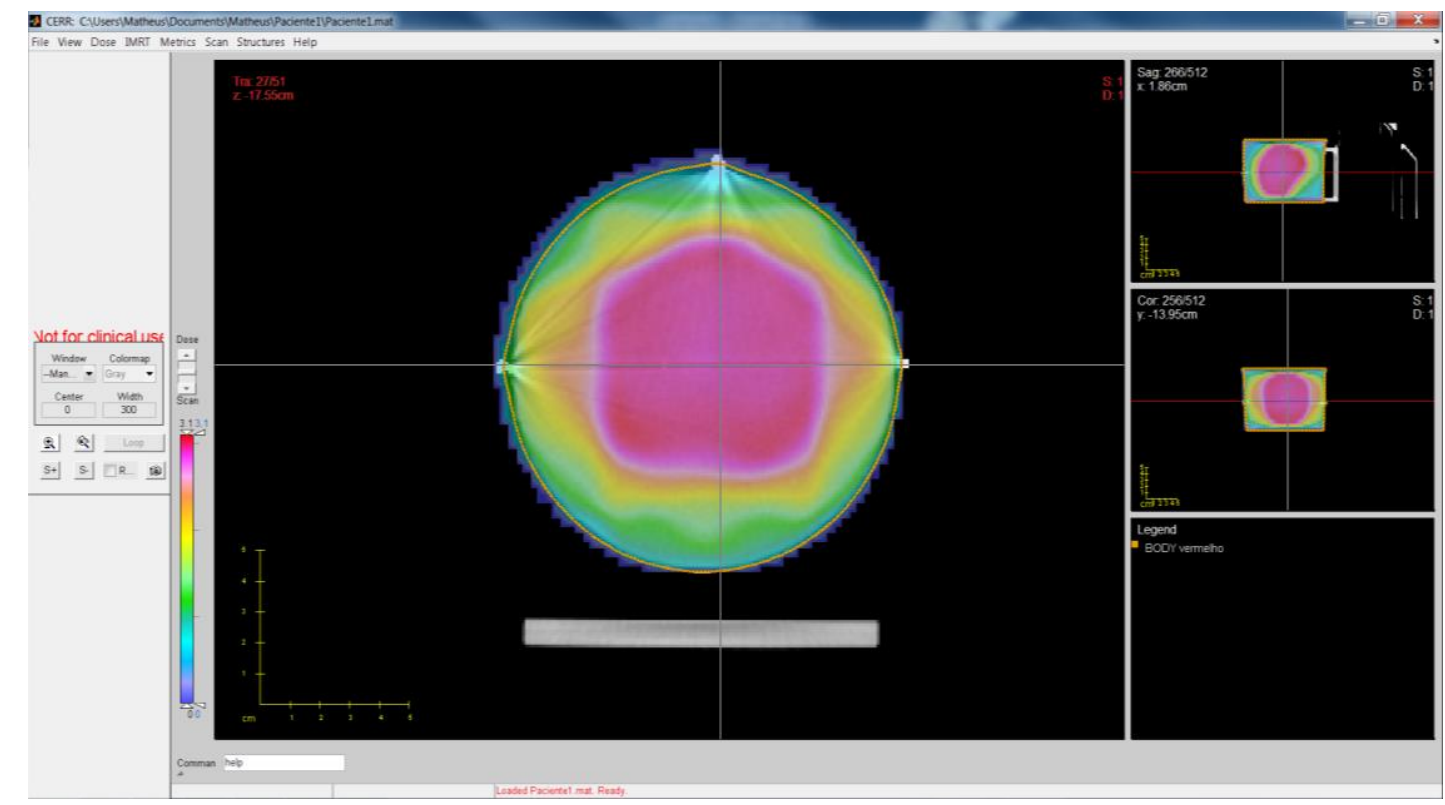

Figura 4.15: Interface do CERR para visualização do planejamento, apresentando os perfis, axial, sagital e coronal.

As imagens foram registradas localizando o isocentro pelas vitaminas $\mathrm{E}$ nas imagens de ressonância magnética e no CT de planejamento pelos 'bibs'. No registro das imagens foram feitas as devidas correções, rotação, localização, e a transformada espacial necessária para colocar no mesmo tamanho de pixel e resolução. 


\section{6 - Comparação das Doses}

A comparação entre as doses planejadas e adquiridas foi feita ao longo das regiões do fantom, onde as 10 fatias de $5 \mathrm{~mm}$ de espessura e espaçamento entre elas de $5 \mathrm{~mm}$ avaliavam as região onde se tinha necessariamente PTV. Através dessa informação pode-se inferir se o planejamento calculado está qualificado para o tratamento.

As distribuições de dose obtidas pelo programa desenvolvido pelo nosso grupo apresentam as doses normalizadas para o ponto de dose máxima, mas para a comparação nesse trabalho optamos por utilizar os valores da distribuição de R2 normalizados para um ponto, que corresponderia ao isocentro marcado no fantom, pois como mencionado, o isocentro foi deslocado no planejamento da para que as doses sejam entregues ao volume do objeto simulador. A abordagem escolhida para a comparação deve-se à possibilidade de flutuações na leitura da dose máxima no tomógrafo de ressonância magnética, e como consequência pode não ser a dose depositada.

Enfim, utilizamos para a comparação das doses adquiridas com o dosímetro gel, os valores de dose normalizados pelos valores de R2 ao ponto escolhido pela localização das vitaminas E, essa mesma coordenada é encontrada pelos "bibs", na imagem calculada pelo sistema de planejamento. Para minimizar os erros nessa normalização foram tiradas as médias de 12 pixels na região da coordenada encontrada, na situação em que aumentamos a resolução do planejamento. No caso em que diminuímos a resolução das imagens com o dosímetro gel, a média dessa região foi feita com 4 pixels.

\section{7 - Análises Gama}

A avaliação quantitativa entre os resultados obtidos com dosimetro gel e o planejamento foi feita pelo cálculo do índice gama pixel a pixel, para isso, utilizamos o software freeware Doselab 4.11, desenvolvido por Nathan Childress e Isacc Rosen na Universidade do Texas e no M.D. Anderson Cancer Center (Childress and Ronsen, 2003).

O programa permite carregar duas imagens a serem comparadas, uma imagem é a calculada, que consideramos a imagem do planejamento, a outra a imagem medida, 
que atribuímos a imagem com os resultados do gel. Para carregar as imagens no software Doselab 4.11, foi necessário salvar as variáveis em TIFF (Tagged Image File Format).

O critério utilizado para validação do planejamento é o padrão na radioterapia em IMRT são de 3\% na porcentagem de dose e $3 \mathrm{~mm}$ na distância de concordância. O resultado considerado bem sucedido será de $90 \%$ ou acima a porcentagem de pixel que possuem gama menor ou igual a 1. O programa irá fornecer o perfil de dose, no sentido horizontal e no sentido vertical, o mapa do índice gama, o histograma de pixels do mapa de índice gama. 


\section{Capítulo 5-Resultados e discussões}

Nesse capítulo são apresentados os resultados com o controle de qualidade pontual, bidimensional e o tridimensional usando a câmara de ionização, MapCHECK2 e o Gel Magic-f. O capítulo inicia apresentando a verificação de calibração do acelerador (Al) para as irradiações com a câmara de ionização e as curvas de calibração para irradiação com o gel Magic-f.

Os resultados são apresentados de forma detalhada para o Paciente 1 e para os demais pacientes apresentaremos o resultado final do controle de qualidade com cada método.

Nas discussões em relação a cada paciente analisamos os resultados, verificando qual corte possui volume alvo (PTV), para avaliar se há aprovação ou reprovação no controle de qualidade tridimensional.

\section{2 - Calibrações}

\subsection{1 - Checagem de calibração do Al}

No capítulo 4 já foi mencionado que foi realizada a checagem de calibração, isso para se fazer a leitura de cada campo com a câmara de ionização. Na tabela 5.1 é apresentada a verificação da calibração para a irradiação dos planejamentos de 1 a 5 e na tabela 5.2 de 6 a 10 .

Tabela 5.1: Verificação da calibração para irradiação dos Pacientes de 1 a 5.

\begin{tabular}{|c|c|c|c|}
\hline \multicolumn{4}{|c|}{ Verificação da Calibração AL } \\
\hline $\mathrm{T}=20,5$ & ${ }^{\mathbf{o}} \mathrm{C}$ & \multirow{2}{*}{\multicolumn{2}{|c|}{$F(P, T)=1,103$}} \\
\hline $\mathrm{P}=690,0$ & mmHg & & \\
\hline \multicolumn{4}{|c|}{ Campo:10x10cm, $U M=100$, isocentro } \\
\hline Eclipse & $\mathbf{n C}$ & Dose & Desv \\
\hline 81,500 & 2,76 & 80,93 & $-0,7 \%$ \\
\hline
\end{tabular}


Tabela 5.2: Verificação da calibração para irradiação dos Pacientes de 6 a 10.

\begin{tabular}{|c|c|c|c|}
\hline \multicolumn{4}{|c|}{ Verificação da Calibração AL } \\
\cline { 1 - 2 } $\mathrm{T}=20,5$ & \multicolumn{1}{|c|}{$\mathbf{F}(\mathbf{P}, \mathbf{T})=\mathbf{1 , 1 0 2}$} \\
\cline { 1 - 2 } $\mathrm{P}=691,0$ & $\mathbf{m m H g}$ & \\
\cline { 1 - 2 } Campo:10x10cm, UM=100, isocentro \\
\cline { 1 - 2 } Eclipse & $\mathbf{n C}$ & Dose & Desv \\
\cline { 1 - 2 } $\mathbf{8 1 , 5 0 0}$ & $\mathbf{2 , 7 6}$ & $\mathbf{8 0 , 8 1}$ & $\mathbf{- 0 , 9 \%}$ \\
\hline
\end{tabular}

\subsection{2 - Curvas de calibração - Magic-f}

Aa figuras 5.1 e 5.2 mostram as curvas de calibração para os pacientes de 1 a 5 e de 6 a 10 respectivamente, em que mostram o comportamento linear entre a taxa de relaxação (R2) e a dose, assim obtemos a sensibilidade do gel correspondente ao coeficiente angular de cada curva.

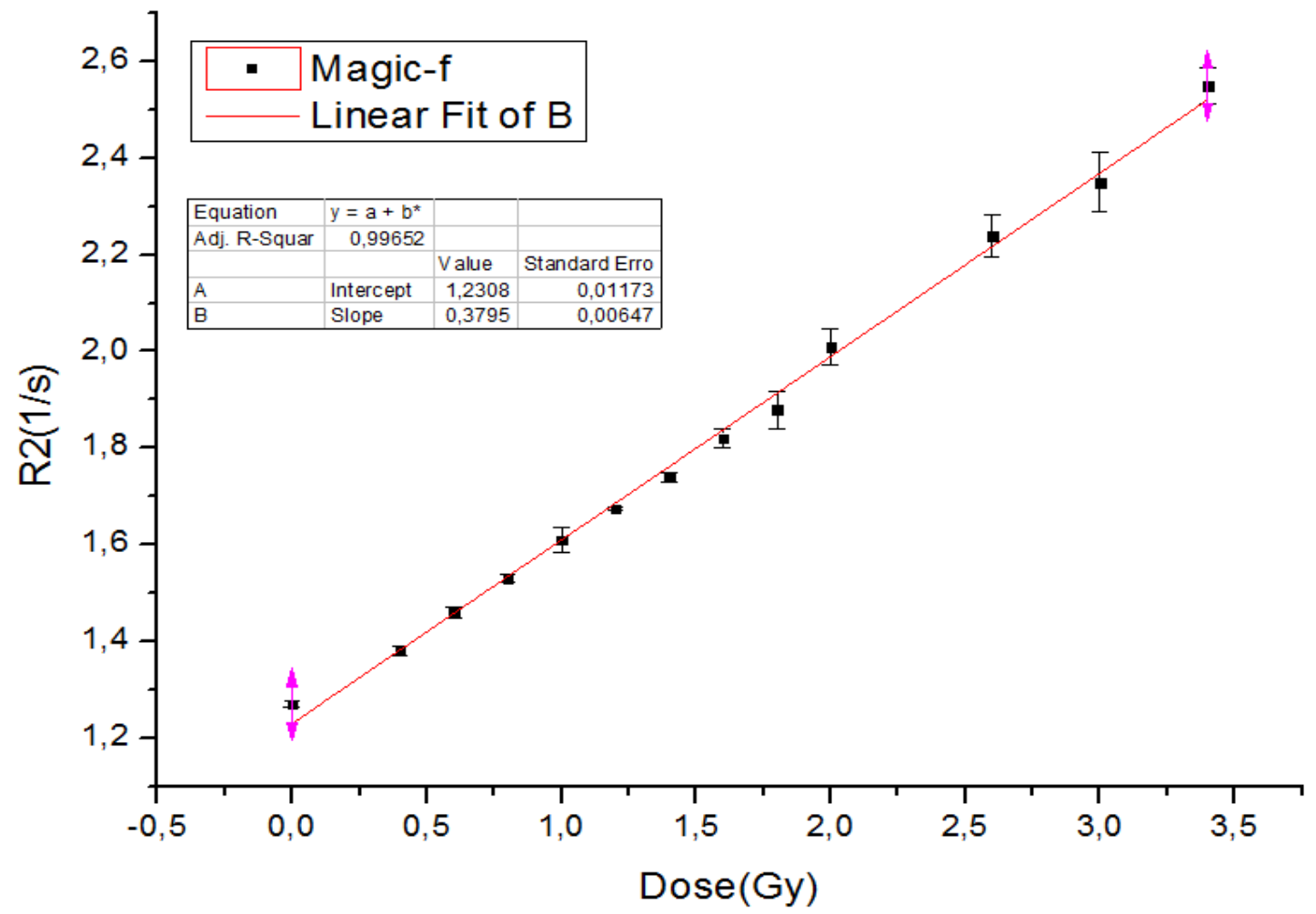

Figura 5.1: Curva de calibração referente aos pacientes de 1 a 5. 


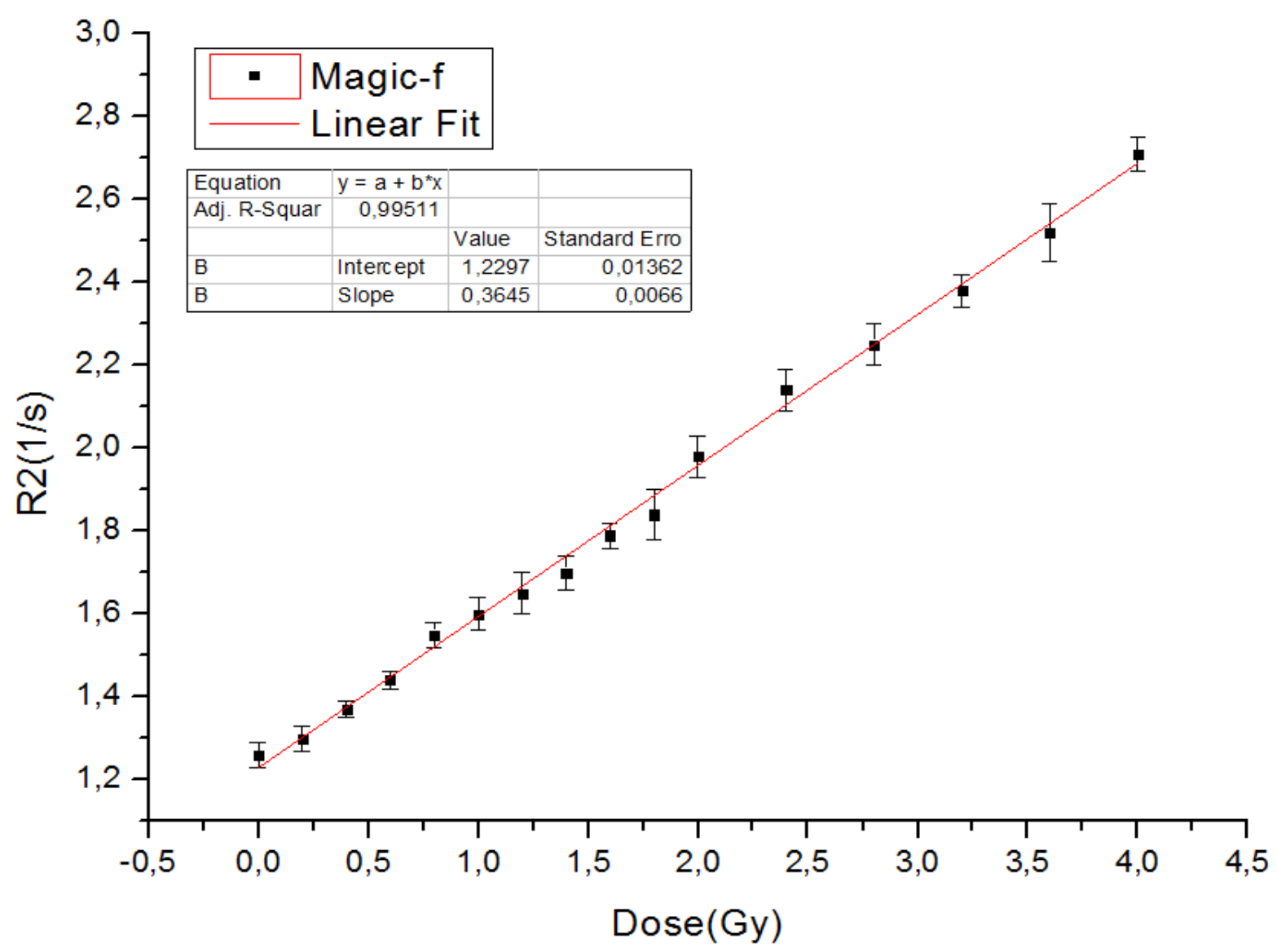

Figura 5.2: Curva de calibração referente aos pacientes de 6 a 10 .

As sensibilidades encontradas são de 0,37 e 0,36 assim podemos verificar a reprodutibilidade para os experimentos realizados, com uma diferença percentual de $2,7 \%$ entre as sensibilidades. A fim de ilustrar a semelhança do comportamento linear do gel nos experimentos realizados a figura 7.3 mostra as duas curvas com R2 e a dose irradiada de mesmo valor, 0 a $2 \mathrm{~Gy}$ em passos de 0,2 em 0,2, apresentando um comportamento semelhante para as doses irradiadas. 


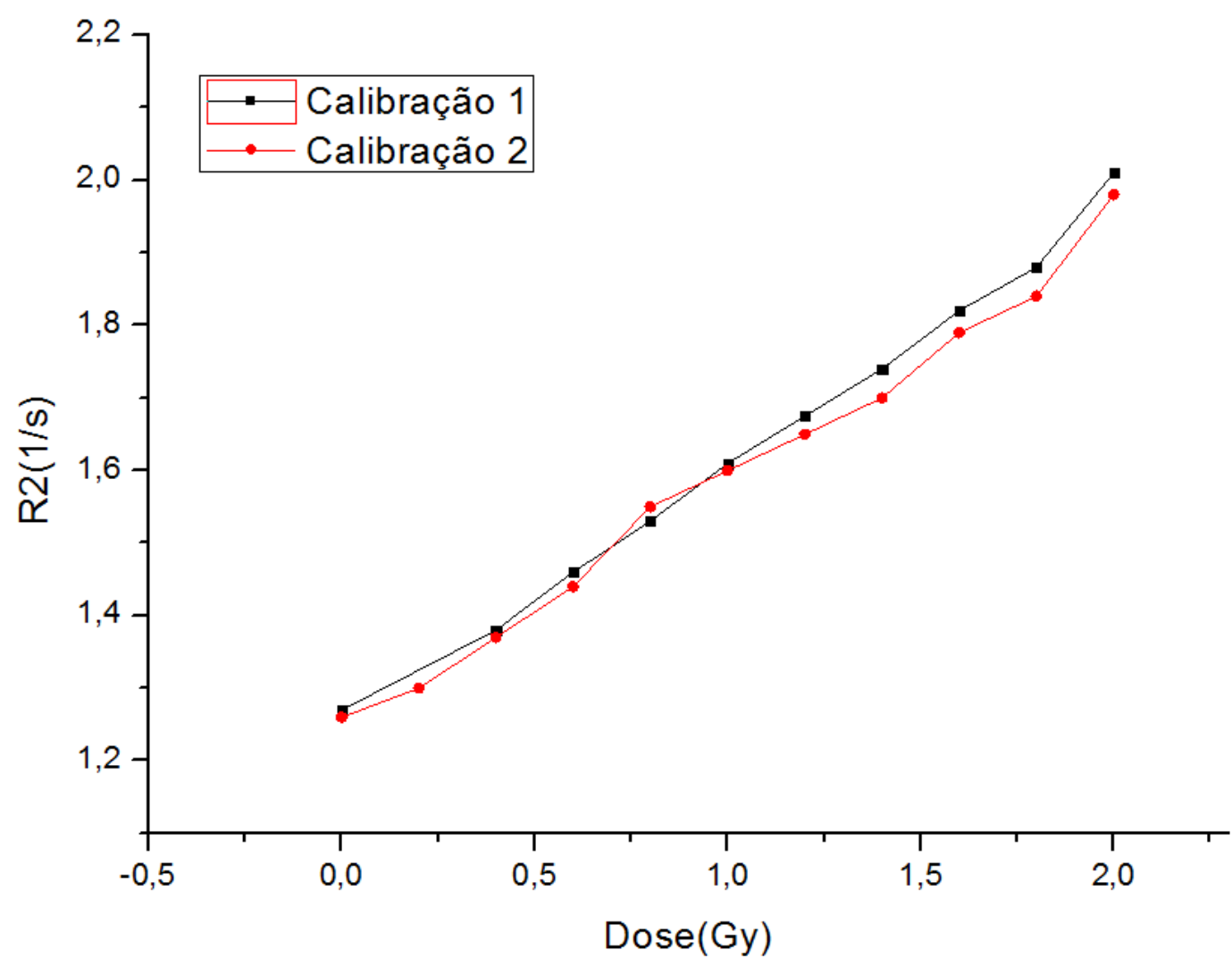

Figura 5.3: Curvas de calibração para os experimentos realizados.

A tabela 5.3 mostra a diferença absoluta e percentual entre as medidas de R2 da calibração 1 e2

Tabela 5.3: Comparação entre as calibrações nas medidas de R2

\begin{tabular}{||c|c|c||c|c|}
\hline \hline Dose (Gy) & R2 & R2 & Dif. abs. & Dif.(\%) \\
\hline \hline 0 & 1,27 & 1,26 & 0,01 & 0,8 \\
\hline 0,2 & 1,32 & 1,30 & 0,02 & 1,5 \\
\hline 0,4 & 1,38 & 1,37 & 0,01 & 0,7 \\
\hline 0,6 & 1,46 & 1,44 & 0,02 & 1,4 \\
\hline 0,8 & 1,53 & 1,55 & $-0,02$ & $-1,3$ \\
\hline 1,0 & 1,61 & 1,60 & 0,01 & 0,6 \\
\hline 1,2 & 1,67 & 1,65 & 0,02 & 1,2 \\
\hline 1,4 & 1,74 & 1,70 & 0,04 & 2,3 \\
\hline 1,6 & 1,82 & 1,79 & 0,03 & 1,6 \\
\hline 1,8 & 1,88 & 1,84 & 0,04 & 2,1 \\
\hline 2,0 & 2,01 & 1,98 & 0,03 & 1,5 \\
\hline
\end{tabular}




\section{3 - Paciente 1}

\subsection{1 - Controle de qualidade pontual - Câmara de ionização}

Os resultados obtidos para câmara de ionização são apresentados na tabela 5.3, que contém a dose obtida em cada campo em seu respectivo ângulo planejado, desvio percentual de cada campo, o resultado total e o desvio percentual em relação a dose planejada pelo sistema de planejamento.

Tabela 5.3: Leitura da câmara de ionização para o Paciente 1.

\begin{tabular}{|c|c|c|c|c|c|c|c|}
\hline \multicolumn{2}{|r|}{$\begin{array}{c}\text { Dose DVH } \\
\text { Eclipse }\end{array}$} & \multicolumn{2}{|c|}{ 268,8 cGy } & \multicolumn{4}{|c|}{ CÂMARA } \\
\hline No & Gantry & SSD & UM & Eclipse & $\mathrm{nC}$ & Dose & Desv \\
\hline 1 & $\mathbf{0}$ & & 113 & 45,3 & 1,54 & 45,15 & $-0,3 \%$ \\
\hline 2 & 75 & & 137 & 65,4 & 2,18 & 63,92 & $-2,3 \%$ \\
\hline 3 & 135 & & 99 & 46,2 & 1,61 & 47,21 & $2,1 \%$ \\
\hline 4 & 225 & & 106 & 49,2 & 1,68 & 49,26 & $0,1 \%$ \\
\hline \multirow[t]{2}{*}{5} & 285 & & 137 & 63,1 & 2,11 & 61,87 & $-2,0 \%$ \\
\hline & Câmara & Eletrom. & $\begin{array}{c}\mathrm{N}_{\mathrm{W}, \mathrm{Q}} \\
(\mathrm{cGy} / \mathrm{nC})\end{array}$ & \multicolumn{2}{|c|}{ Dose CI (cGy): } & \multicolumn{2}{|c|}{267,41} \\
\hline CI & Iba $0.13 \mathrm{cc}$ & MAX4001 & 26,575 & \multicolumn{2}{|c|}{ Desvio \%: } & \multicolumn{2}{|c|}{$-0,5 \%$} \\
\hline
\end{tabular}

A diferença absoluta entre a dose medida e a dose planeja é de - 1,39 cGy, e a diferença percentual de $-0,5 \%$. O critério de aceitação para IMRT para a leitura com a câmara de ionização é de $\pm 3,0 \%$ portanto o resultado obtido passa no controle de qualidade. 


\subsection{2 - Controle de qualidade bidimensional - MapCHECK2}

No controle de qualidade bidimensional utilizando o MapCHECK2 temos um resultado qualitativo, que consiste na comparação entre a distribuição medida pela sobreposição de todos os campos com a distribuição planejada, e quantitativo pelo Cálculo do índice gama realizado pelo próprio software do MapCHECK2

A figura 5.4 apresenta as distribuições de dose normalizadas de 10 a $100 \%$, a sobreposição das linhas de isodose e o histograma de índices gama.

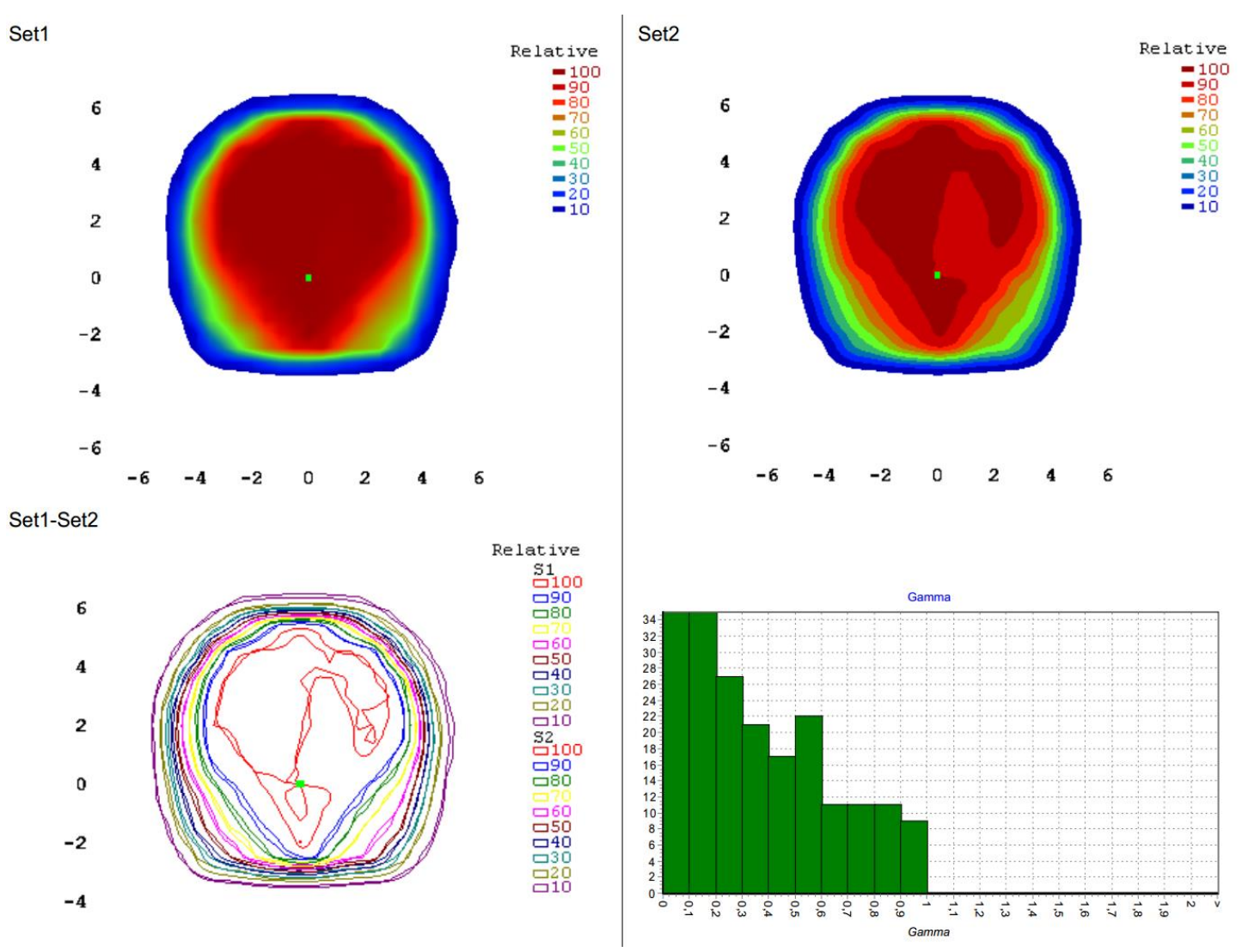

Figura 5.4: Resultados apresentados pelo MapCHeck2 para o Paciente 1

A leitura realizada com o MapCHeck2 para o paciente 1 mostra de maneira qualitativa a semelhança entre as distribuições adquirida (Set1) e planejada (Set2). O resultado da análise gama mostra que $100 \%$ dos pontos analisados passam no critério $3 \% / 3 \mathrm{~mm}$ e assim o planejamento é validado no controle de qualidade bidimensional. 


\subsubsection{Controle de qualidade Tridimensional - Resultados com Gel Magic-f}

A avaliação tridimensional foi realizada utilizando como dosímetro o gel Magicf, a fim de se avaliar o planejamento ao longo do seu volume, assim obtemos uma informação nova para avaliar o planejamento. Os resultados obtidos pelo processamento das imagens de ressonância magnética estão normalizados para o ponto localizado pelas cápsulas de vitaminas $\mathrm{E}$, e os dados das matrizes de dose do planejamento normalizados para o ponto localizado pelos "bibs".

A figura 5.2 mostra na primeira coluna os resultados obtidos utilizando a dosimetria com gel Magic-f e na segunda coluna mostra a fatia de distribuição de dose do planejamento, referente à mesma localização que a fatia obtida pelas IRM. Os dez cortes são localizados pela coordenada $\mathrm{z}$, nas posições de $-3 \mathrm{~cm}$ a $6 \mathrm{~cm}$ o isocentro foi estabelecido como $0 \mathrm{~cm}$. Os resultados mostram de maneira qualitativa a semelhança entre as distribuições.

- $\mathrm{Z}=-3,0 \mathrm{~cm}$
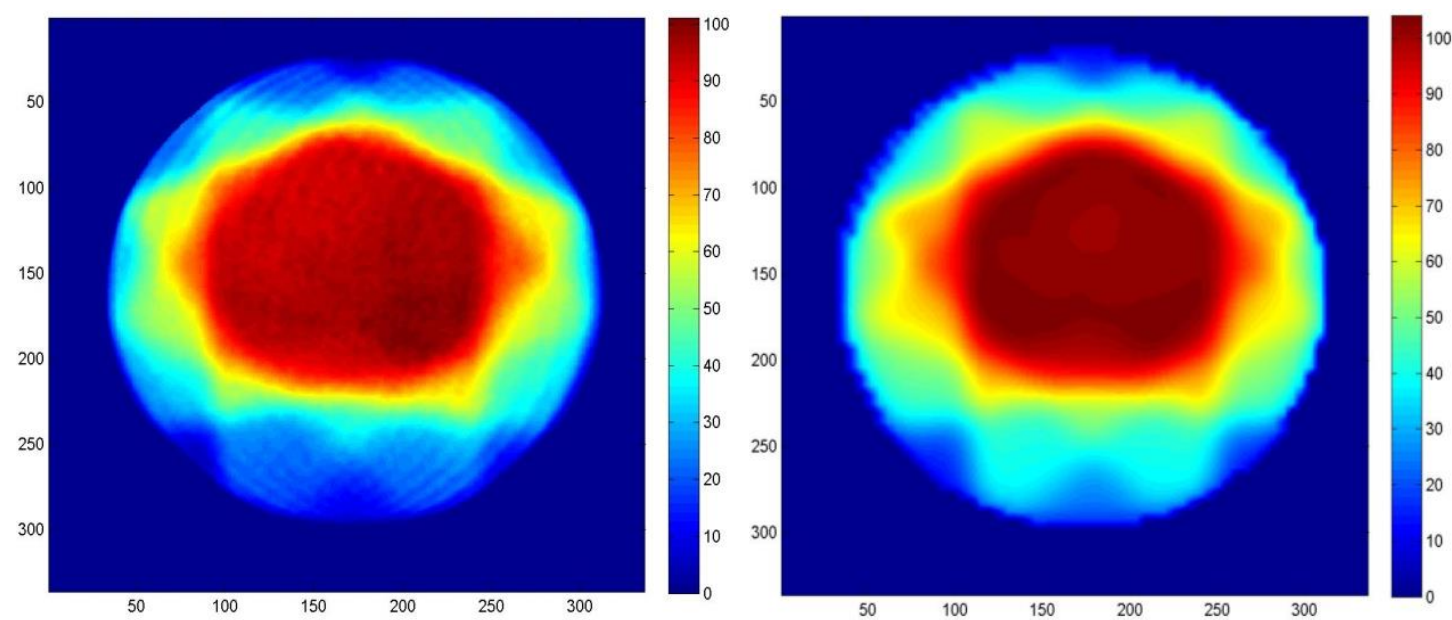
- $\mathrm{Z}=-2,0 \mathrm{~cm}$
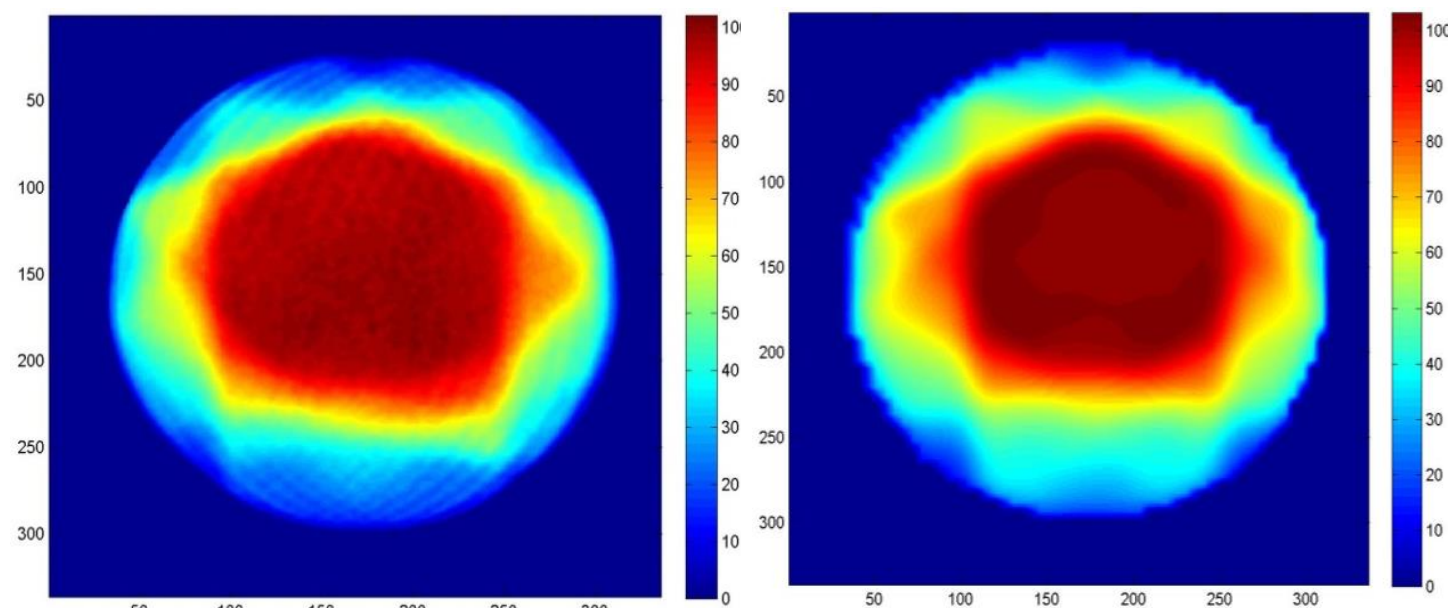

- $\mathrm{Z}=-1,0 \mathrm{~cm}$
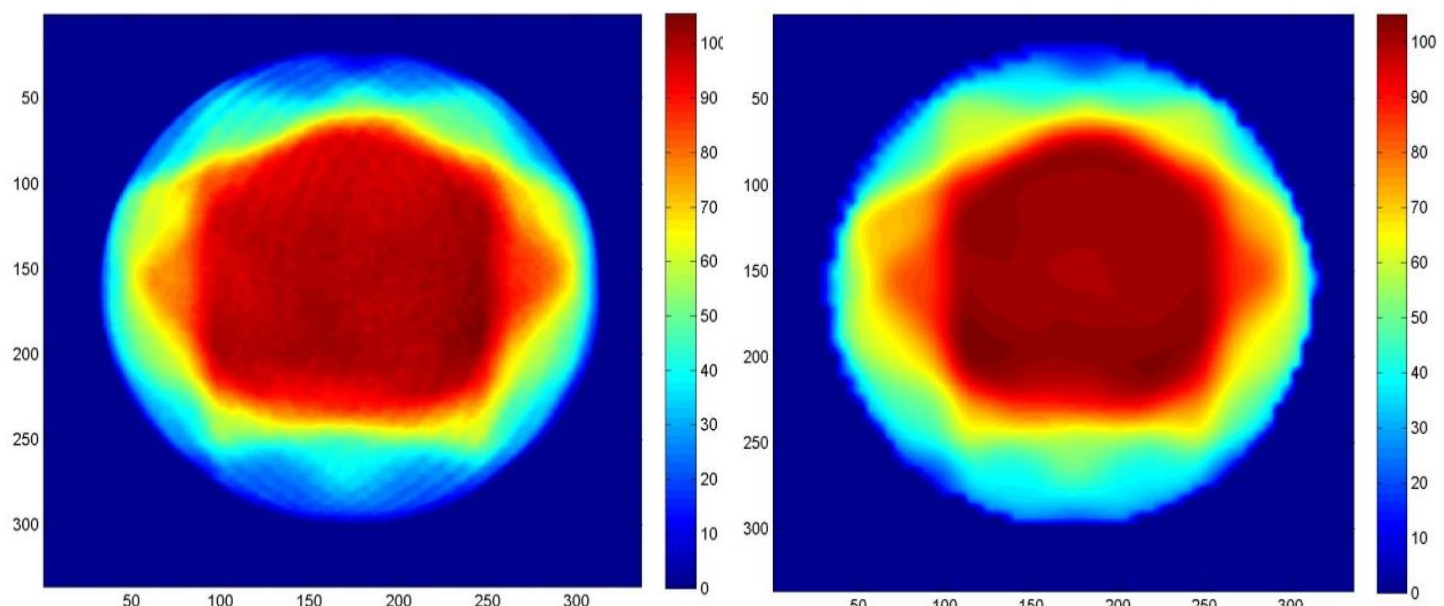

- $\mathrm{Z}=0 \mathrm{~cm}$ (isocentro)
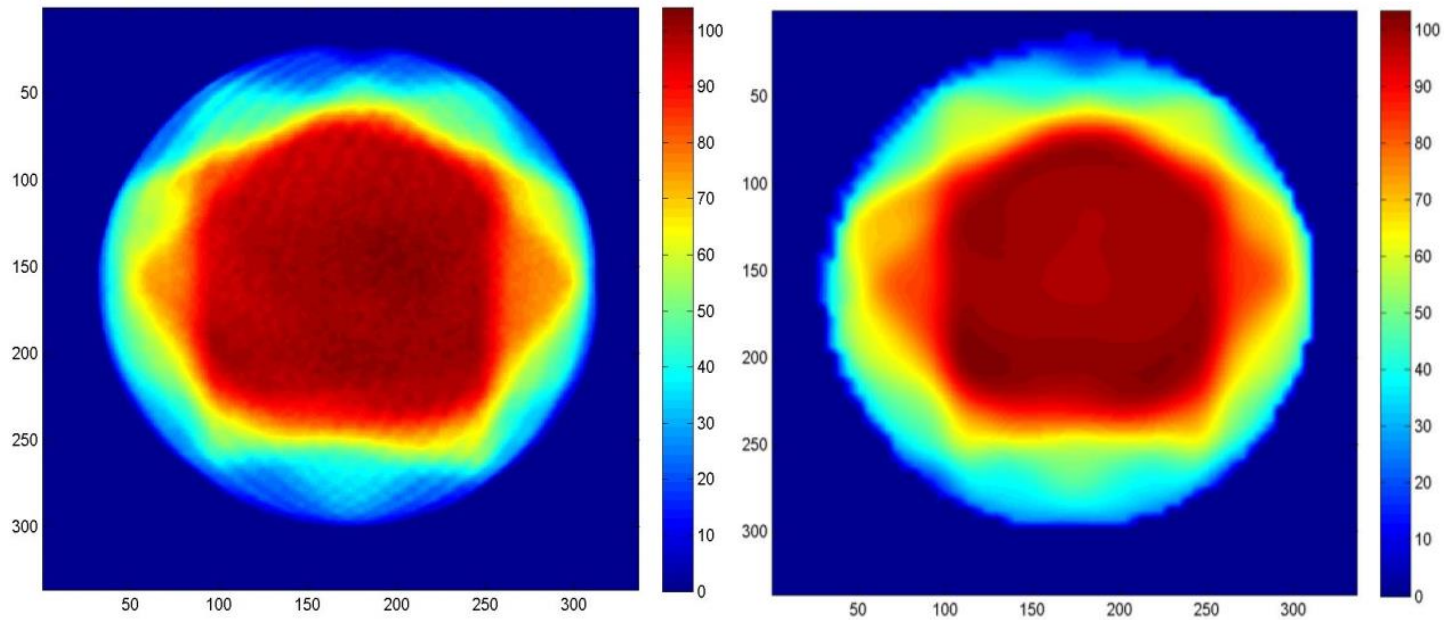
- $\mathrm{Z}=1,0 \mathrm{~cm}$
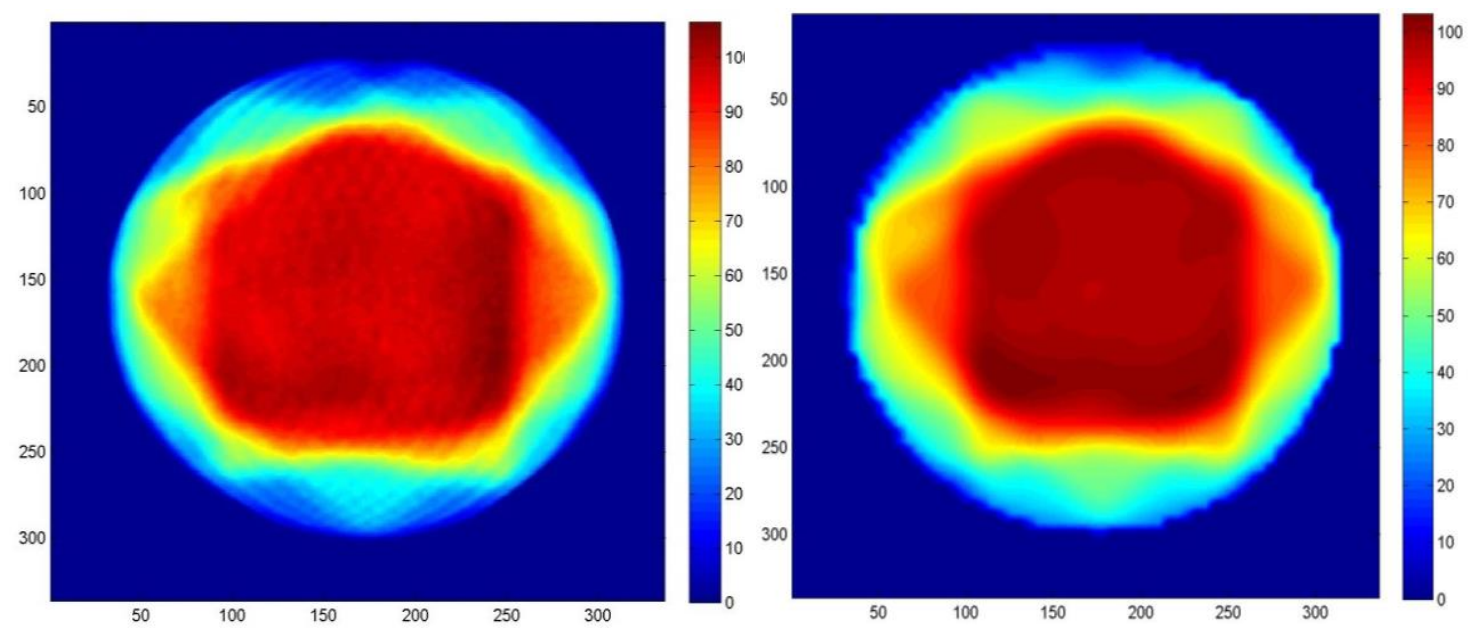

- $\mathrm{Z}=2,0 \mathrm{~cm}$
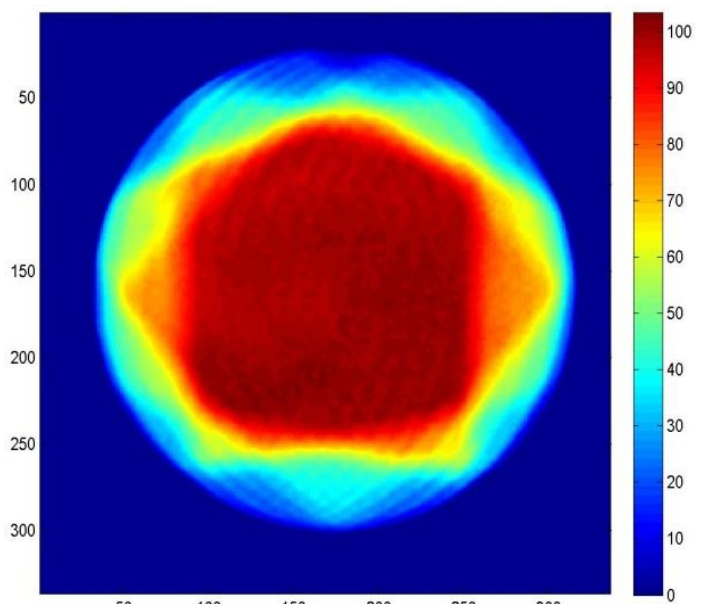

- $\mathrm{Z}=3,0 \mathrm{~cm}$
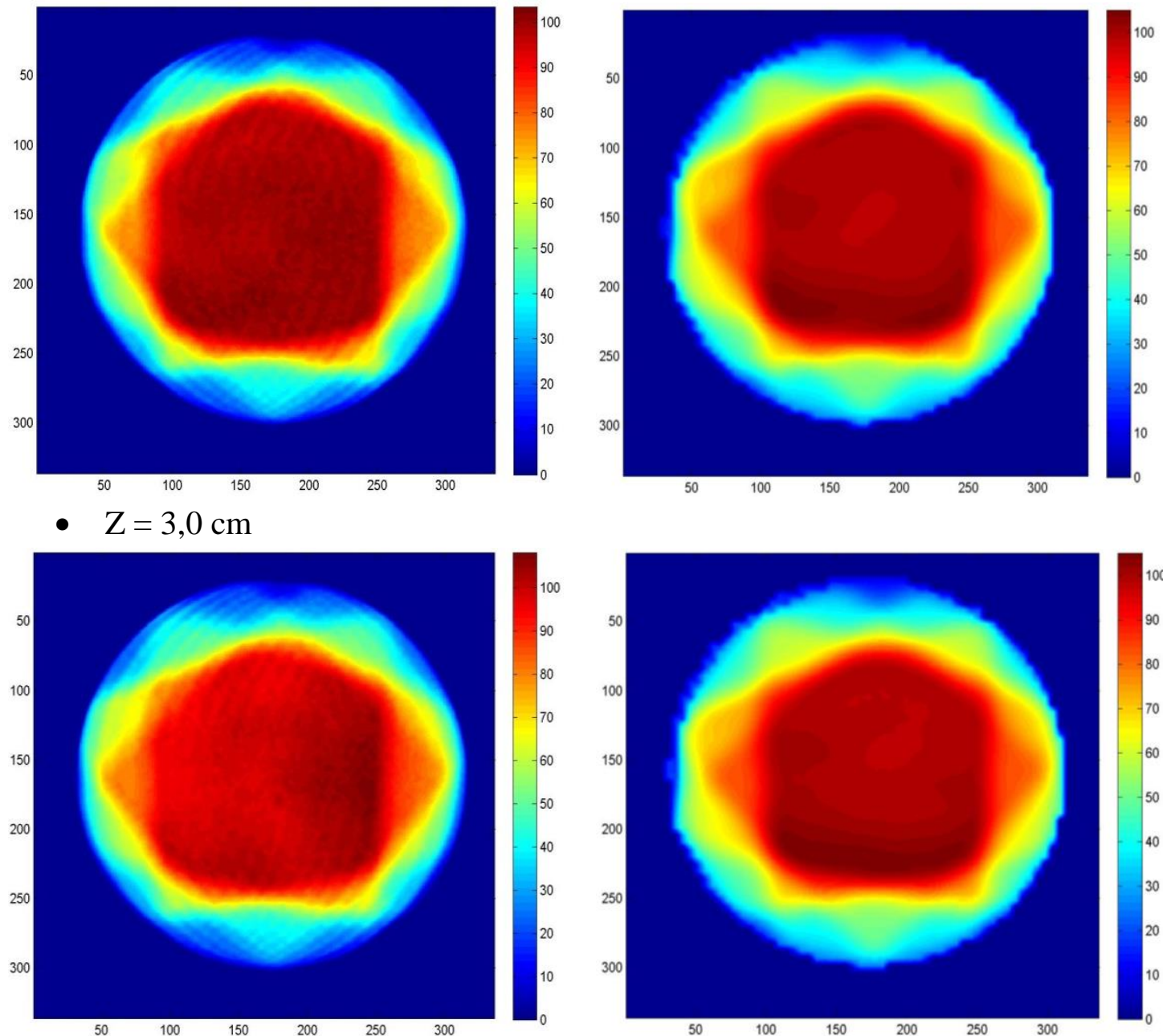
- $\mathrm{Z}=4,0 \mathrm{~cm}$

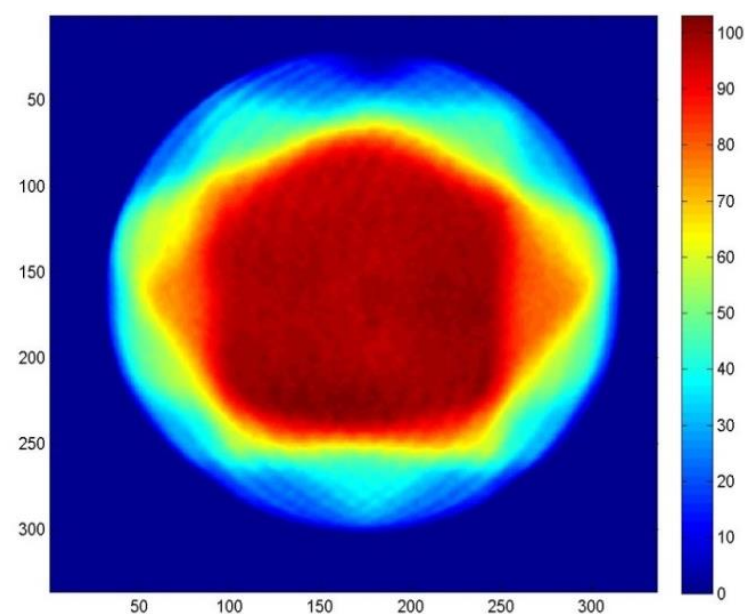

- $\mathrm{Z}=5,0 \mathrm{~cm}$

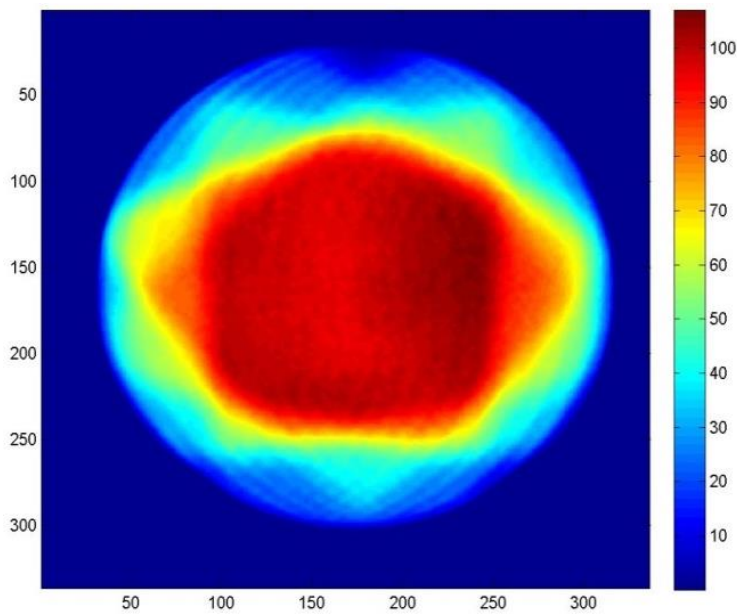

- $\mathrm{Z}=6,0 \mathrm{~cm}$

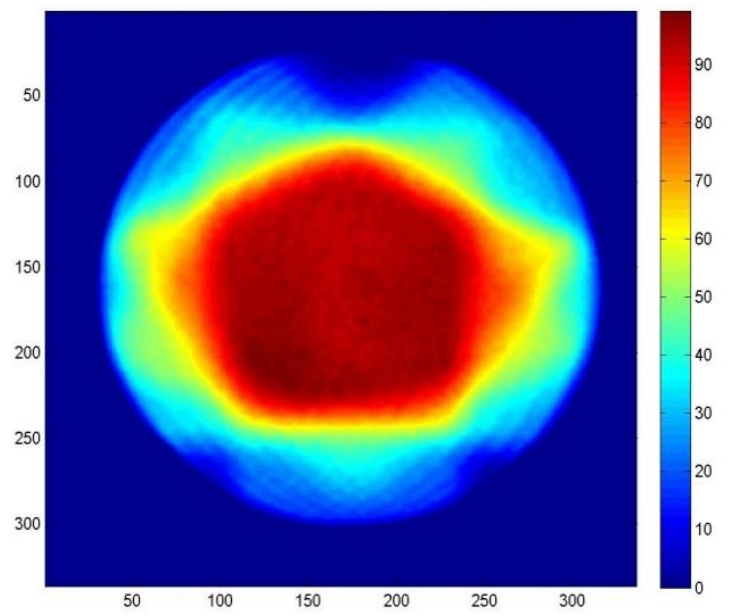

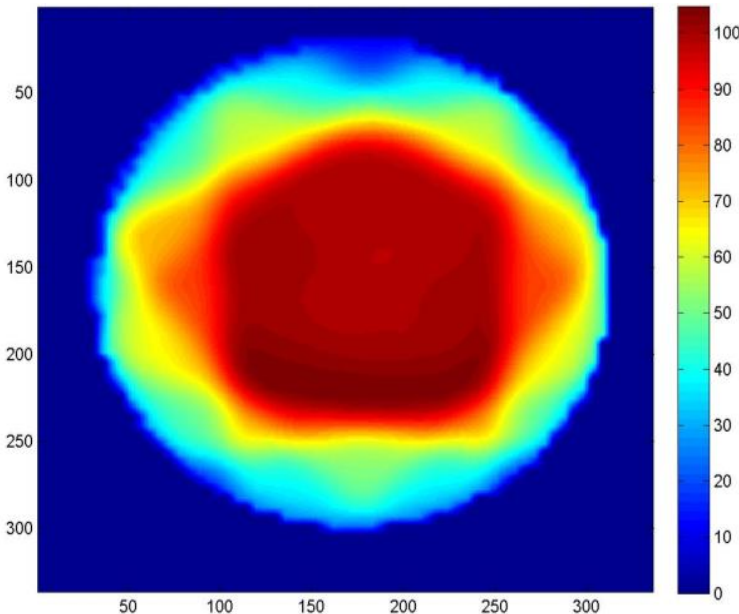

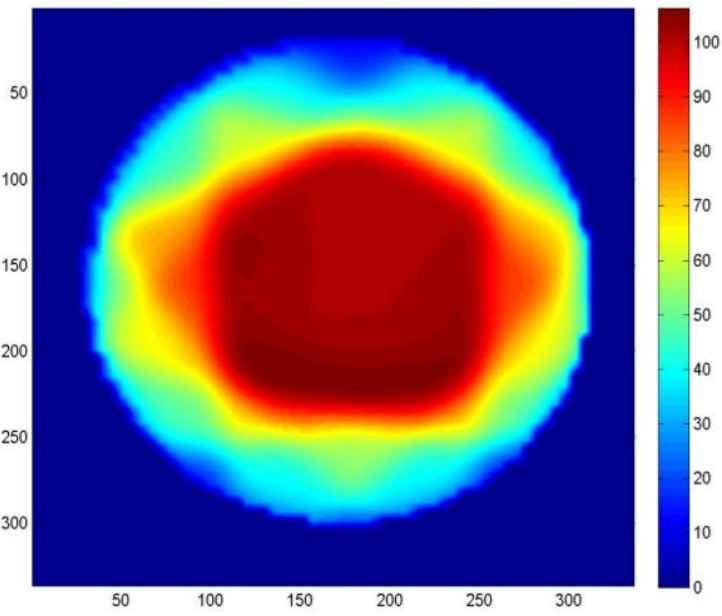

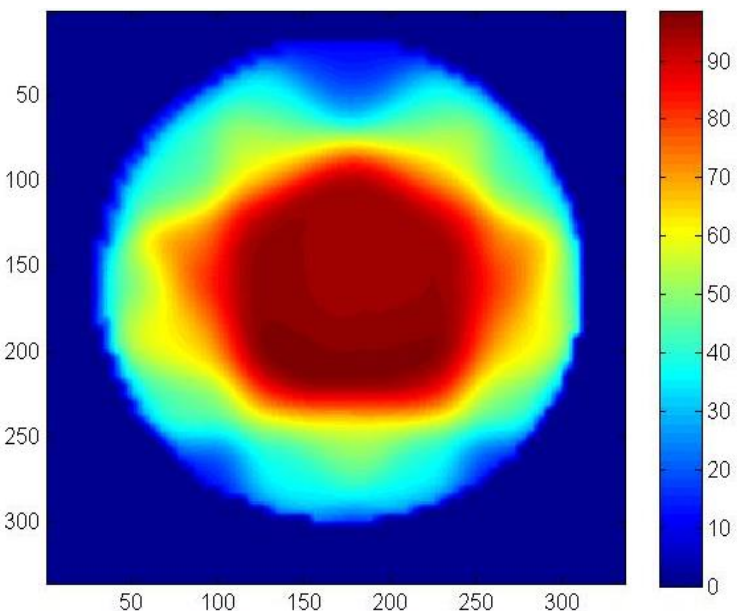

Figura 5.5: Primeira coluna apresenta as distribuições de dose obtidas com Gel Magicf. Na segunda coluna apresenta as distribuições calculadas pelo planejamento. 
A fim de ilustrar a semelhança entre a distribuição medida e planejada a figura 7.3 mostra a sobreposição para o isocentro os perfis de dose planejada e medida, para trás regiões horizontais e verticais, assim podemos verificar a similaridade das doses, encontrando apenas uma oscilação nos pontos medidos com gel, sendo esse ruído característica da dosimetria gel.
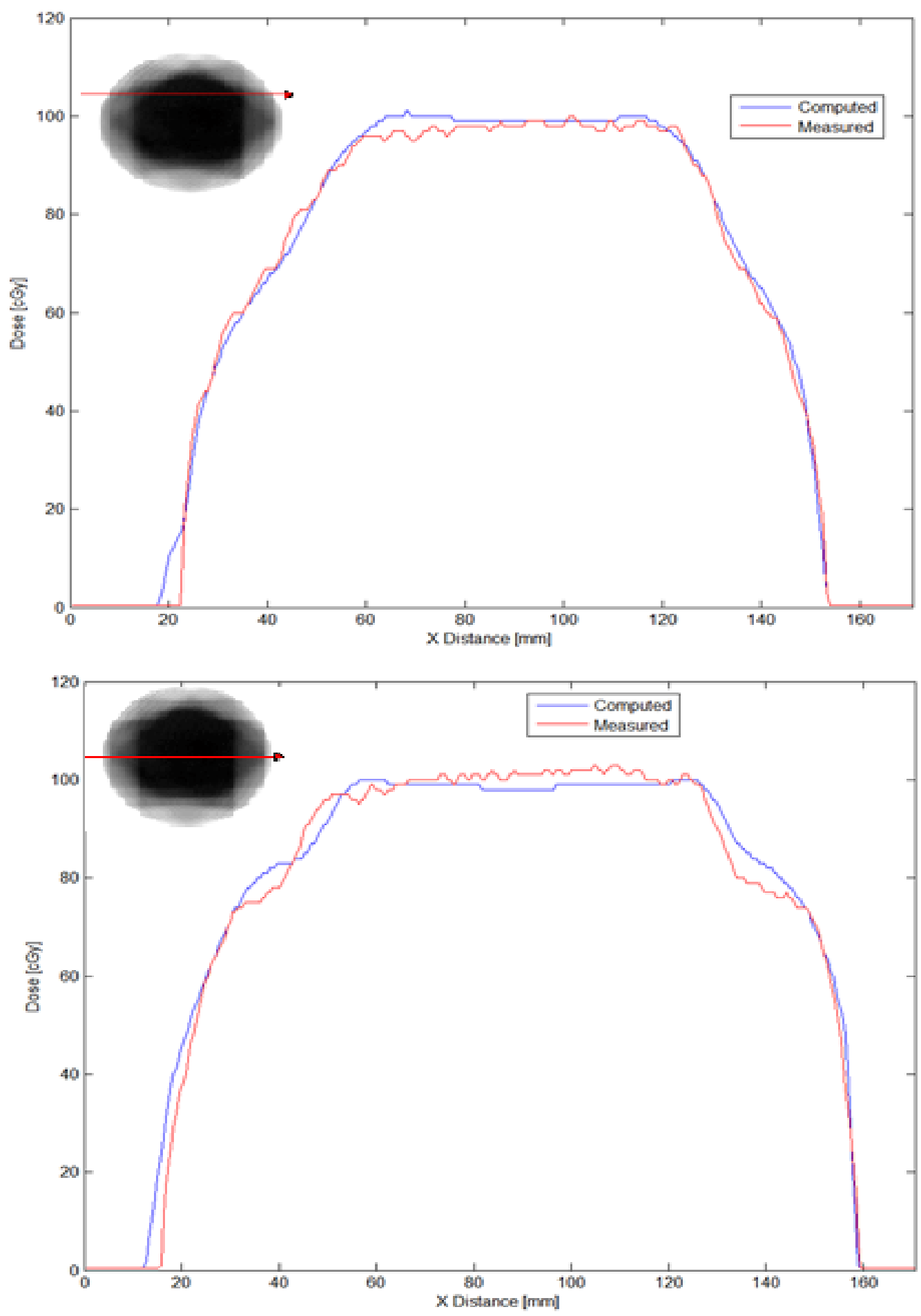

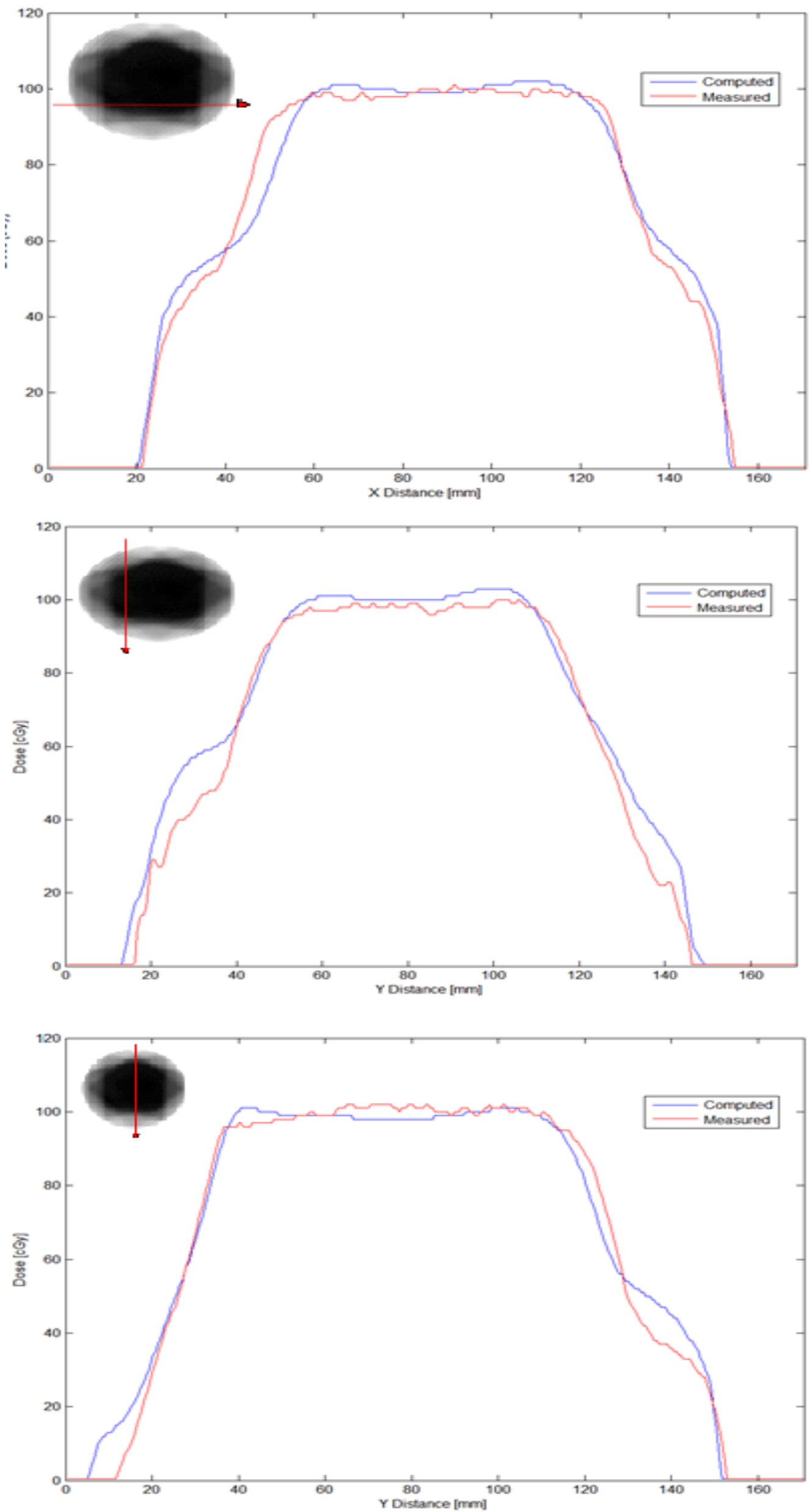


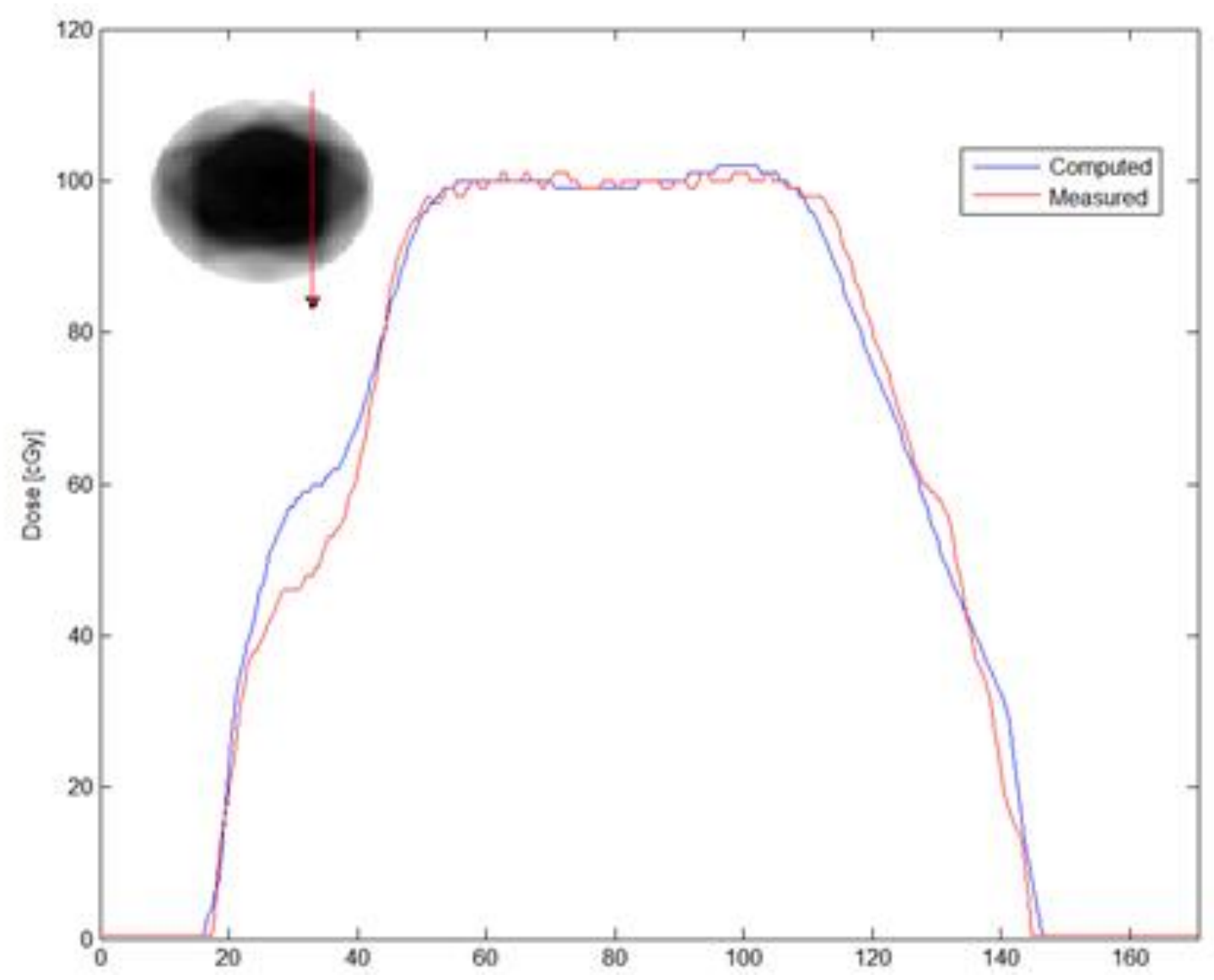

Figura 5.6: Sobreposição dos perfis de dose. Em azul mostra o perfil de dose do sistema de planejamento e em vermelho o perfil de dose medida pelo gel Magic-f.

Para analisar quantitativamente as distribuições de dose calculada pelo sistema de planejamento, fizemos o Cálculo do índice gama entre as distribuições planejadas e obtidas pelas IRMN em todos os cortes adquiridos. O critério escolhido para a distribuição passar nos testes das análises gama é de $90 \%$ dos pixels com $\gamma \leq 1$ (Stock et al, 2005) , no critério de aceitação 3\%/ 3mm, padrão em radioterapia. A figura 5.7 mostra o mapa de índices gama na coluna 1, e na coluna 2 o respectivo histograma de pixels. 


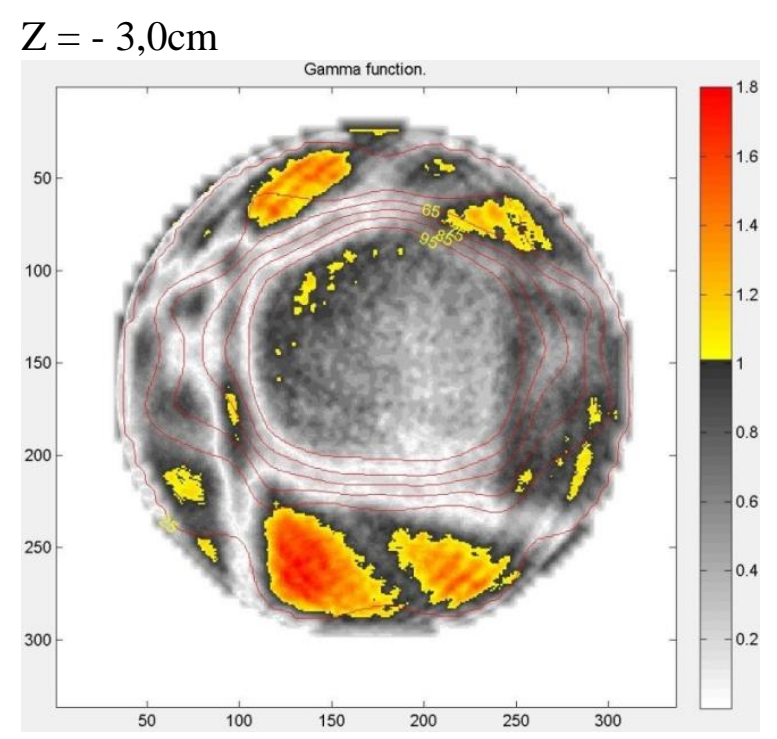

\section{$Z=-2,0 \mathrm{~cm}$}
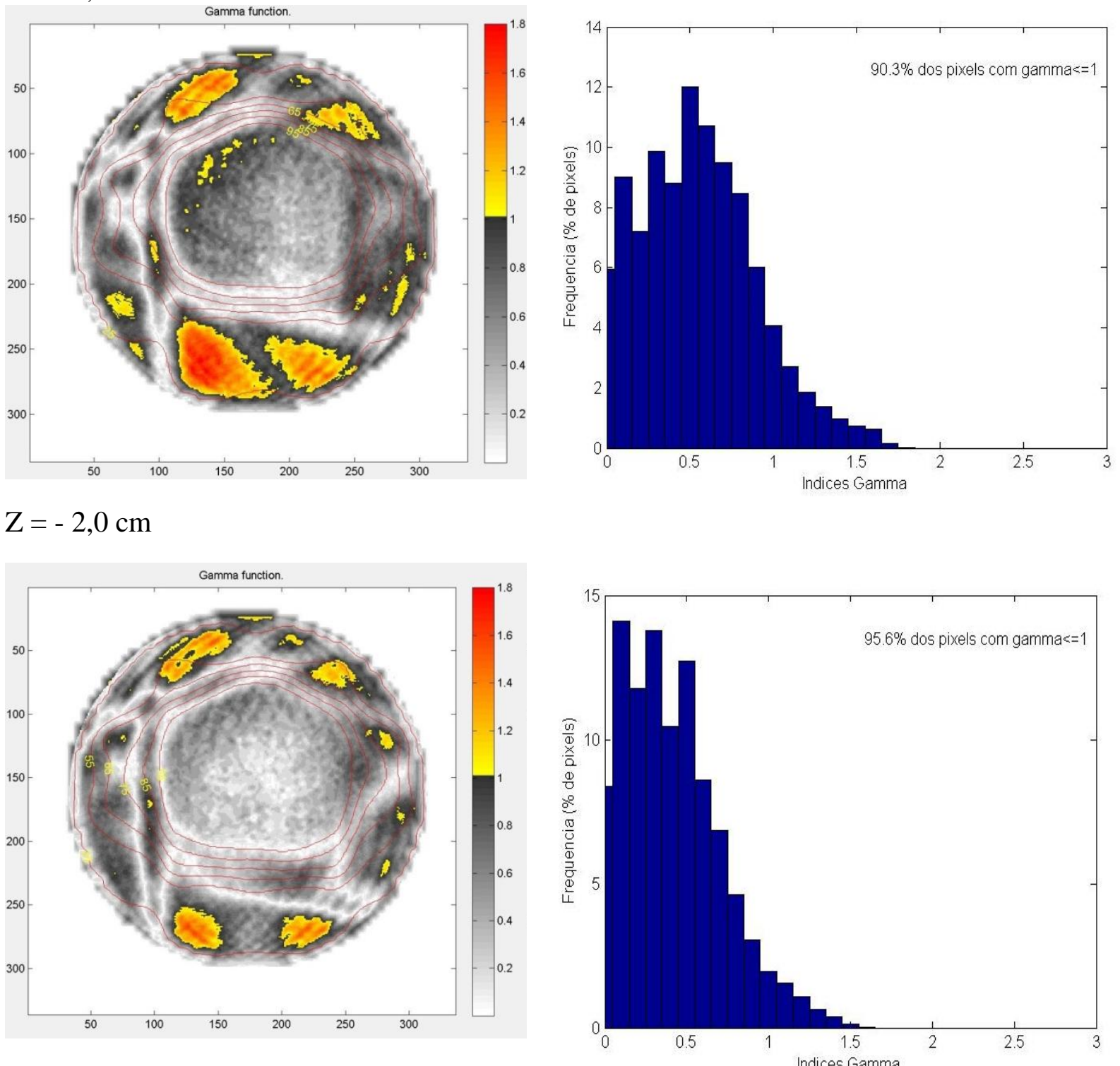

\section{$Z=-1,0 \mathrm{~cm}$}
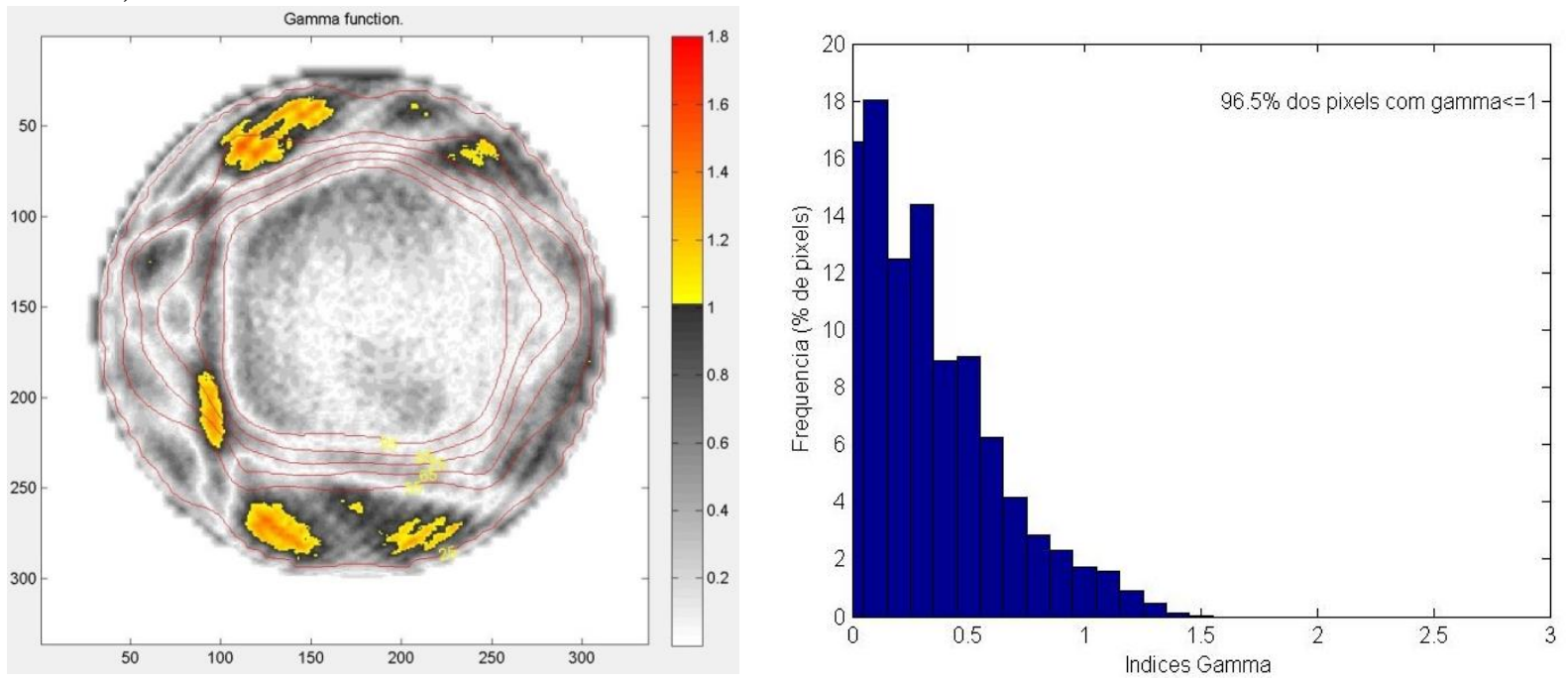


\section{$\mathrm{Z}=0 \mathrm{~cm}$ (isocentro)}

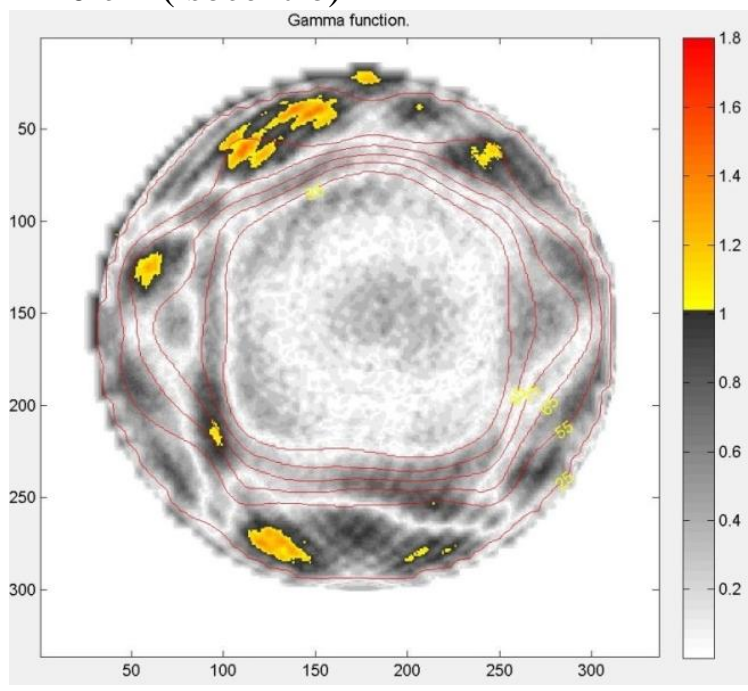

\section{$\mathrm{Z}=1,0 \mathrm{~cm}$}
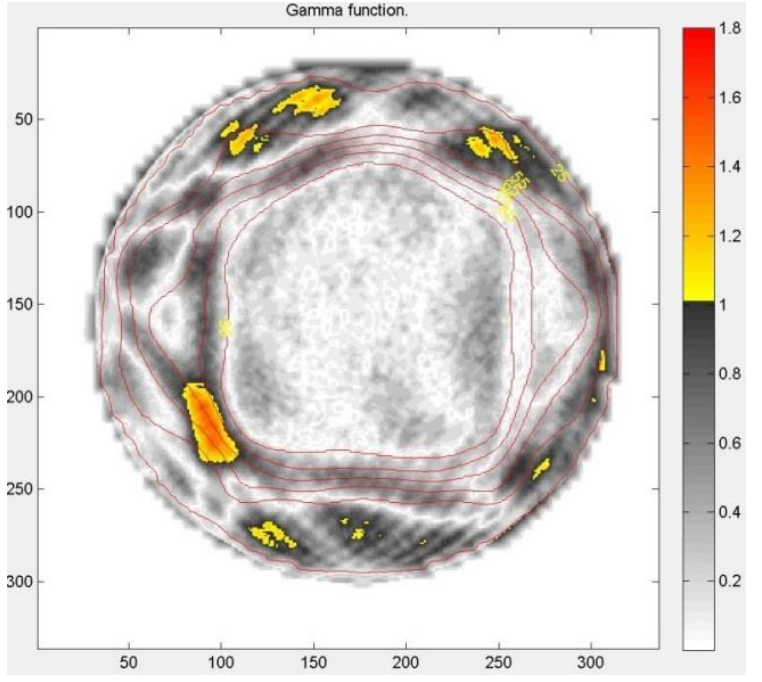

$\mathrm{Z}=2,0 \mathrm{~cm}$

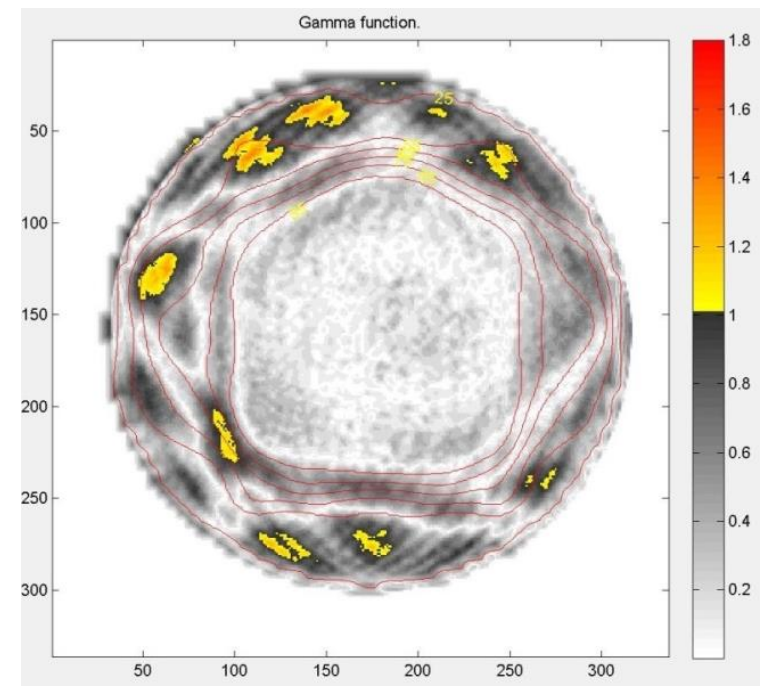

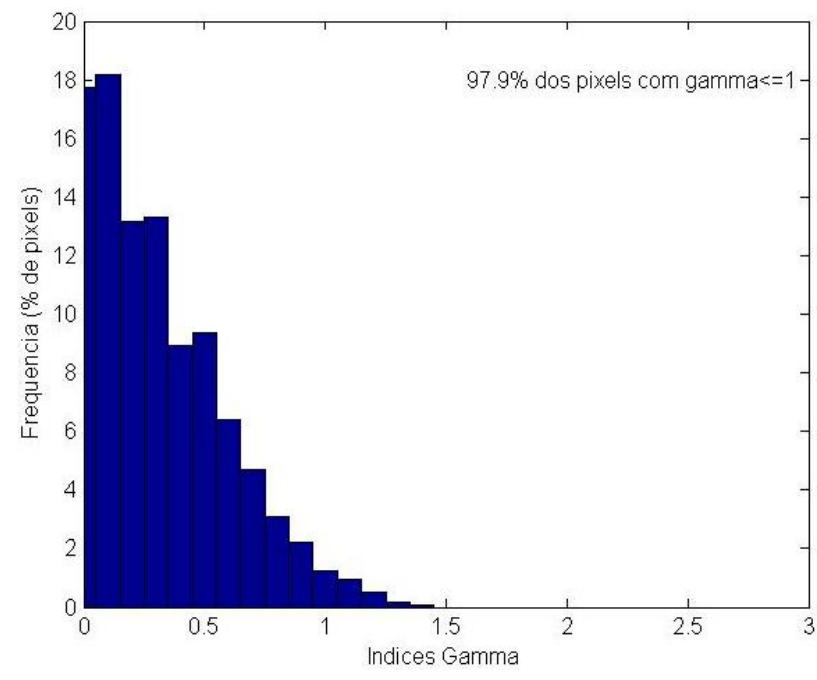
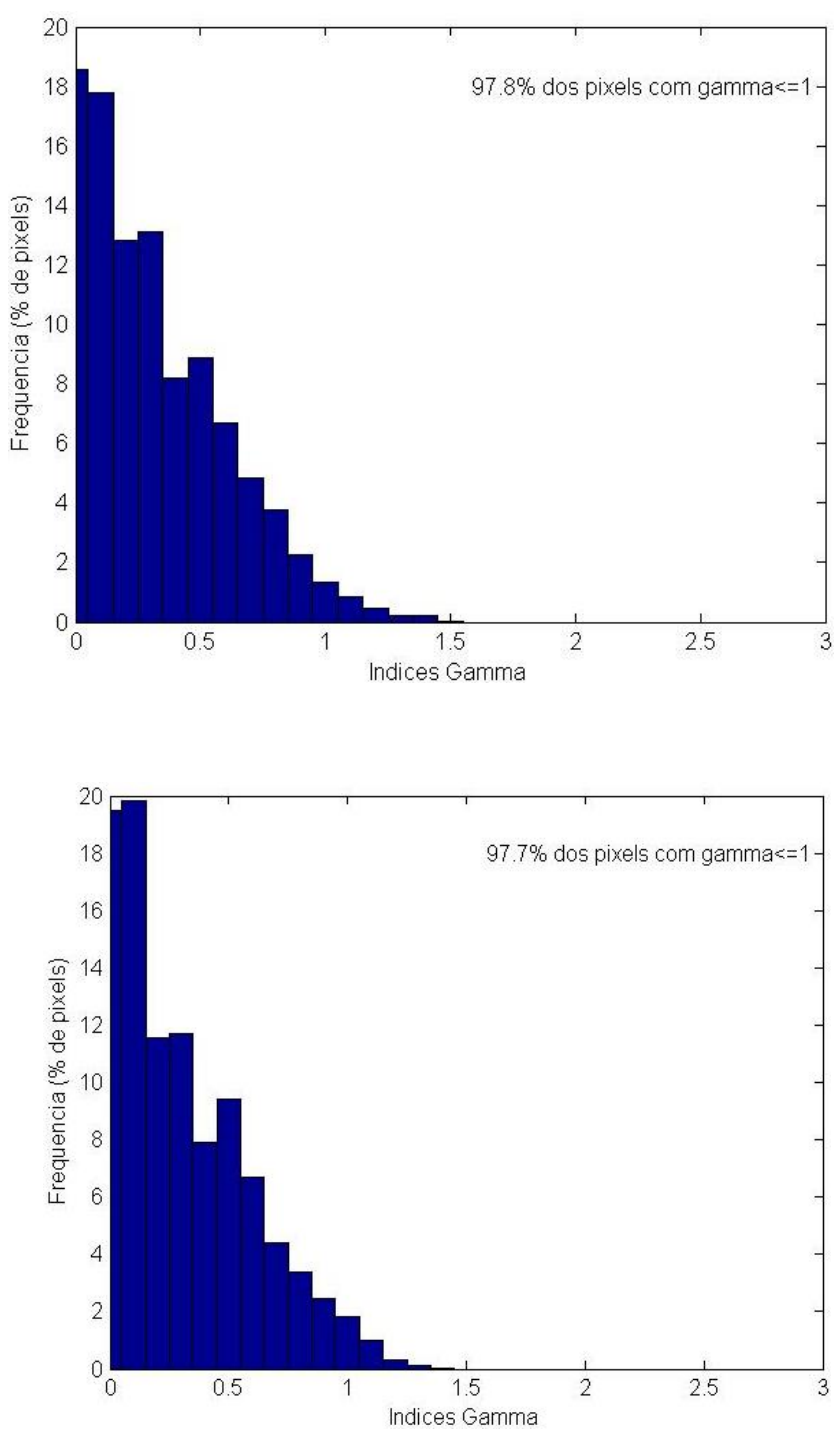


$$
\mathrm{Z}=3,0 \mathrm{~cm}
$$
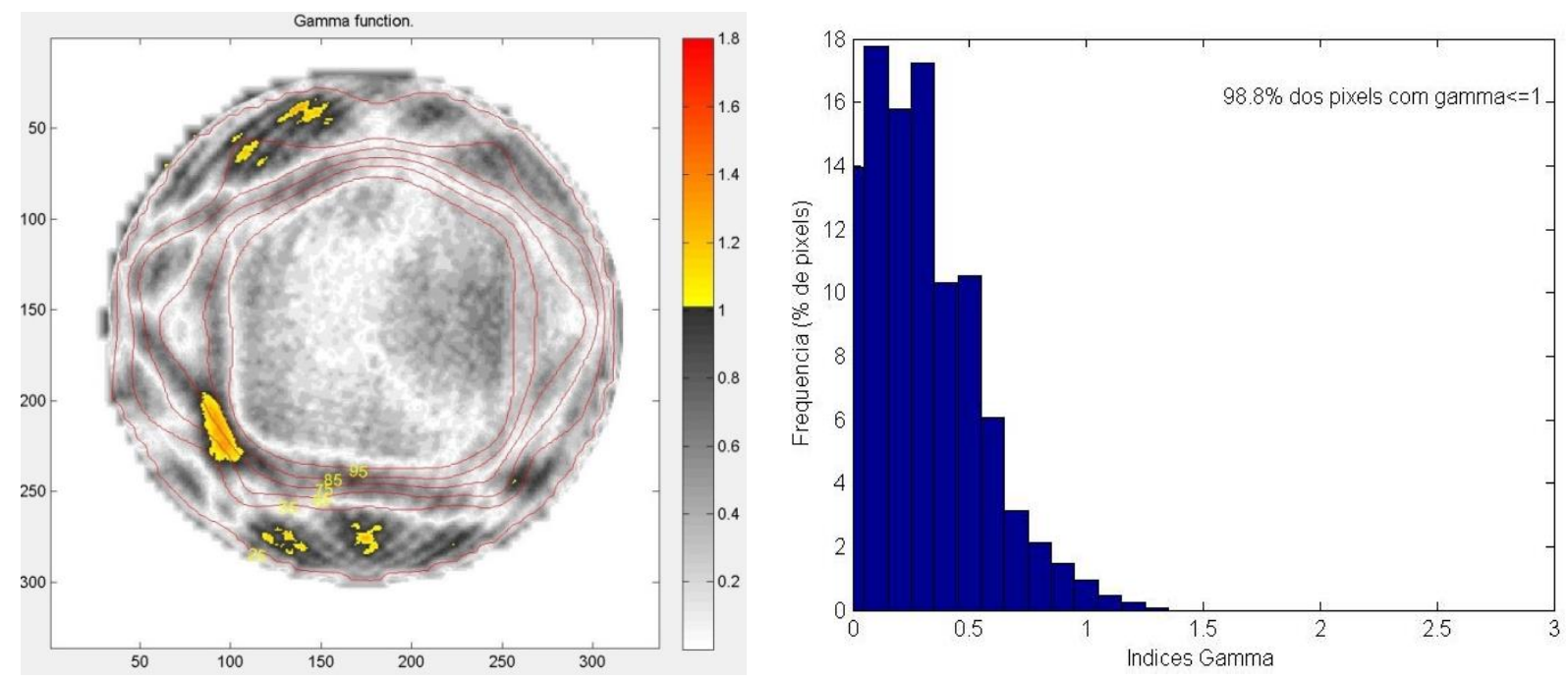

\section{$\mathrm{Z}=4,0 \mathrm{~cm}$}
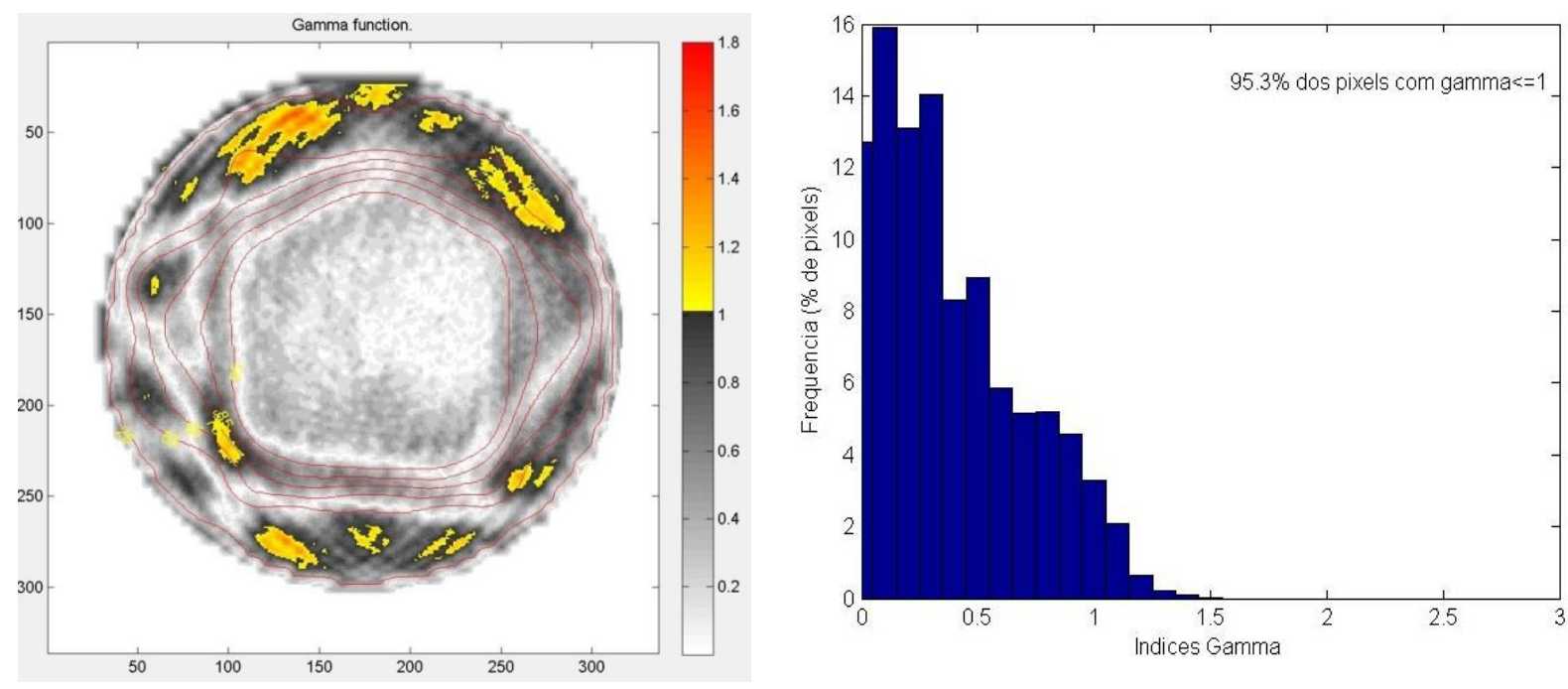

$\mathrm{Z}=5,0 \mathrm{~cm}$
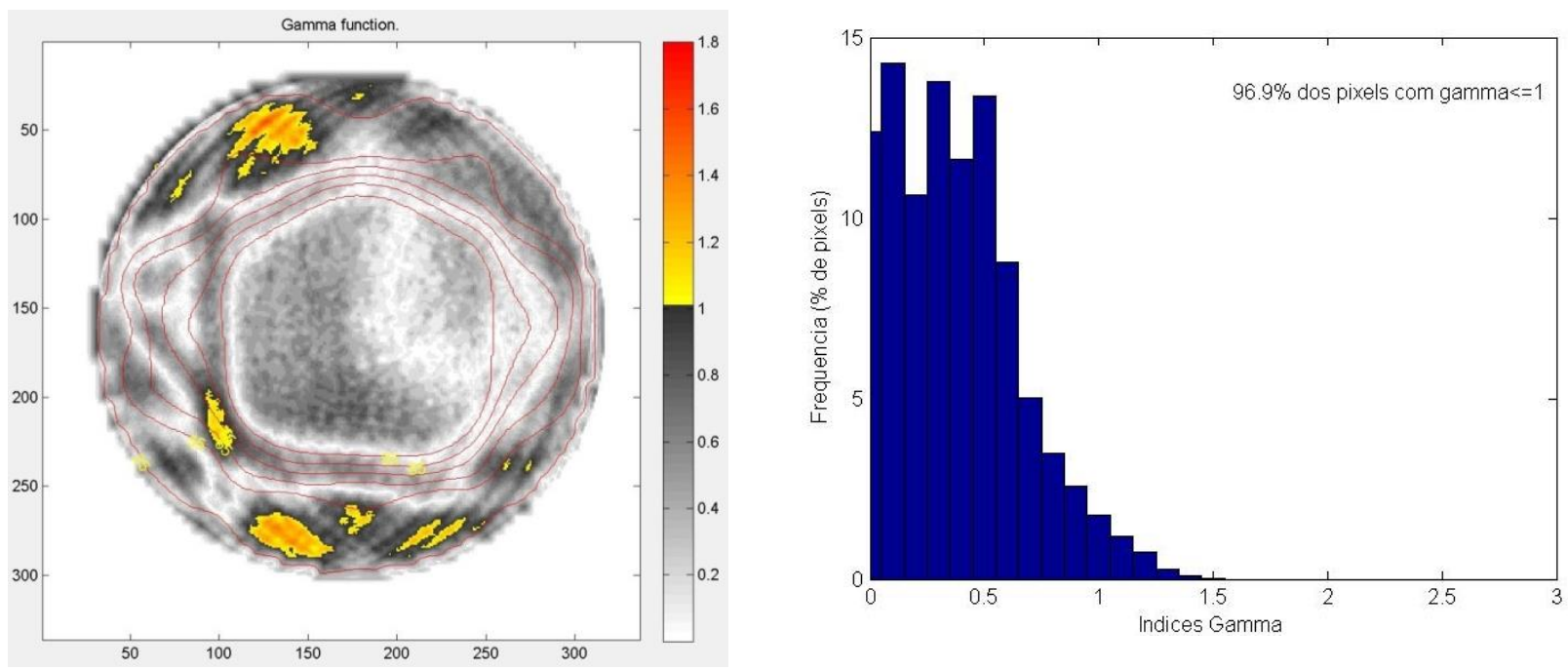
$\mathrm{Z}=6,0 \mathrm{~cm}$
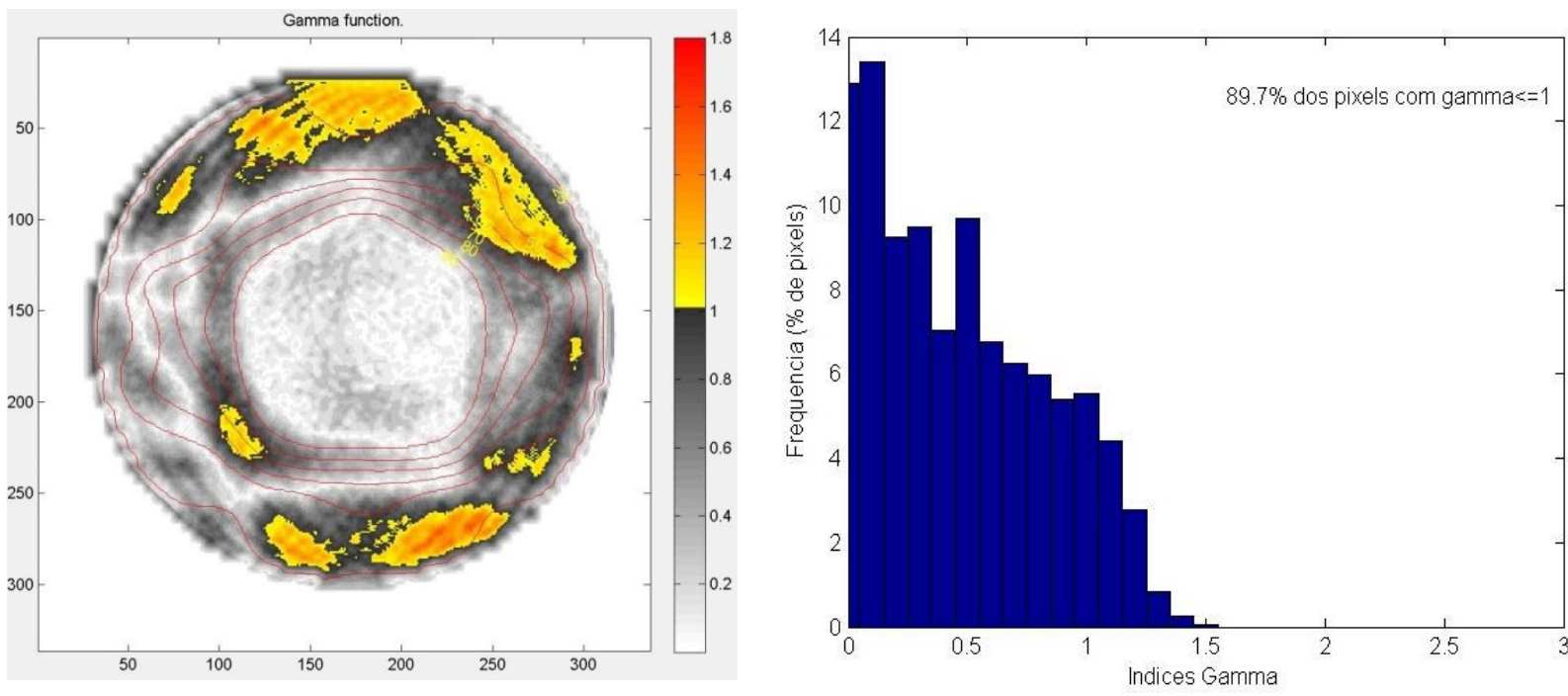

Figura 5.7: Na primeira coluna mapas de distribuições dos índices gama em cada fatia.

$\mathrm{Na}$ segunda coluna Histograma de pixel apresentando a porcentagem de pixels com gama $\leq 1$.

A tabela 5.6 resume os resultados apresentados na figura 5.7.

Tabela 5.6: Porcentagem de índices gama na posição de cada corte.

\begin{tabular}{|c|c|c|c|c|c|c|c|c|c|c|}
\hline \multicolumn{1}{|c|}{ Paciente 1 } \\
\hline Gama (\%) & 90,3 & 95,6 & 96,5 & 97,9 & 97,8 & 97,7 & 98,8 & 95,3 & 96,9 & 89,7 \\
\hline Z (cm) & $-3,0$ & $-2,0$ & $-1,0$ & 0,0 & 1,0 & 2,0 & 3,0 & 4,0 & 5,0 & 6,0 \\
\hline
\end{tabular}

\section{Análises dos cortes com PTV}

De acordo com os dados extraídos do sistema de planejamento a partir do isocentro na direção Cranial (sentido positivo em Z) há PTV até a posição $5,1 \mathrm{~cm}$, e na direção Caudal (sentido negativo em Z) até $3,0 \mathrm{~cm}$, portanto apenas a fatia na posição $6,0 \mathrm{~cm}$ não possui PTV. Concluindo a análise do planejamento para o paciente 1, nas fatias em que há volume alvo, os índices gama estão acima de $90 \%$ portanto planejamento passa no controle de qualidade tridimensional. 


\section{4 - Paciente 2}

Controle de qualidade Pontual - Câmara de Ionização

Tabela 5.7: Leituras usando CI para o Paciente 2

\begin{tabular}{|c|c|}
\hline Dose Planejada (cGy) & 284,60 \\
\hline Dose Medida (cGy) & 282,95 \\
\hline Diferença Abs (cGy) & 1,65 \\
\hline Desvio (\%) & $-0,6$ \\
\hline
\end{tabular}

Controle de qualidade bidimensional - Mapcheck2

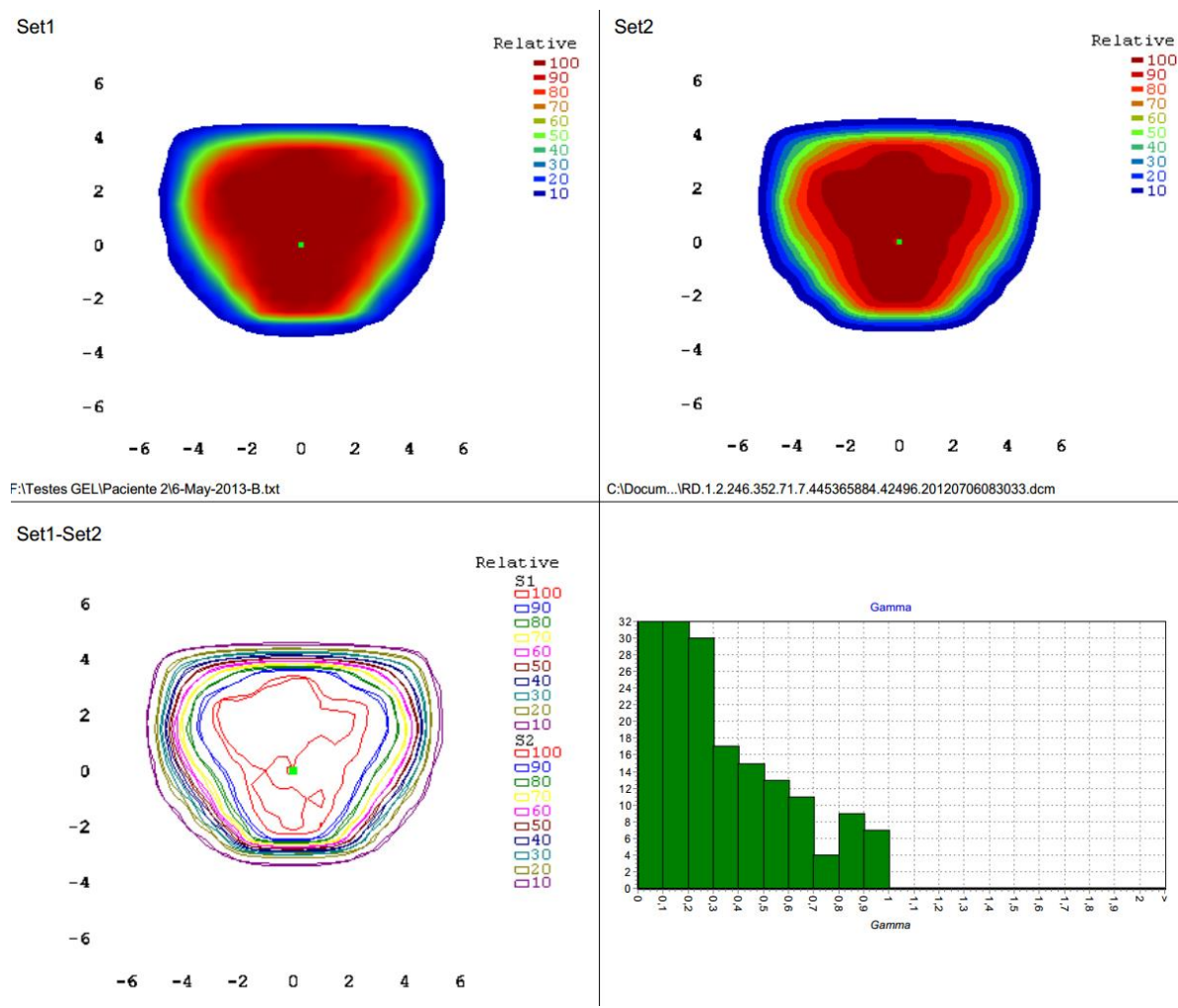

Figura 5.8: Distribuições de dose medida, planejada, sobreposição das isodose e histograma de Pixels com índice gama para o paciente 2.

\section{Análise gama}

$100 \%$ dos pixels com $\gamma \leq 1$, o planejamento passa no controle de qualidade bidimensional 


\section{Controle de qualidade Tridimensional - Gel Magic-f}

$\mathrm{Z}=0 \mathrm{~cm}$
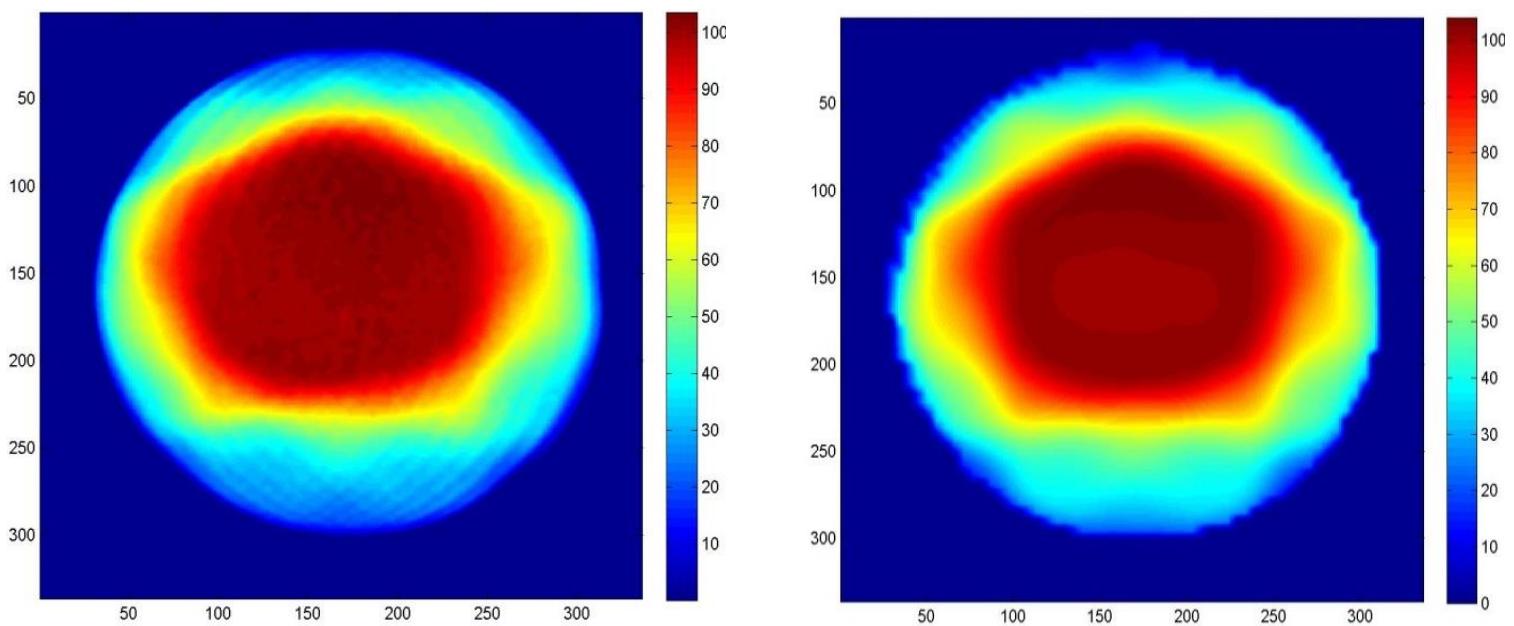

Figura 5.9: Distribuições de dose para os cortes no isocentro, medida e planejada.
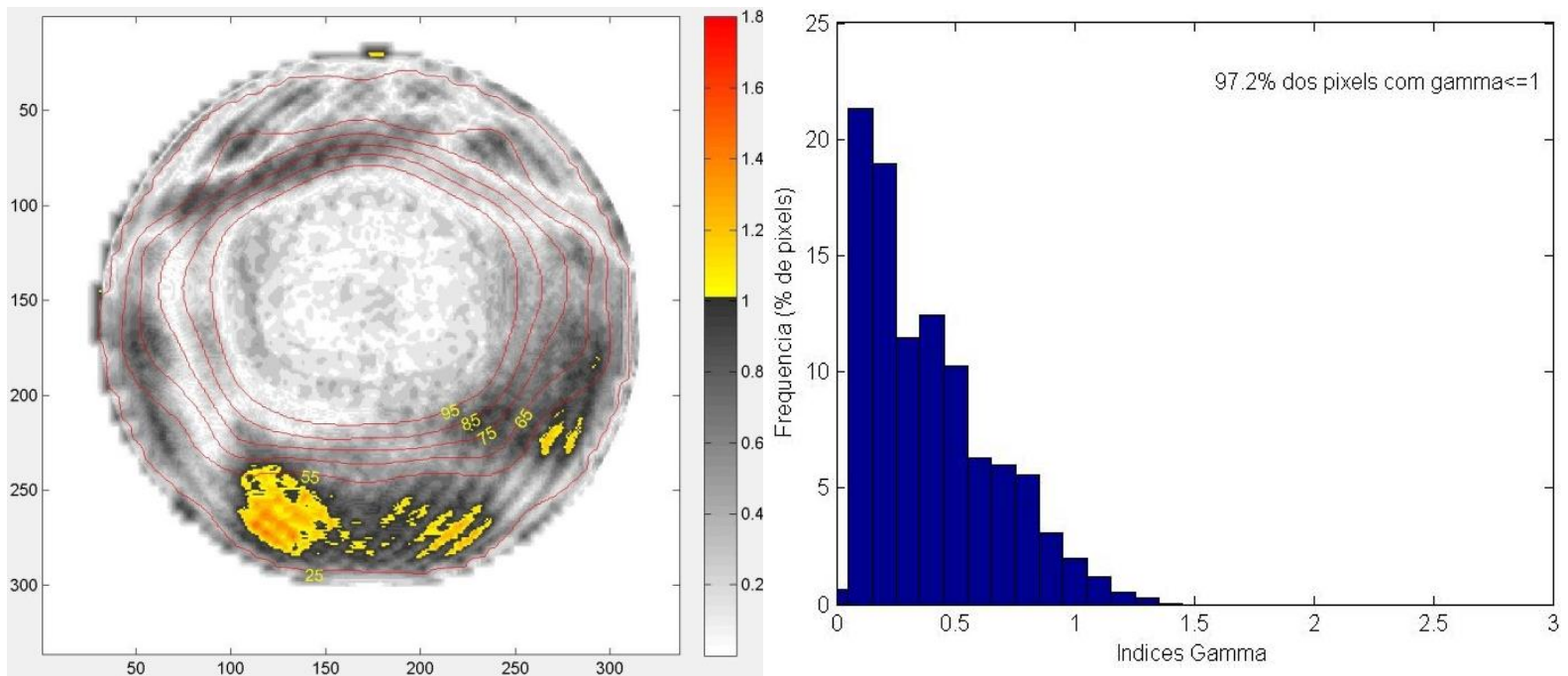

Figura 5.10: Mapa de índices gama e seu respectivo histograma de pixels para o isocentro, apresentando $97,2 \%$ dos pixels com $\gamma \leq 1$.

Tabela 5.8: Apresenta os índices gama para cada corte na posição respectiva

\begin{tabular}{|c|c|c|c|c|c|c|c|c|c|c|}
\hline \multicolumn{10}{|c|}{ Paciente 2 } \\
\hline Gama (\%) & 88,5 & 94,6 & 96,6 & 95,9 & 97,2 & 98,0 & 98,1 & 97,1 & 98,5 & 95,3 \\
\hline Z (cm) & $-4,0$ & $-3,0$ & $-2,0$ & $-1,0$ & 0,0 & 1,0 & 2,0 & 3,0 & 4,0 & 5,0 \\
\hline
\end{tabular}

\section{Análise das fatias com PTV}

De acordo com os dados extraídos do sistema de planejamento o Paciente 2 possui $3,3 \mathrm{~cm}$ de PTV na direção cranial e $2,4 \mathrm{~cm}$ na direção caudal, sendo assim o corte na posição $-4,0 \mathrm{~cm}$ que falham na aceitação de $90 \%$, não possui PTV portanto o planejamento passa no controle de qualidade tridimensional. 


\section{5 - Paciente 3}

Controle de qualidade Pontual - Câmara de Ionização

Tabela 5.9: Leituras usando CI para o Paciente 3

\begin{tabular}{|c|c|}
\hline Dose Planejada (cGy) & 256,30 \\
\hline Dose Medida (cGy) & 255,39 \\
\hline Diferença Abs (cGy) & 0,91 \\
\hline Desvio (\%) & $-0,4$ \\
\hline
\end{tabular}

Controle de qualidade bidimensional - Mapcheck2

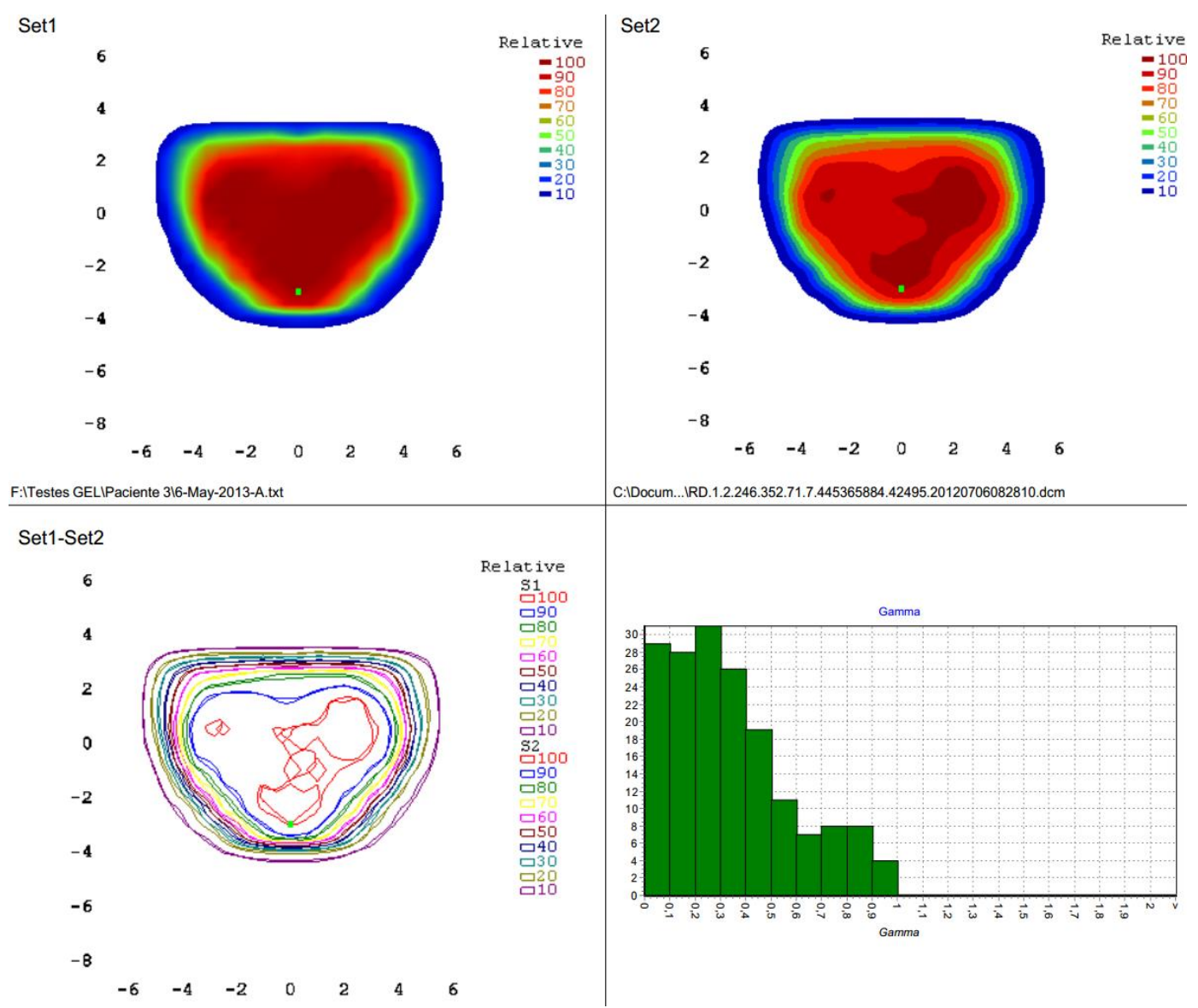

Figura 5.11: Distribuições de dose medida, planejada, sobreposição das isodose e histograma de Pixels com índice gama para o paciente 3.

\section{Análise gama}

$100 \%$ dos pixels com $\gamma \leq 1$, o planejamento passa no controle de qualidade bidimensional 


\section{Controle de qualidade Tridimensional - Gel Magic-f}

$\mathrm{Z}=0 \mathrm{~cm}$
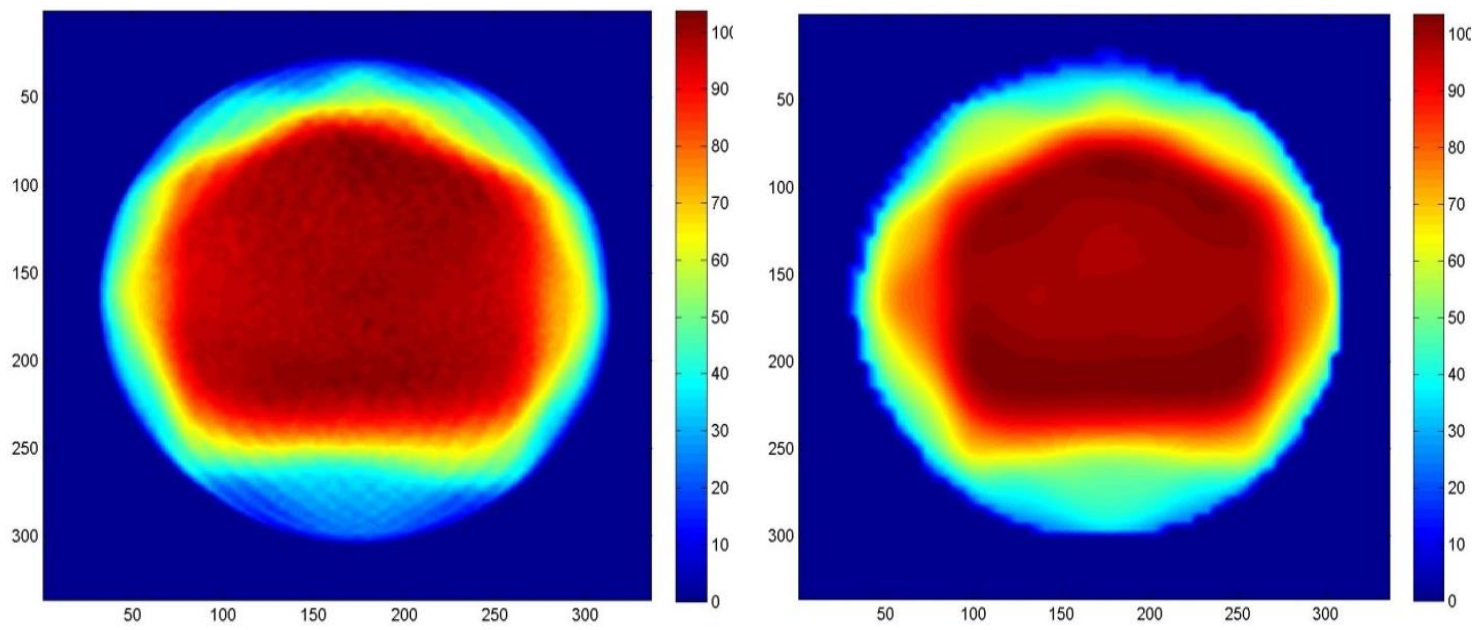

Figura 5.12: Distribuições de dose para os cortes no isocentro, medida e planejada.
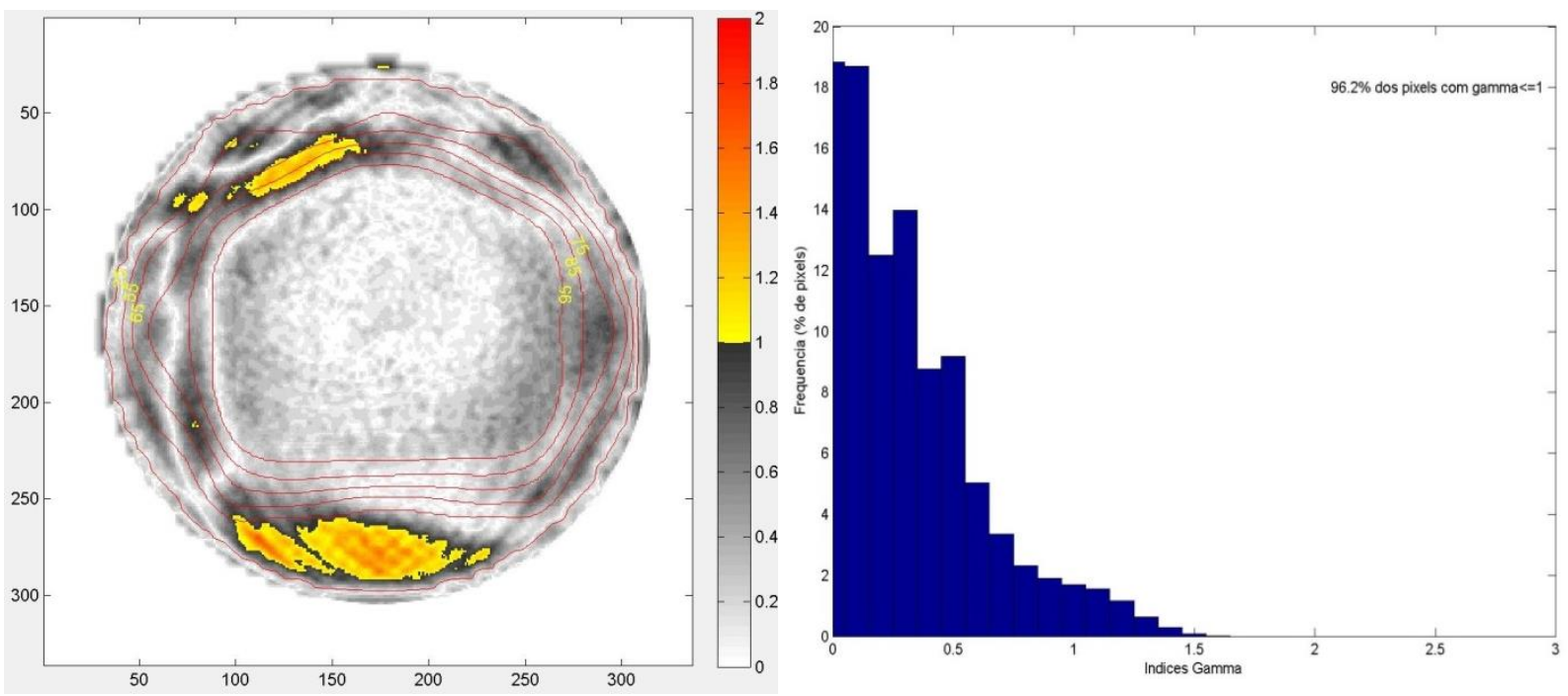

Figura 5.13: Mapa de índices gama e seu respectivo histograma de pixels para o isocentro, apresentando $96,2 \%$ dos pixels com $\gamma \leq 1$.

Tabela 5.10: Apresenta os índices gama para cada corte na posição respectiva Paciente 3

\begin{tabular}{|c|c|c|c|c|c|c|c|c|c|c|}
\hline \multicolumn{10}{|c|}{ Paciente 3 } \\
\hline Gama (\%) & 85,8 & 91,3 & 93,5 & 94,3 & 96,2 & 97,9 & 96,8 & 96,4 & 93,4 & 84,1 \\
\hline Z (cm) & $-4,0$ & $-3,0$ & $-2,0$ & $-1,0$ & 0,0 & 1,0 & 2,0 & 3,0 & 4,0 & 5,0 \\
\hline
\end{tabular}

\section{Análise das fatias com PTV}

De acordo com a informação extraída do sistema de planejamento o paciente 3 possui PTV até 3,3 cm na direção cranial e 2,4 $\mathrm{cm}$ na direção caudal, sendo assim as fatias nas posições $-4,0 \mathrm{~cm}$ e $5,0 \mathrm{~cm}$ que falham na aceitação de $90 \%$, portanto o planejamento passa no controle de qualidade tridimensional. 


\section{6 - Paciente 4}

Controle de qualidade Pontual - Câmara de Ionização

Tabela 5.11: Leituras usando CI para o Paciente 4

\begin{tabular}{|c|c|}
\hline Dose Planejada (cGy) & 249,30 \\
\hline Dose Medida (cGy) & 246,88 \\
\hline Diferença Abs (cGy) & 2,42 \\
\hline Desvio (\%) & $-1,0$ \\
\hline
\end{tabular}

\section{Controle de qualidade bidimensional - Mapcheck2}

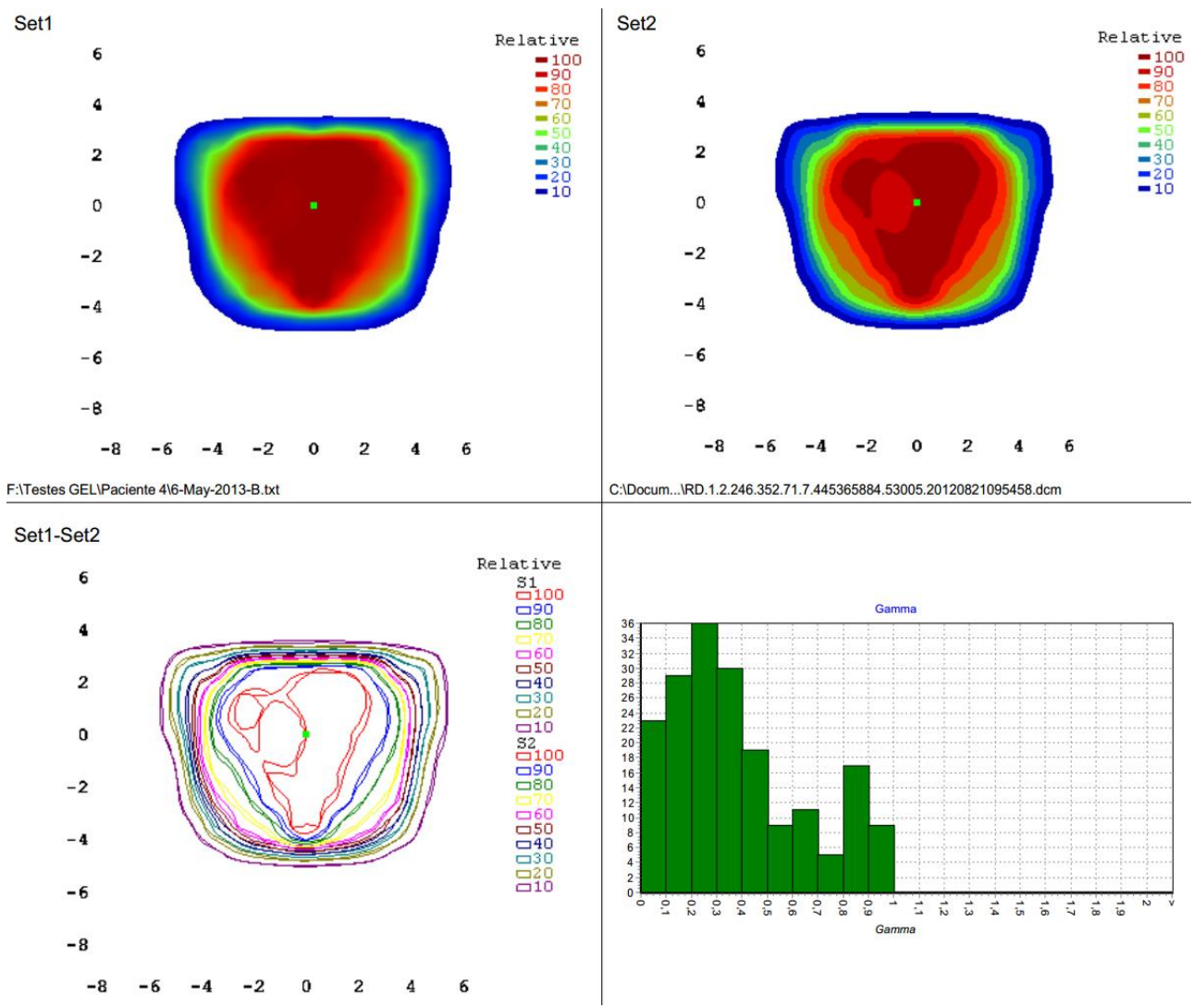

Figura 5.14: Distribuições de dose medida, planejada, sobreposição das isodose e histograma de Pixels com índice gama para o paciente 4.

\section{Análise gama}

$100 \%$ dos pixels com $\gamma \leq 1$, o planejamento passa no controle de qualidade bidimensional. 


\section{Controle de qualidade Tridimensional - Gel Magic-f}

$\mathrm{Z}=0 \mathrm{~cm}$
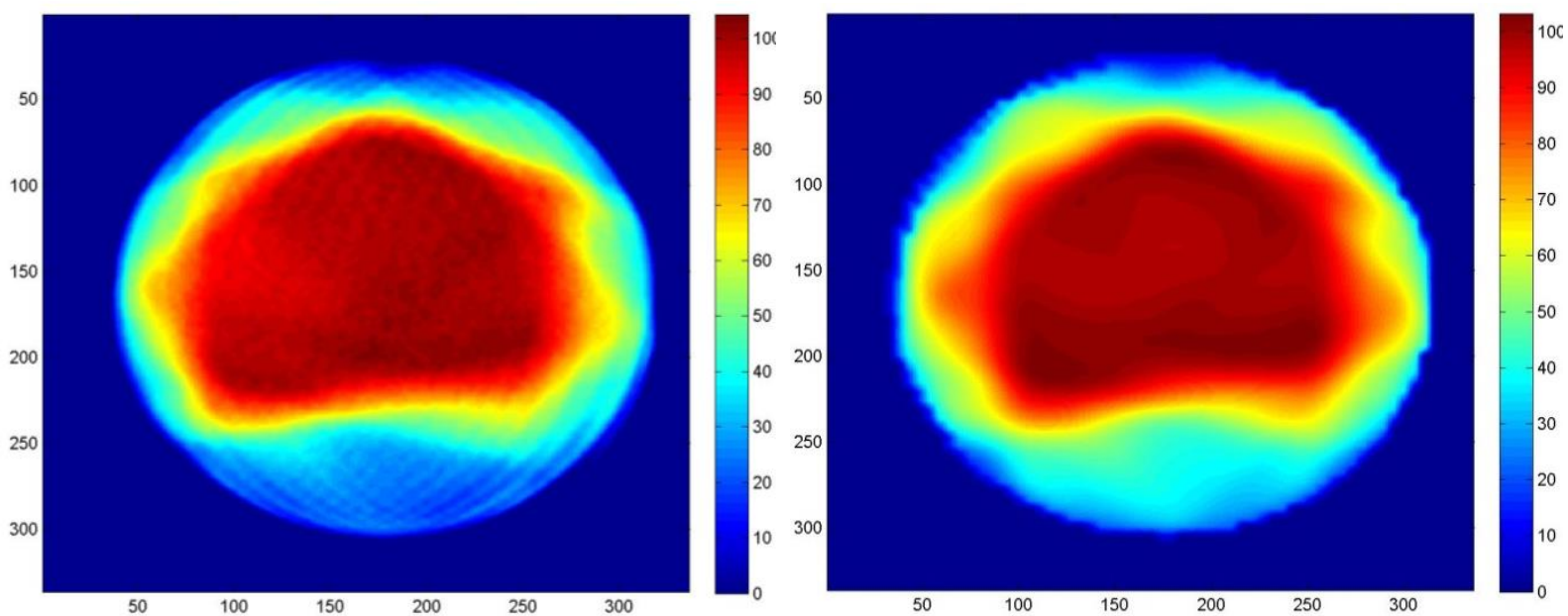

Figura 5.15: Distribuições de dose para os cortes no isocentro, medida e planejada.
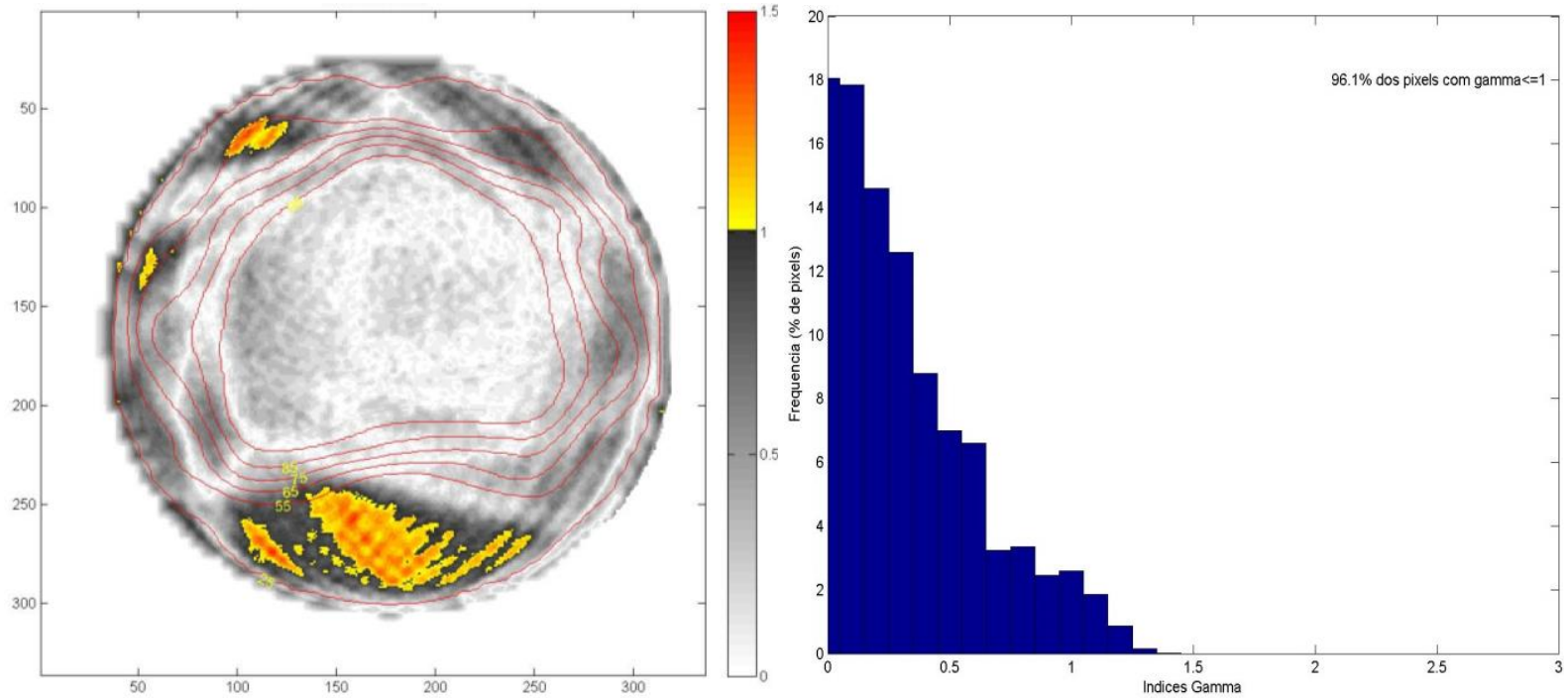

Figura 5.16: Mapa de índices gama e seu respectivo histograma de pixels para o isocentro, apresentando $96,1 \%$ dos pixels com $\gamma \leq 1$.

Tabela 5.12: Apresenta os índices gama para cada corte na posição respectiva

\begin{tabular}{|c|c|c|c|c|c|c|c|c|c|c|}
\hline \multicolumn{10}{|c|}{ Paciente 4 } \\
\hline Gama (\%) & 85,0 & 88,9 & 91,5 & 94,3 & 96,1 & 95,9 & 97,6 & 96,9 & 96,5 & 88,4 \\
\hline $\mathbf{Z}(\mathbf{c m})$ & $-4,0$ & $-3,0$ & $-2,0$ & $-1,0$ & 0,0 & 1,0 & 2,0 & 3,0 & 4,0 & 5,0 \\
\hline
\end{tabular}

\section{Análise das fatias com PTV}

De acordo com a informação extraída do sistema de planejamento o paciente 4 possui PTV até 4,2cm na direção cranial e até $2,4 \mathrm{~cm}$ na direção caudal, sendo assim os cortes nas posições $-4,0,-3,0$ e 5,0 cm que falham na aceitação de $90 \%$ dos pixels, não possuem PTV e portando o planejamento passa no controle de qualidade tridimensional. 


\section{7 - Paciente 5}

Controle de qualidade Pontual - Câmara de Ionização

Tabela 5.13: Leituras usando CI para o Paciente 5

\begin{tabular}{|c|c|}
\hline Dose Planejada (cGy) & 274,20 \\
\hline Dose Medida (cGy) & 271,22 \\
\hline Diferença Abs (cGy) & 2,98 \\
\hline Desvio (\%) & $-1,1$ \\
\hline
\end{tabular}

\section{Controle de qualidade bidimensional - Mapcheck2}

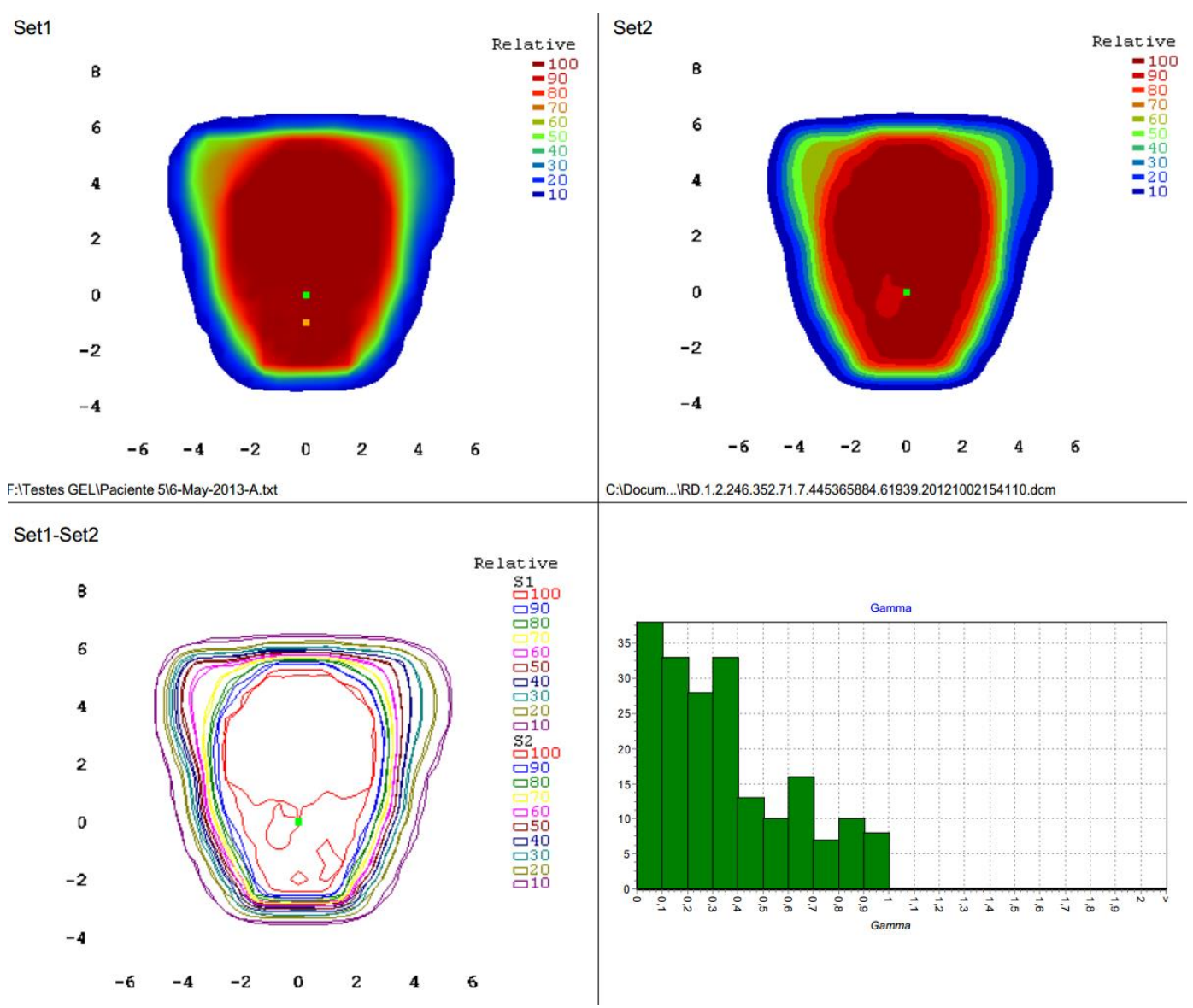

Figura 5.17: Distribuições de dose medida, planejada, sobreposição das isodose e histograma de Pixels com índice gama para o paciente 5.

\section{Análise gama}

$100 \%$ dos pixels com $\gamma \leq 1$, o planejamento passa no controle de qualidade bidimensional. 


\section{Controle de qualidade Tridimensional - Gel Magic-f}

$\mathrm{Z}=0 \mathrm{~cm}$

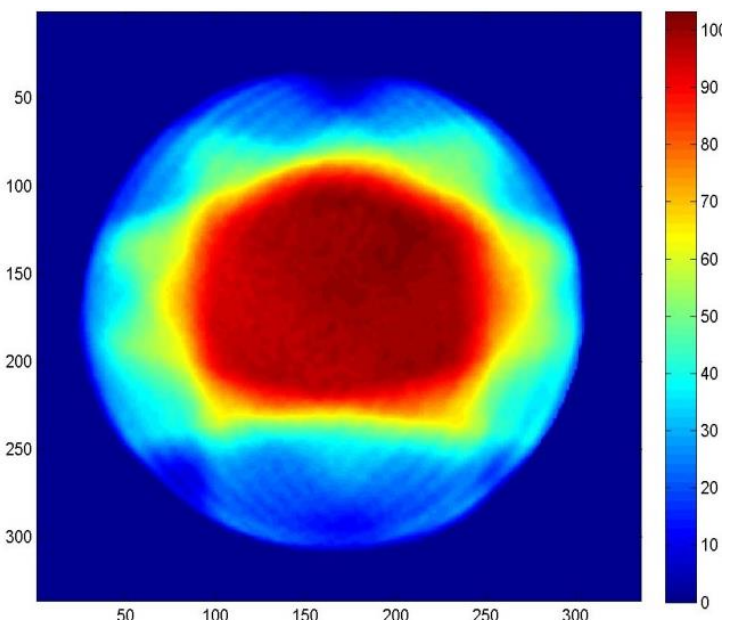

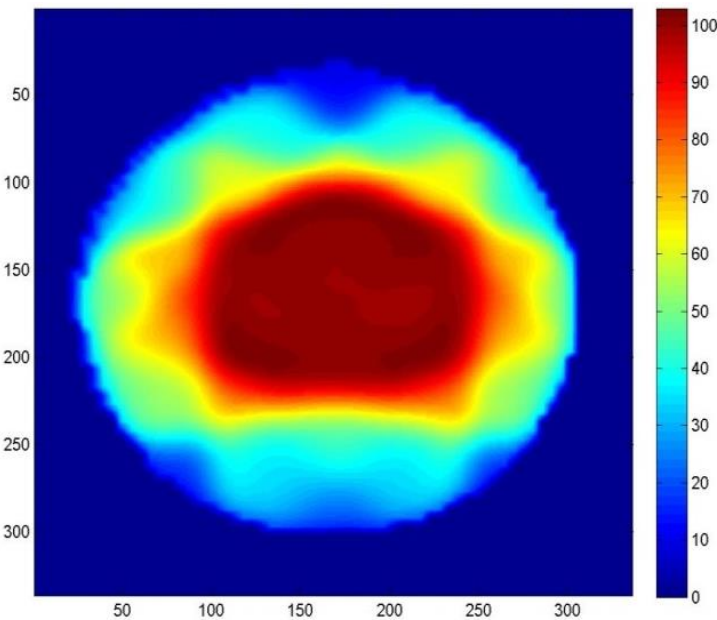

$50 \quad 100$

Figura 5.18: Distribuições de dose para os cortes no isocentro, medida e planejada.
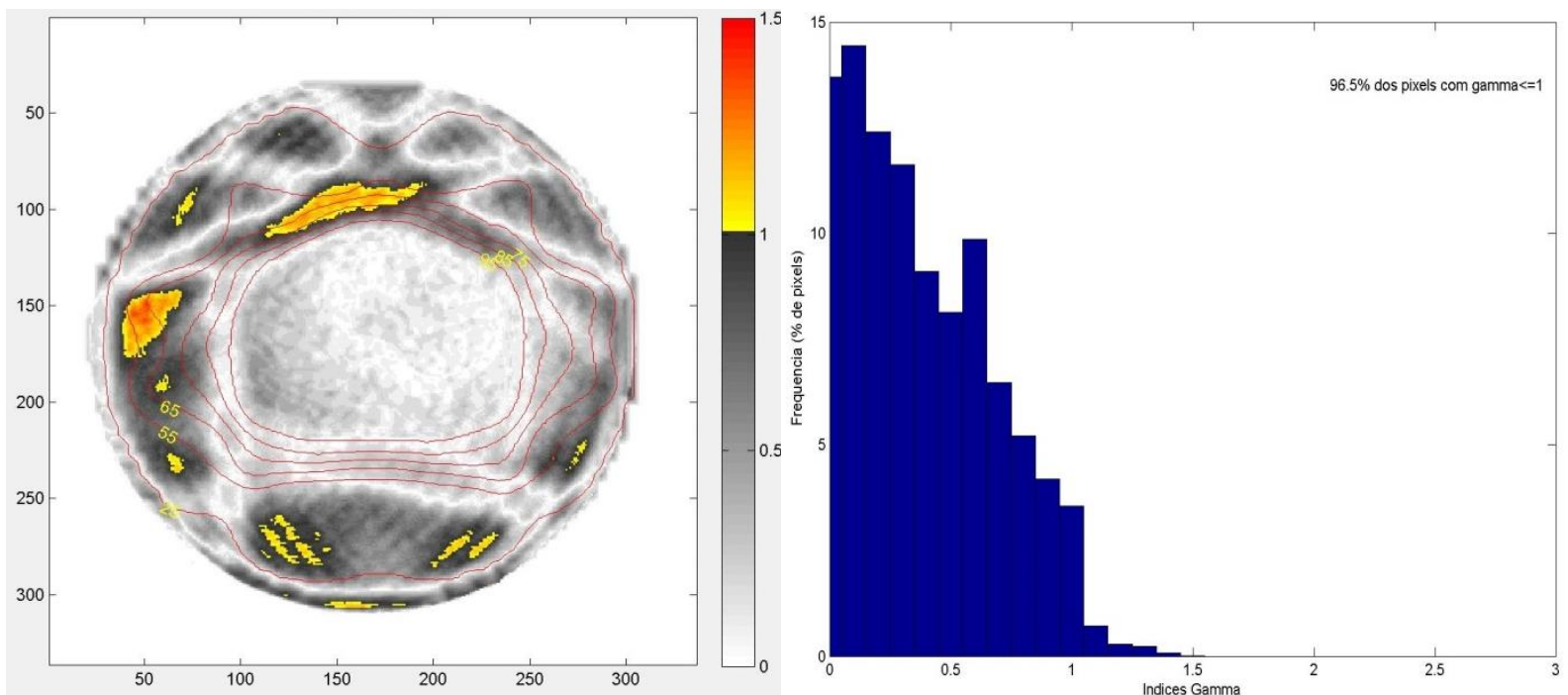

Figura 5.19: Mapa de índices gama e seu respectivo histograma de pixels para o isocentro, apresentando $96,5 \%$ dos pixels com $\gamma \leq 1$.

Tabela 5.14: Apresenta os índices gama para cada corte na posição respectiva

\begin{tabular}{|c|c|c|c|c|c|c|c|c|c|c|}
\hline \multicolumn{10}{|c|}{ Paciente 5 } \\
\hline Gama (\%) & 92,3 & 95,1 & 95,0 & 96,5 & 97,2 & 97,9 & 98,3 & 98,8 & 98,6 & 93,8 \\
\hline $\mathbf{Z}(\mathbf{c m})$ & $-3,0$ & $-2,0$ & $-1,0$ & 0,0 & 1,0 & 2,0 & 3,0 & 4,0 & 5,0 & 6,0 \\
\hline
\end{tabular}

\section{Análise das fatias com PTV}

Nesse planejamento há PTV até $5,1 \mathrm{~cm}$ na direção cranial e 2,4 na direção caudal, portando analisando assim todo o PTV, e como todos os cortes analisados estão acima 
da aceitação de $90 \%$ dos pixels com $\gamma \leq 1$ o planejamento passa no controle de qualidade tridimensional. Nesse caso as fatias nas posições $-3,0 \mathrm{~cm}$ e $6,0 \mathrm{~cm}$ sem PTV.

\section{8 - Paciente 6}

\section{Controle de qualidade Pontual - Câmara de Ionização}

Tabela 5.15: Leituras usando CI para o Paciente 6

\begin{tabular}{|c|c|}
\hline Dose Planejada (cGy) & 259,90 \\
\hline Dose Medida (cGy) & 258,24 \\
\hline Diferença Abs. (cGy) & 1,66 \\
\hline Desvio (\%) & $-0,6$ \\
\hline
\end{tabular}

\section{Controle de qualidade bidimensional - Mapcheck2}

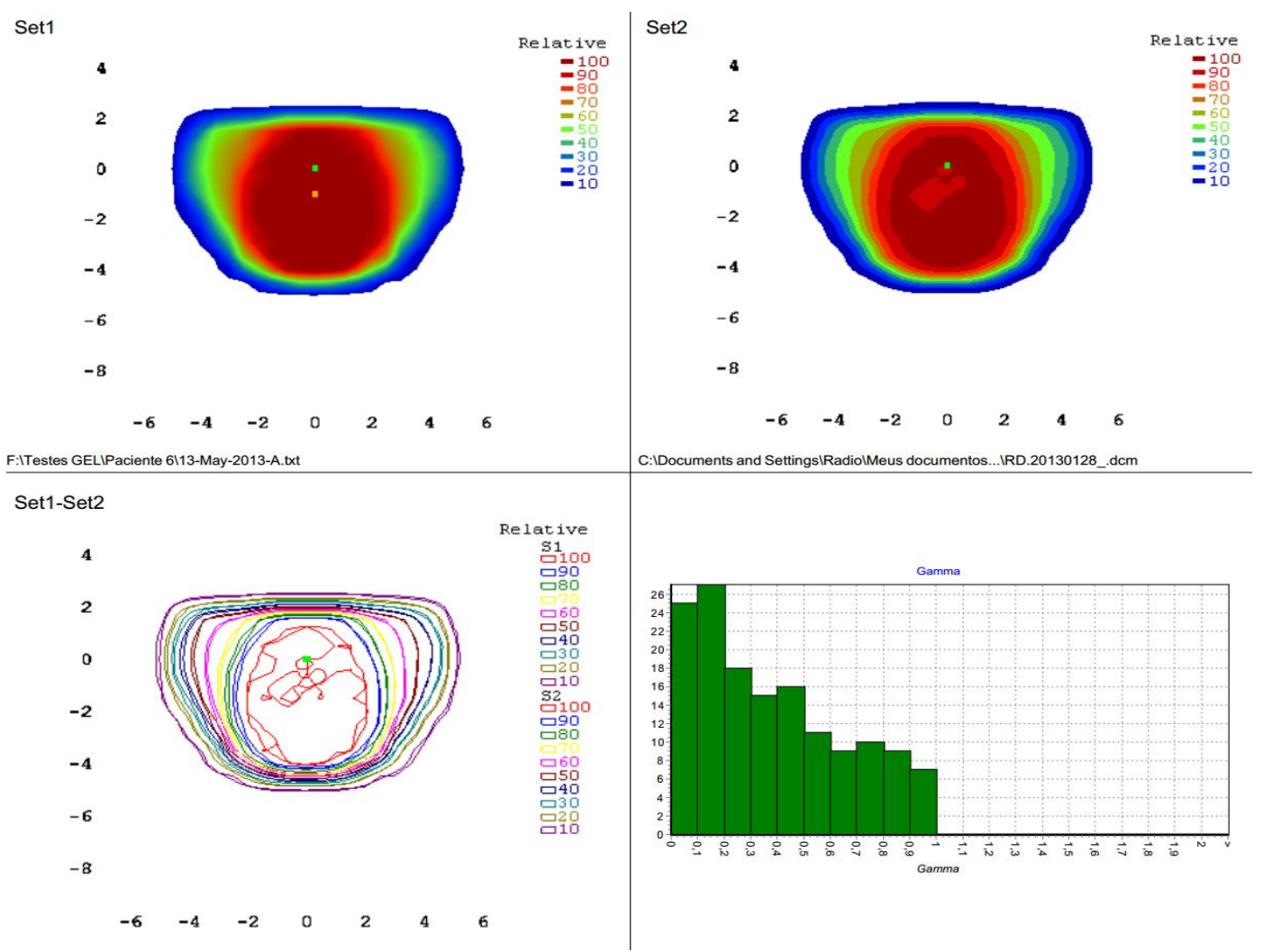

Figura 5.20: Distribuições de dose medida, planejada, sobreposição das isodose e histograma de Pixels com índice gama para o paciente 6.

\section{Análise gama}

$100 \%$ dos pixels com $\gamma \leq 1$, o planejamento passa no controle de qualidade bidimensional. 


\section{Controle de qualidade Tridimensional - Gel Magic-f}

$\mathrm{Z}=0 \mathrm{~cm}$
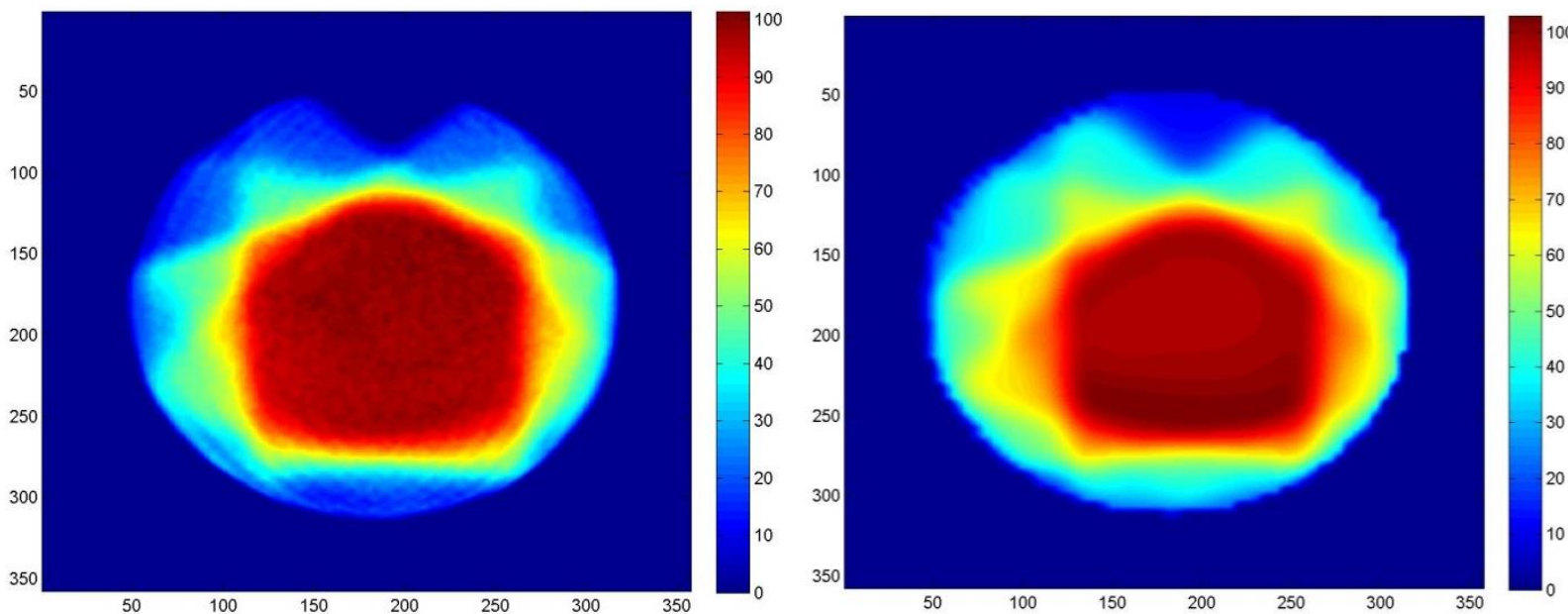

Figura 5.21: Distribuições de dose para os cortes no isocentro, medida e planejada.
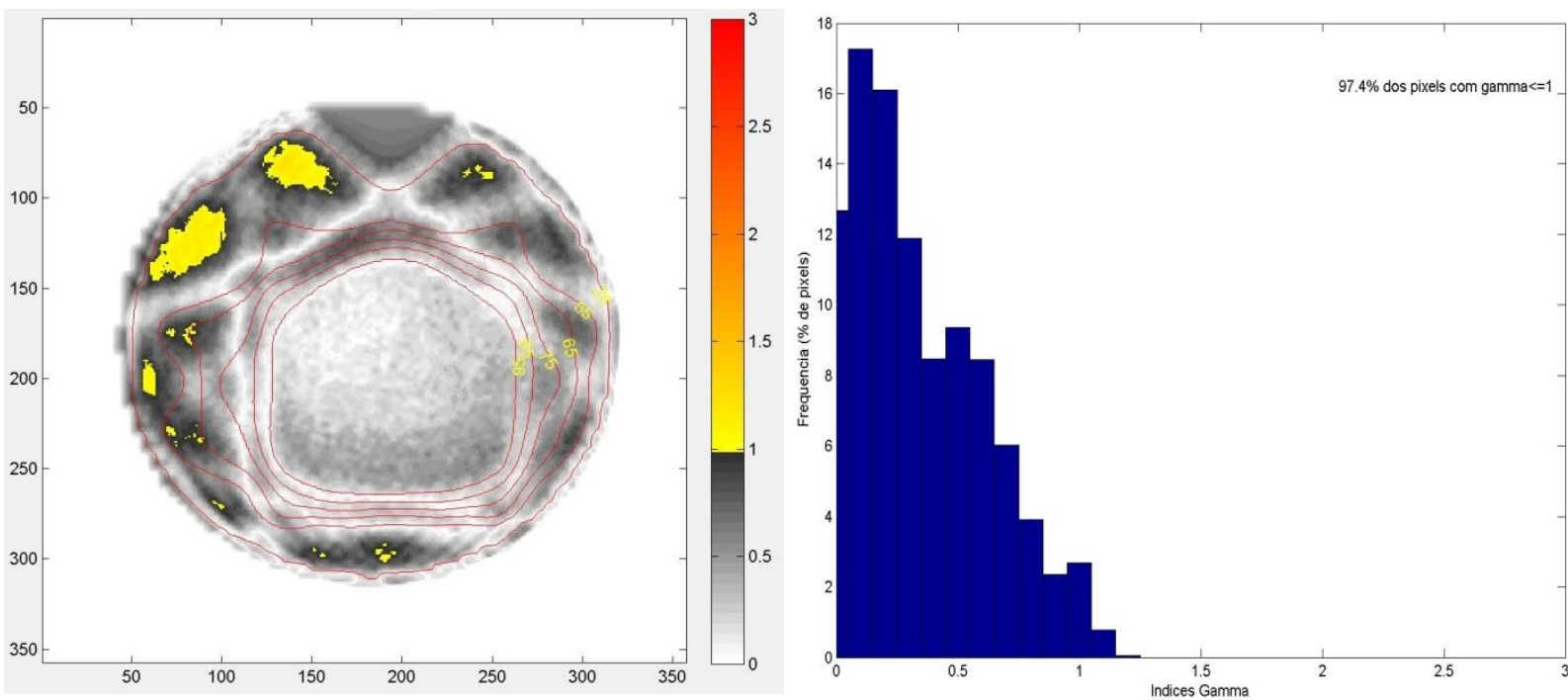

Figura 5.22: Mapa de índices gama e seu respectivo histograma de pixels para o isocentro, apresentando 97,4\% dos pixels com $\gamma \leq 1$.

Tabela 5.16: Apresenta os índices gama para cada corte na posição respectiva

\section{Paciente 6}

\begin{tabular}{|c|c|c|c|c|c|c|c|c|c|c|}
\hline Gama (\%) & 93,8 & 95,8 & 95,6 & 97,4 & 97,7 & 97,8 & 96,6 & 97,3 & 96,4 & 71,4 \\
\hline $\mathbf{Z}(\mathbf{c m})$ & $-3,0$ & $-2,0$ & $-1,0$ & 0,0 & 1,0 & 2,0 & 3,0 & 4,0 & 5,0 & 6,0 \\
\hline
\end{tabular}

\section{Análise das fatias com PTV}

Na direção cranial há PTV até a posição 4,2 cm e na direção caudal até $1,2 \mathrm{~cm}$, assim o corte na posição $6,0 \mathrm{~cm}$ não possui PTV. Os cortes que possuem PTV com porcentagens de índices gama acima de $90 \%$ portanto o planejamento par o paciente 6 passa no controle de qualidade tridimensional. 


\section{9 - Paciente 7}

Controle de qualidade Pontual - Câmara de Ionização

Tabela 5.17: Leituras usando CI para o Paciente 7

\begin{tabular}{|c|c|}
\hline Dose Planejada (cGy) & 264,10 \\
\hline Dose Medida (cGy) & 264,97 \\
\hline Diferença Abs. (cGy) & $-0,87$ \\
\hline Desvio (\%) & 0,3 \\
\hline
\end{tabular}

Controle de qualidade bidimensional - Mapcheck2

Set1

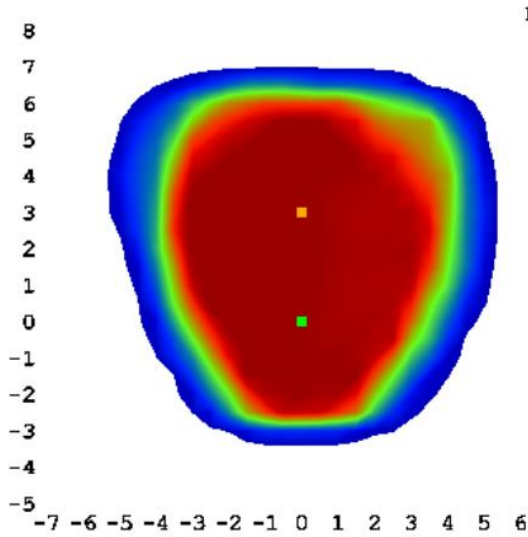

F:ITestes GELIPaciente 7113-May-2013-A.txt

Set1-Set2

8

6

5

4

3

2

0

$-1$

$-2$

$-3$

$-4$

$\begin{array}{lllllllllllllll}-5 & -7 & -6 & -5 & -4 & -3 & -2 & -1 & 0 & 1 & 2 & 3 & 4 & 5 & 6\end{array}$
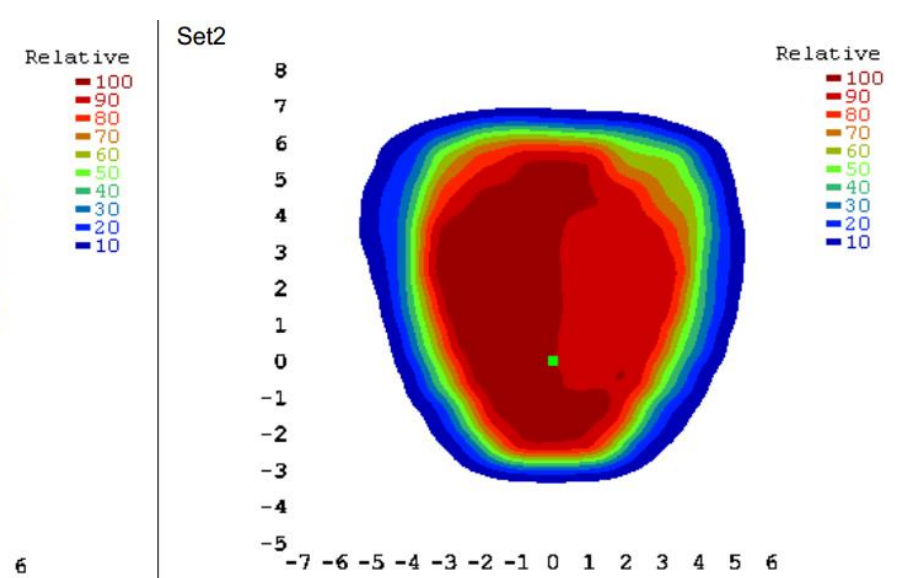

C:IDocum...IRD.1.2.246.352.71.7.445365884.68855.20121023132144.dcm
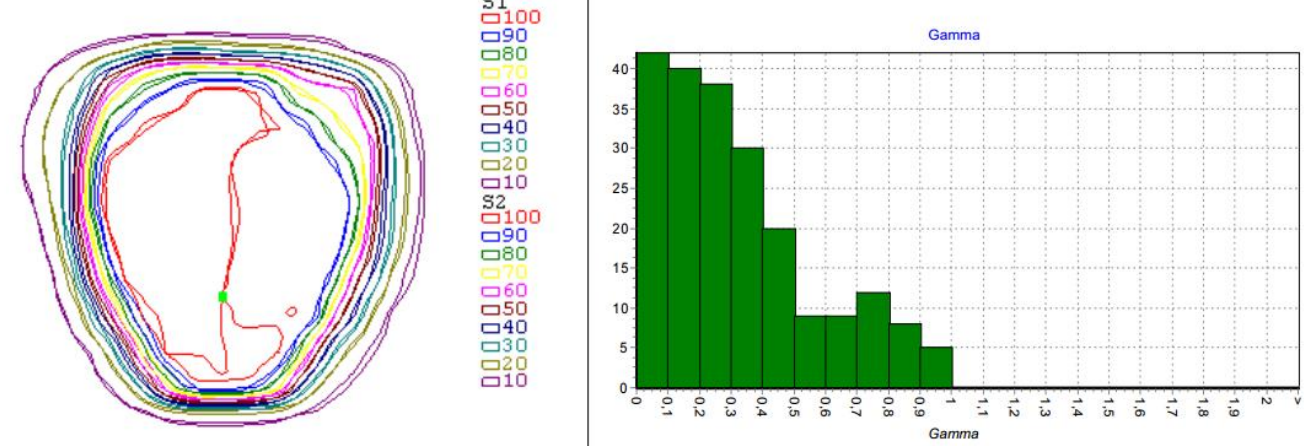

Figura 5.23: Distribuições de dose medida, planejada, sobreposição das isodose e histograma de Pixels com índice gama para o paciente 7.

\section{Análise gama}

$100 \%$ dos pixels com $\gamma \leq 1$, o planejamento passa no controle de qualidade bidimensional. 


\section{Controle de qualidade Tridimensional - Gel Magic-f}

$\mathrm{Z}=0 \mathrm{~cm}$
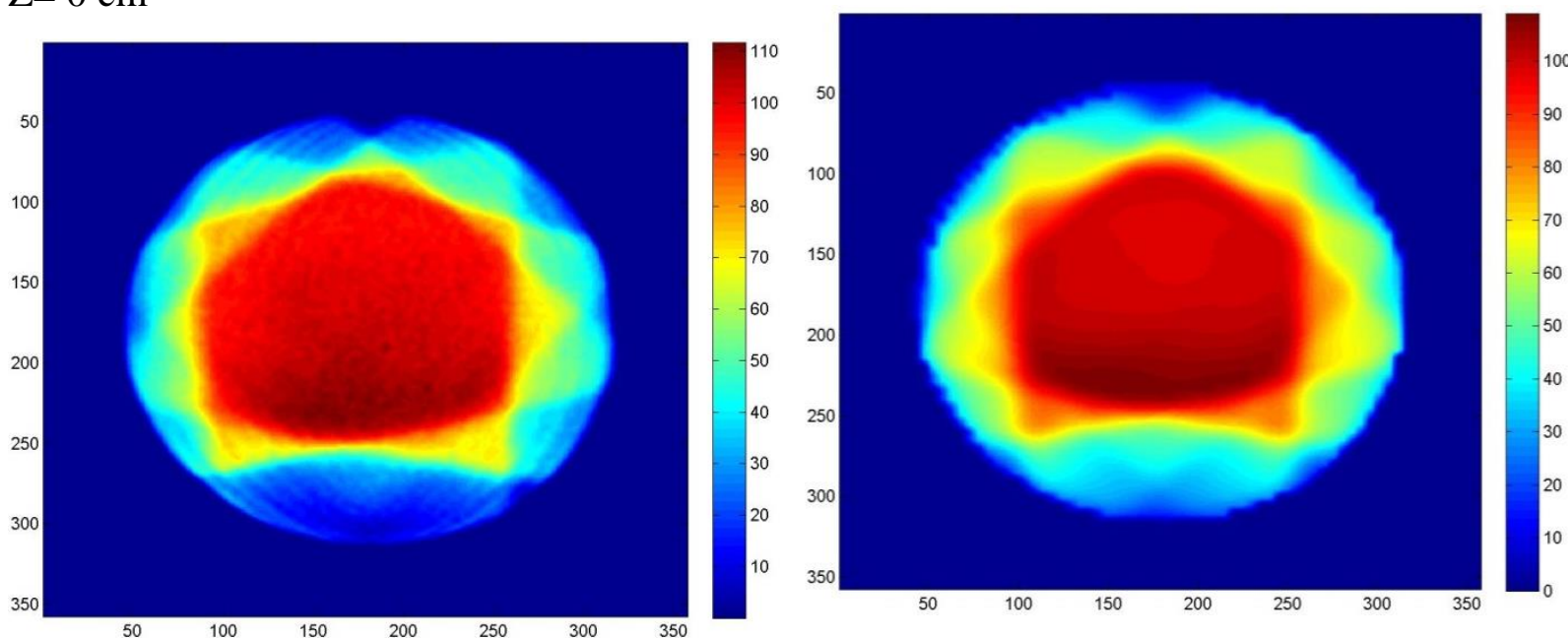

Figura 5.24: Distribuições de dose para os cortes no isocentro, medida e planejada.
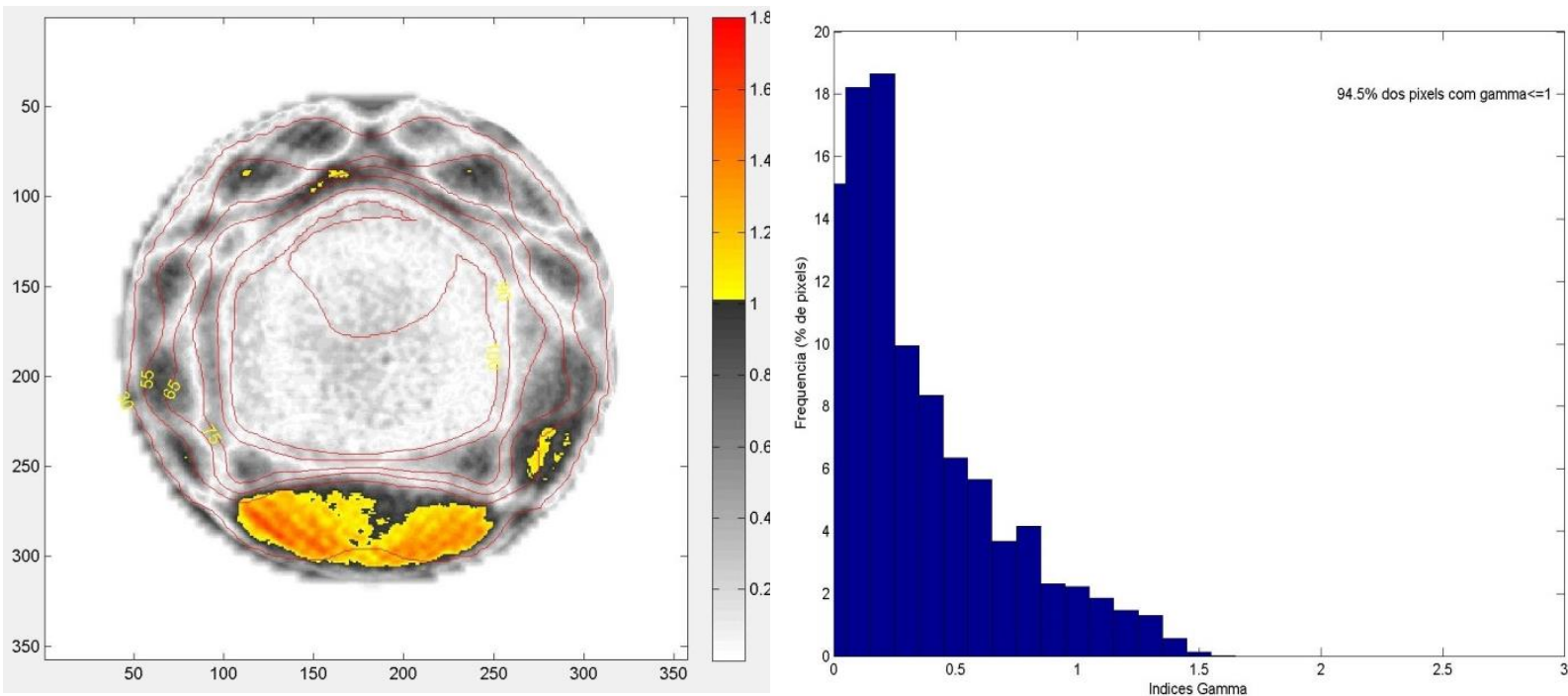

Figura 5.25: Mapa de índices gama e seu respectivo histograma de pixels para o isocentro, apresentando $94,5 \%$ dos pixels com $\gamma \leq 1$.

Tabela 5.18: Apresenta os índices gama para cada corte na posição respectiva

\begin{tabular}{|c|c|c|c|c|c|c|c|c|c|c|}
\hline \multicolumn{10}{|c|}{ Paciente 7 } \\
\hline Gama (\%) & 90,7 & 92,2 & 94,4 & 94,5 & 95,0 & 96,5 & 96,1 & 96,7 & 95,3 & 90,3 \\
\hline Z (cm) & $-3,0$ & $-2,0$ & $-1,0$ & 0,0 & 1,0 & 2,0 & 3,0 & 4,0 & 5,0 & 6,0 \\
\hline
\end{tabular}

\section{Análise das fatias com PTV}

Na direção cranial há PTV ate a posição $5,7 \mathrm{~cm}$ e na direção caudal até $2,4 \mathrm{~cm}$,então toda região onde há PTV foi avaliada e todos os cortes analisados estão acima da aceitação de $90 \%$ dos pixels com $\gamma \leq 1$ portanto o planejamento passa no controle de qualidade tridimensional. 
5.10 - Paciente 8

Controle de qualidade Pontual - Câmara de Ionização

Tabela 5.19: Leituras usando CI para o Paciente 8

\begin{tabular}{|c|c|}
\hline Dose Planejada (cGy) & 261,20 \\
\hline Dose Medida (cGy) & 260,58 \\
\hline Diferença Abs (cGy) & 0,62 \\
\hline Desvio (\%) & $-0,2$ \\
\hline
\end{tabular}

Controle de qualidade bidimensional - Mapcheck2

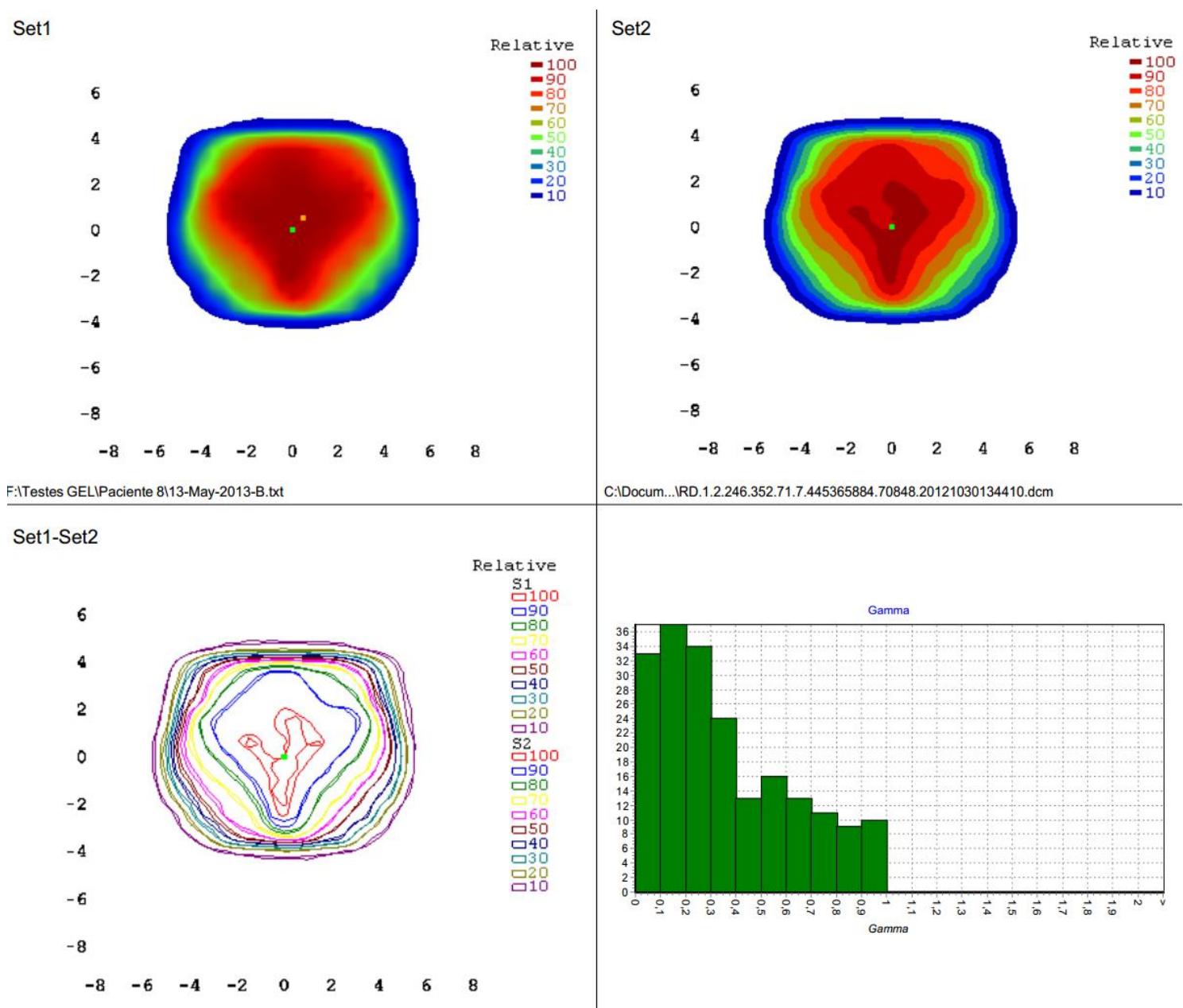

Figura 5.26: Distribuições de dose medida, planejada, sobreposição das isodose e histograma de Pixels com índice gama para o paciente 8 .

\section{Análise gama}

$100 \%$ dos pixels com $\gamma \leq 1$, o planejamento passa no controle de qualidade bidimensional. 


\section{Controle de qualidade Tridimensional - Gel Magic-f}

$\mathrm{Z}=0$
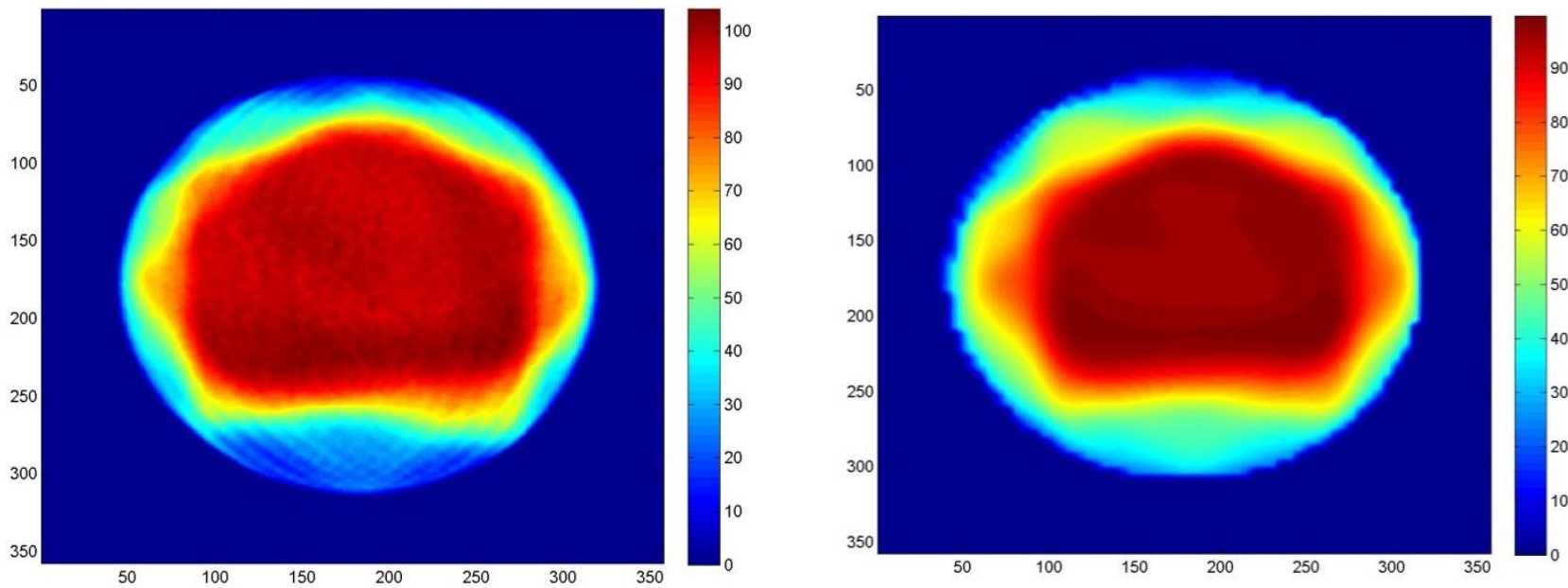

Figura 5.27: Distribuições de dose para os cortes no isocentro, medida e planejada
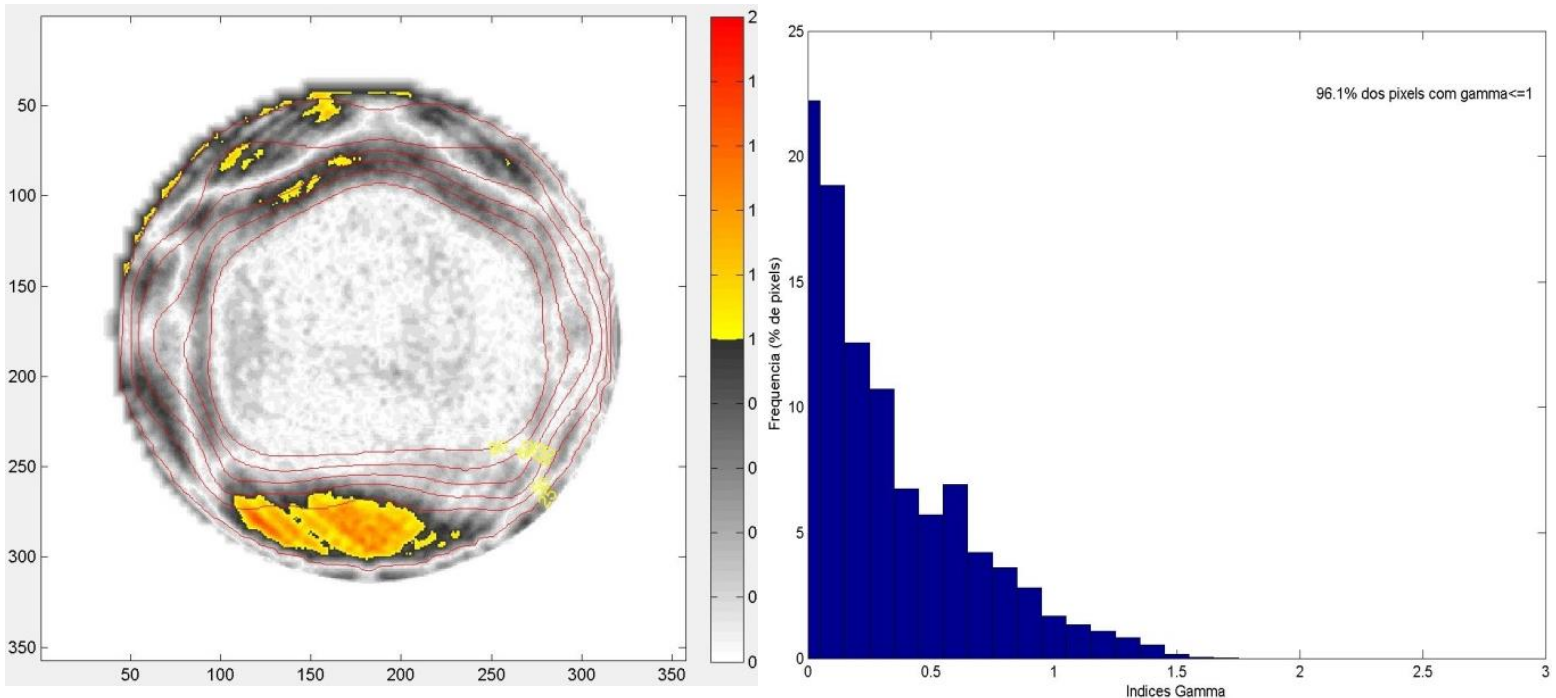

Figura 5.28: Mapa de índices gama e seu respectivo histograma de pixels para o isocentro, apresentando $94,5 \%$ dos pixels com $\gamma \leq 1$.

Tabela 5.20: Apresenta os índices gama para cada corte na posição respectiva

\begin{tabular}{|c|c|c|c|c|c|c|c|c|c|c|}
\hline \multicolumn{10}{|c|}{ Paciente 8 } \\
\hline Gama (\%) & 80,0 & 87,0 & 90,9 & 94,4 & 96,1 & 97,5 & 96,5 & 92,8 & 86,7 & 81,7 \\
\hline Z (cm) & $-3,0$ & $-2,0$ & $-1,0$ & 0,0 & 1,0 & 2,0 & 3,0 & 4,0 & 5,0 & 6,0 \\
\hline
\end{tabular}

\section{Análise das fatias com PTV}

Na direção cranial há PTV até a posição $3,6 \mathrm{~cm}$ e até 3,0 na direção caudal, onde os cortes na posição $-2,0$ e $-3,0 \mathrm{~cm}$ possuem PTV, nesse caso o planejamento para o paciente 8 falha nos $90 \%$ de aceitação e deve se investigar o porquê da falha, ou usar outros métodos para controle de qualidade(De Deene et al, 2012). 


\subsection{1 - Paciente 9}

Controle de qualidade Pontual - Câmara de Ionização

Tabela 5.21: Leituras usando CI para o Paciente 9

\begin{tabular}{|c|c|}
\hline Dose Planejada (cGy) & 303,40 \\
\hline Dose Medida (cGy) & 303,62 \\
\hline Diferença Abs (cGy) & $-0,22$ \\
\hline Desvio (\%) & 0,1 \\
\hline
\end{tabular}

Controle de qualidade bidimensional - Mapcheck2

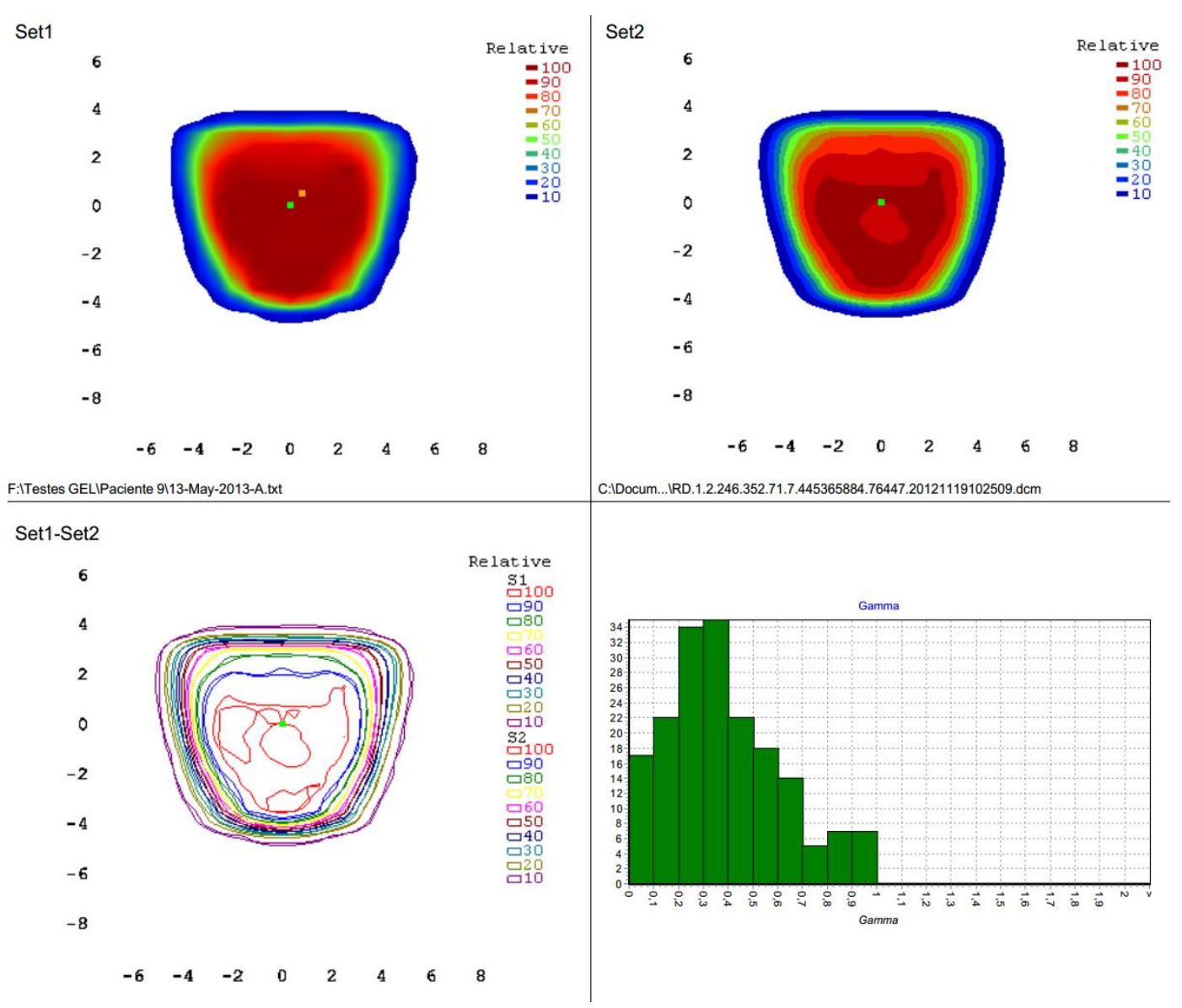

Figura 5.29: Distribuições de dose medida, planejada, sobreposição das isodose e histograma de Pixels com índice gama para o paciente 9.

\section{Análise gama}

$100 \%$ dos pixels com $\gamma \leq 1$, o planejamento passa no controle de qualidade bidimensional. 


\section{Controle de qualidade Tridimensional - Gel Magic-f}

$\mathrm{Z}=0 \mathrm{~cm}$
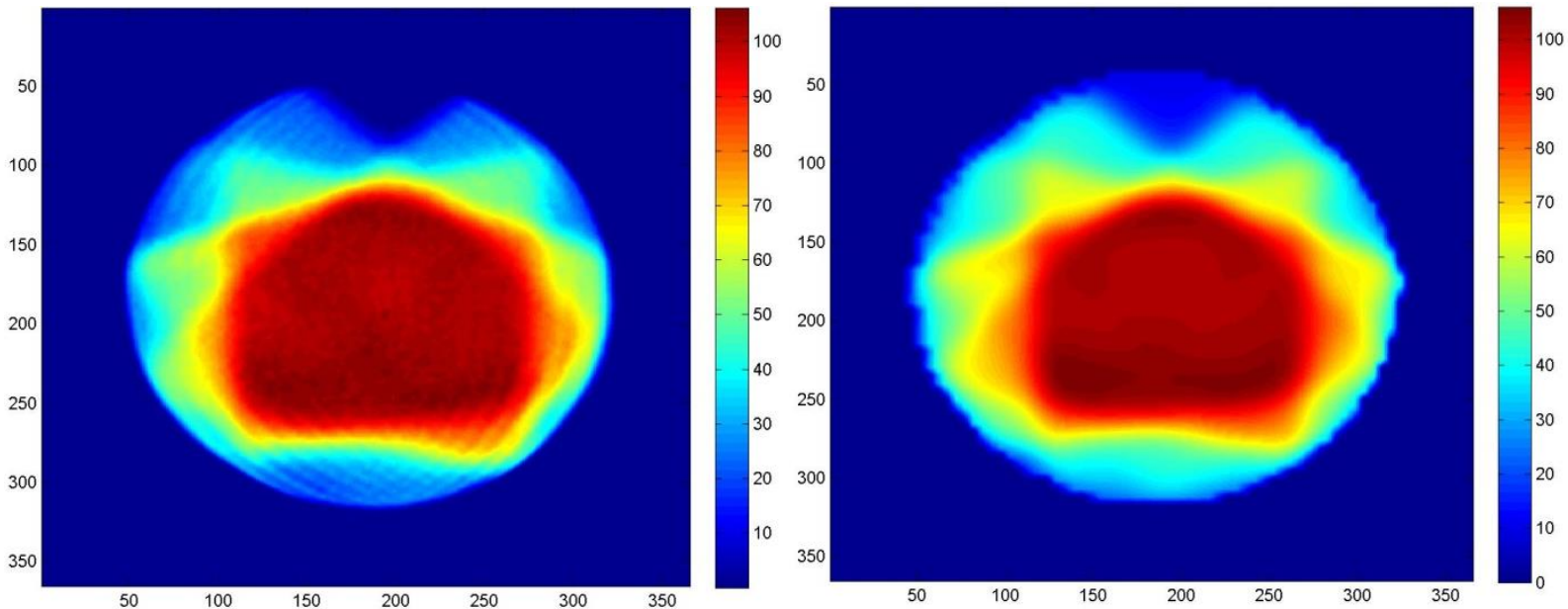

Figura 5.30: Distribuições de dose para os cortes no isocentro, medida e planejada.
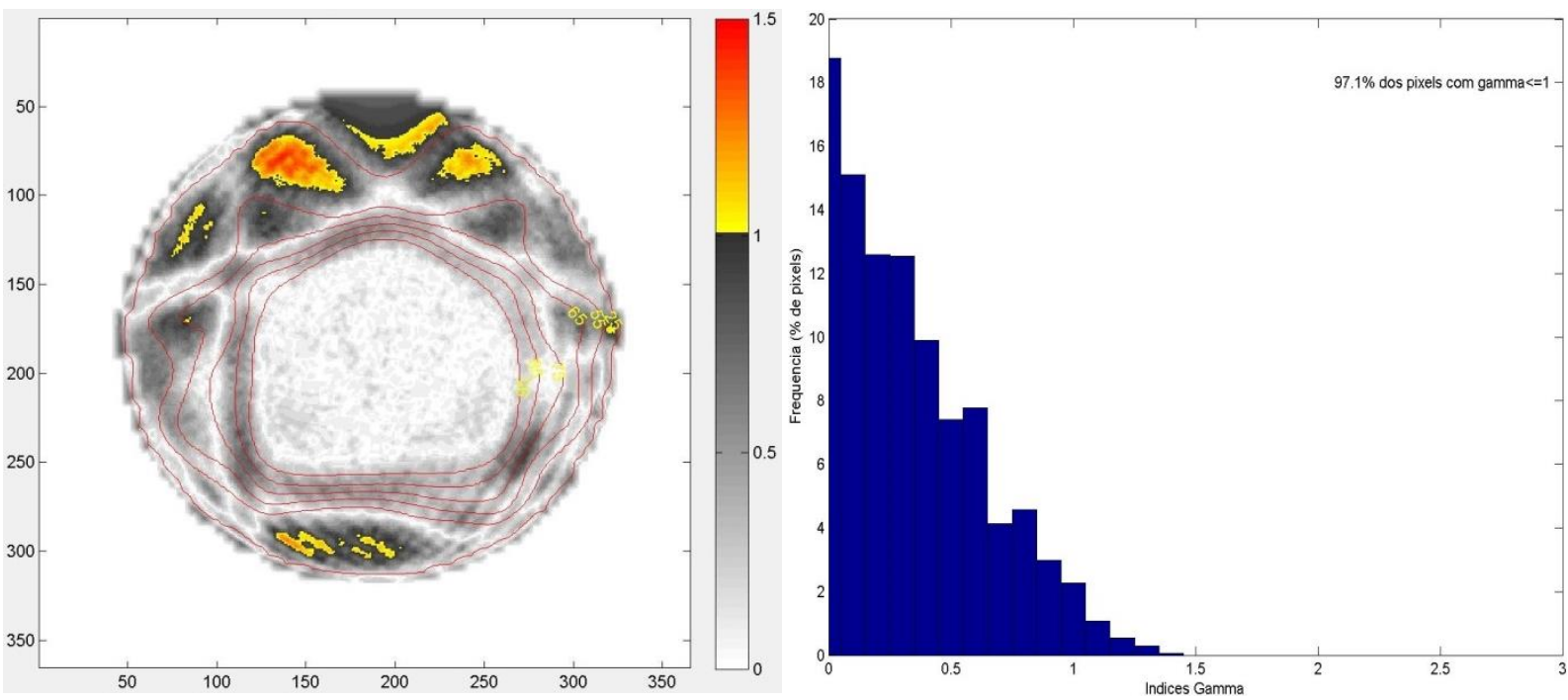

Figura 5.31: Mapa de índices gama e seu respectivo histograma de pixels para o isocentro, apresentando 97,1\% dos pixels com $\gamma \leq 1$.

Tabela 5.22: Apresenta os índices gama para cada corte na posição respectiva

\begin{tabular}{|c|c|c|c|c|c|c|c|c|c|c|}
\hline \multicolumn{10}{|c|}{ Paciente 9 } \\
\hline Gama (\%) & 96,2 & 97,2 & 96,2 & 97,2 & 95,8 & 92,2 & 91,2 & 94,2 & 94,8 & 79,9 \\
\hline Z (cm) & $-3,0$ & $-2,0$ & $-1,0$ & 0,0 & 1,0 & 2,0 & 3,0 & 4,0 & 5,0 & 6,0 \\
\hline
\end{tabular}

\section{Análise das fatias com PTV}

O PTV se localiza na direção cranial até a posição $3,9 \mathrm{~cm}$ e na direção caudal até 2,7 cm, então no corte situado na posição $6,0 \mathrm{~cm}$, que falha na aceitação de $90 \%$ dos pixels com gama $\gamma \leq 1$ não possui PTV, portanto o planejamento para o paciente 9 passa no controle de qualidade tridimensional. 


\subsection{2 - Paciente 10}

Controle de qualidade Pontual - Câmara de Ionização

Tabela 5.23: Leituras usando CI para o Paciente 10

\begin{tabular}{|c|c|}
\hline Dose Planejada (cGy) & 259,90 \\
\hline Dose Medida (cGy) & 259,11 \\
\hline Diferença Abs (cGy) & 0,79 \\
\hline Desvio (\%) & $-0,30$ \\
\hline
\end{tabular}

\section{Controle de qualidade bidimensional - Mapcheck2}

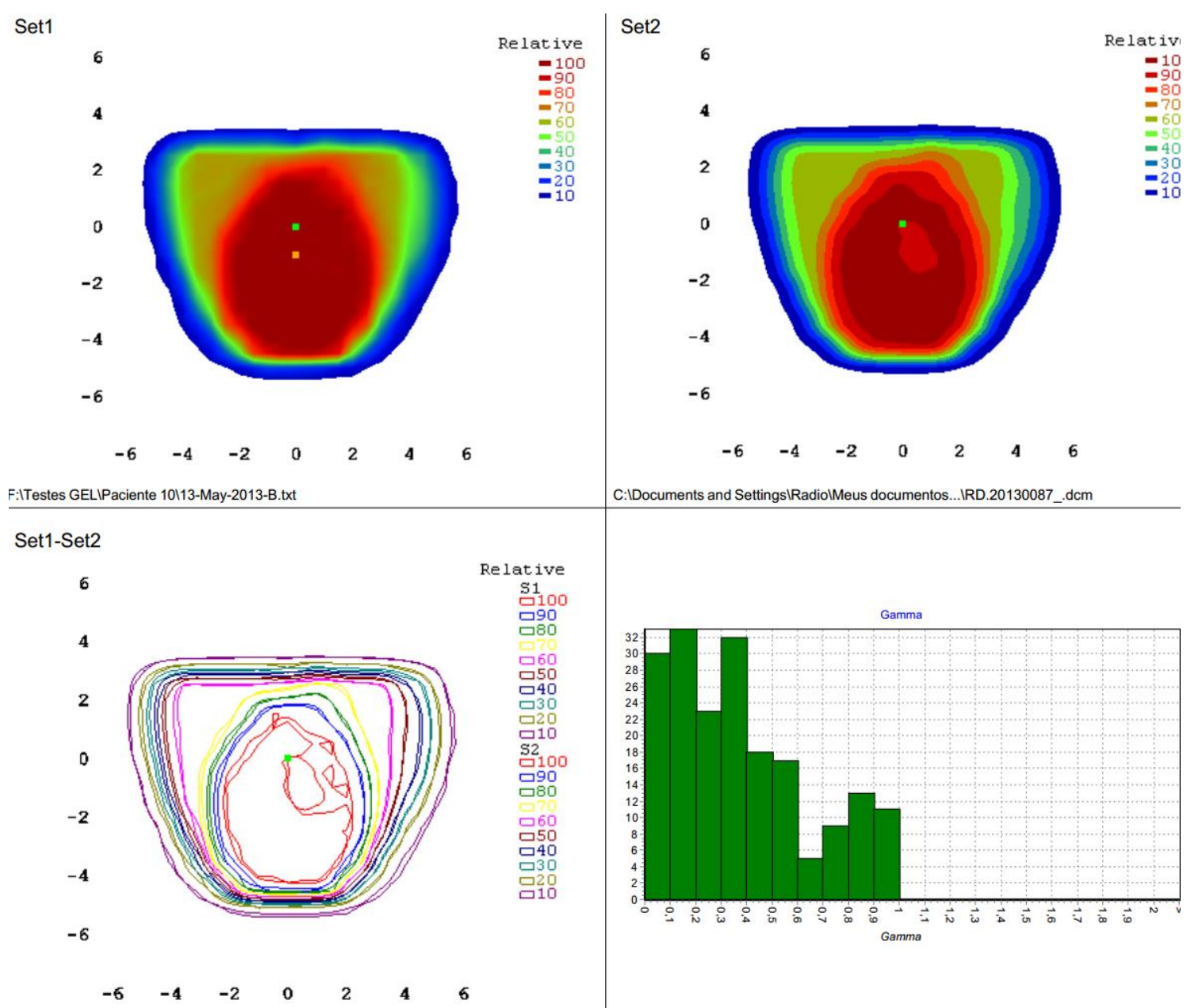

Figura 5.32: Distribuições de dose medida, planejada, sobreposição das isodose e histograma de Pixels com índice gama para o paciente 10.

\section{Análise gama}

$100 \%$ dos pixels com $\gamma \leq 1$, o planejamento passa no controle de qualidade bidimensional. 


\section{Controle de qualidade Tridimensional - Gel Magic-f}

$\mathrm{Z}=0 \mathrm{~cm}$
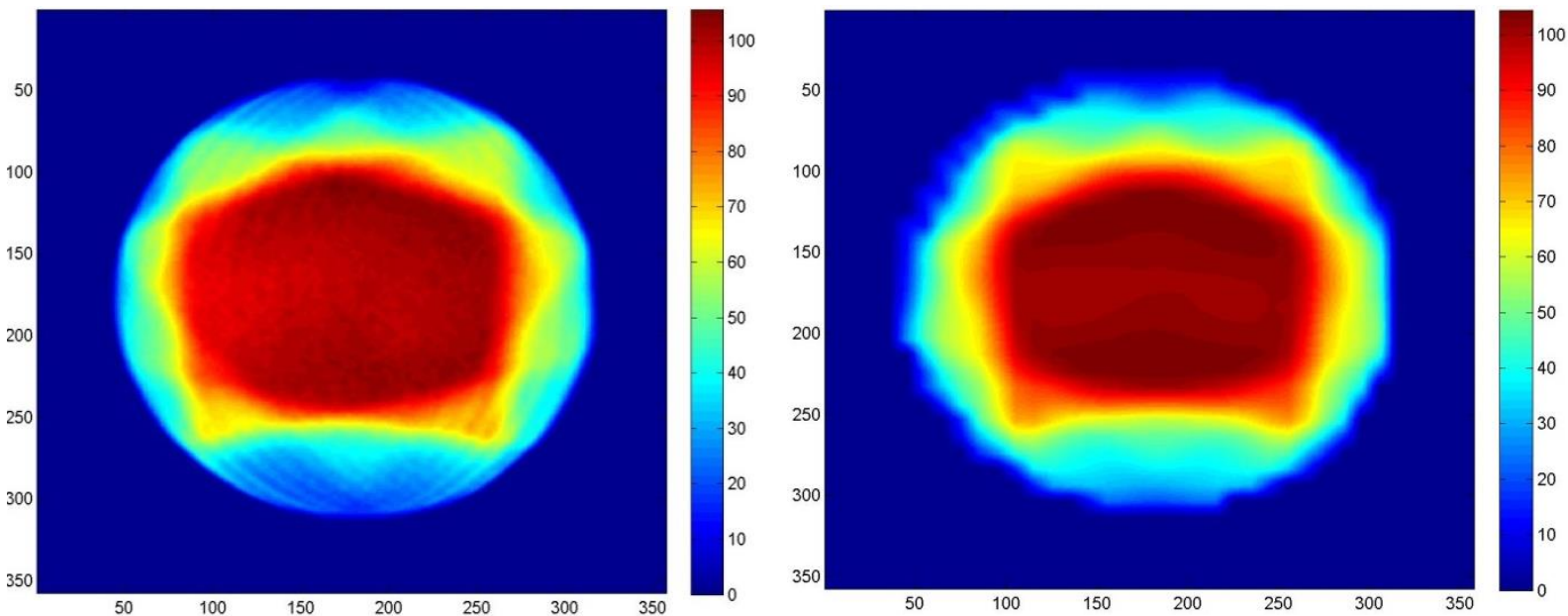

Figura 5.33: Distribuições de dose para os cortes no isocentro, medida e planejada.
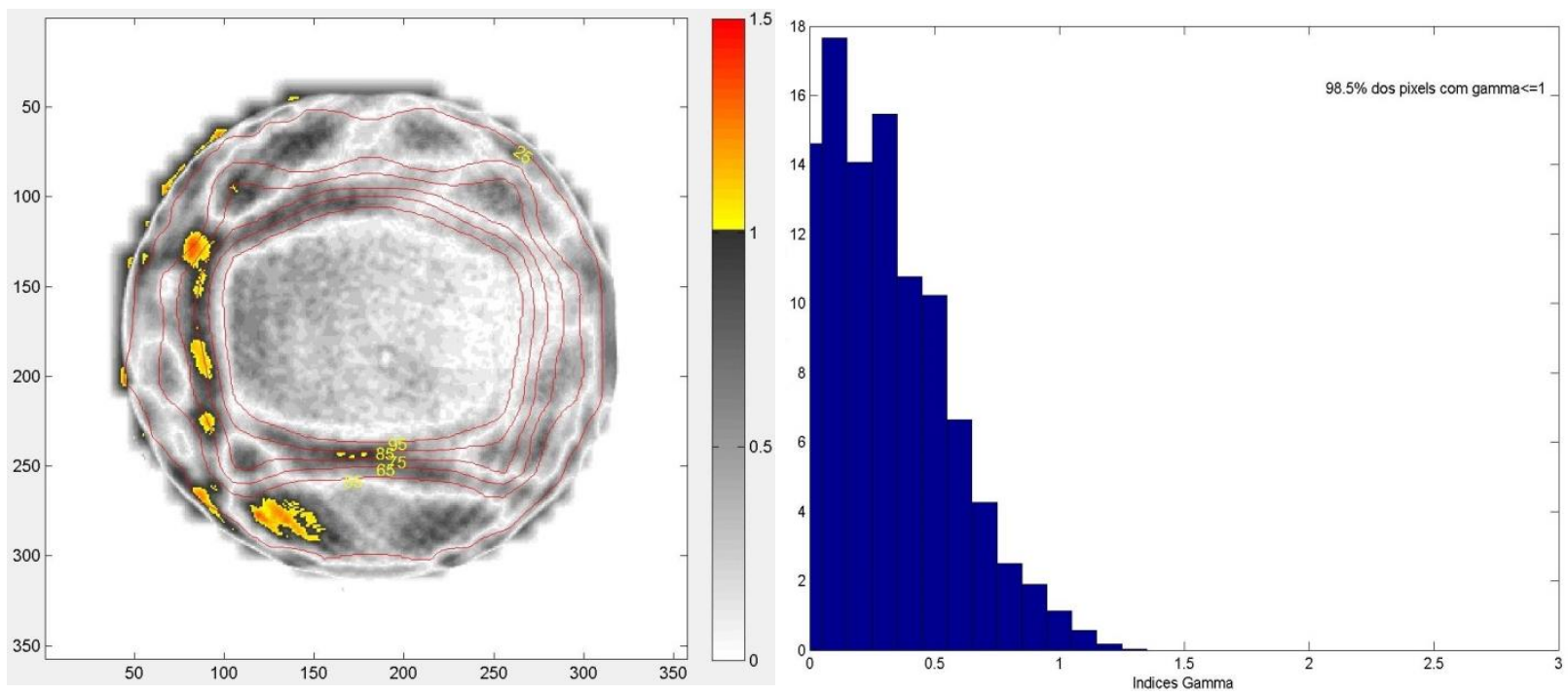

Figura 5.34: Mapa de índices gama e seu respectivo histograma de pixels para o isocentro, apresentando 98,5\% dos pixels com $\gamma \leq 1$.

Tabela 5.24: Apresenta os índices gama para cada corte na posição respectiva

\begin{tabular}{|c|c|c|c|c|c|c|c|c|c|c|}
\hline \multicolumn{10}{|c|}{ Paciente 10 } \\
\hline Gama (\%) & 95,3 & 98,1 & 97,2 & 98,5 & 94,9 & 95,7 & 95,8 & 95,9 & 94,9 & 87,0 \\
\hline $\mathbf{Z}(\mathbf{c m})$ & $-3,0$ & $-2,0$ & $-1,0$ & 0,0 & 1,0 & 2,0 & 3,0 & 4,0 & 5,0 & 6,0 \\
\hline
\end{tabular}

\section{Análise das fatias com PTV}

Na direção Cranial há PTV até a posição 4,5 cm e na direção caudal até a 2,4cm então o corte na posição $6,0 \mathrm{~m}$ que falha na aceitação de $90 \%$ dos pixels com gama $\gamma \leq 1$ não possui PTV. Os cortes que contem PTV possuem índices gama maior que $90 \%$ portanto o planejamento para o paciente 10 passa no controle de qualidade tridimensional. 


\subsection{3 - Discussões dos resultados}

\subsection{1 - Considerações gerais dos resultados}

A dosimetria usando gel Magic-f se mostrou reprodutivo no conjunto de experimentos, apresentando sensibilidade de 0,37 e 0,36 1/Gy.s com uma diferença percentual de $2,7 \%$ para um conjunto de dez experimentos.

Os resultados com os controle de qualidade usuais, câmara de ionização e o MapCHECHK2 passaram nos controles de qualidades sendo que os resultados apresentados com a câmara de ionização apresentam apenas pequenos desvios dentro do critério de tolerância de $\pm 3 \%$ na diferença percentual na dose absoluta. As distribuições de dose obtidas com o MapCHECK2, qualitativamente apresentam semelhanças entre as distribuições calculadas e medidas pelo detector e quantitativamente avaliado pelo cálculo dos índices gama pixel a pixel em todos os planejamentos avaliados $100 \%$ dos pixels avaliados passam nos critérios de tolerância $\pm 3 \%$ e $\pm 3 \mathrm{~mm}$, o padrão em radioterapia.

Para complementar esses resultados, nesse trabalho foram introduzidos aos planejamentos o controle de qualidade tridimensional pela dosimetria gel usando gel Magic-f e a leitura por ressonância magnética nuclear. Os dez planejamentos irradiados nos objetos simuladores foram exportados de pacientes reais em que os tratamentos foram bem sucedidos na realidade, então o esperado é que o teste o controle de qualidade tridimensional também seja bem sucedido. Qualitativamente todos os cortes apresentaram grande semelhança entre as distribuições planejadas e medidas. O esperado pelo controle de qualidade com a dosimetria gel é que os resultados também passem na avaliação do índice gama, com critérios de tolerância de $\pm 3 \%$ e $\pm 3 \mathrm{~mm}$. Fazendo as médias das porcentagens de índices gama de cada corte em cada paciente, todos ficaram acima de $90 \%$ dos pixels com gama $\leq 1$ figura (8.1). 


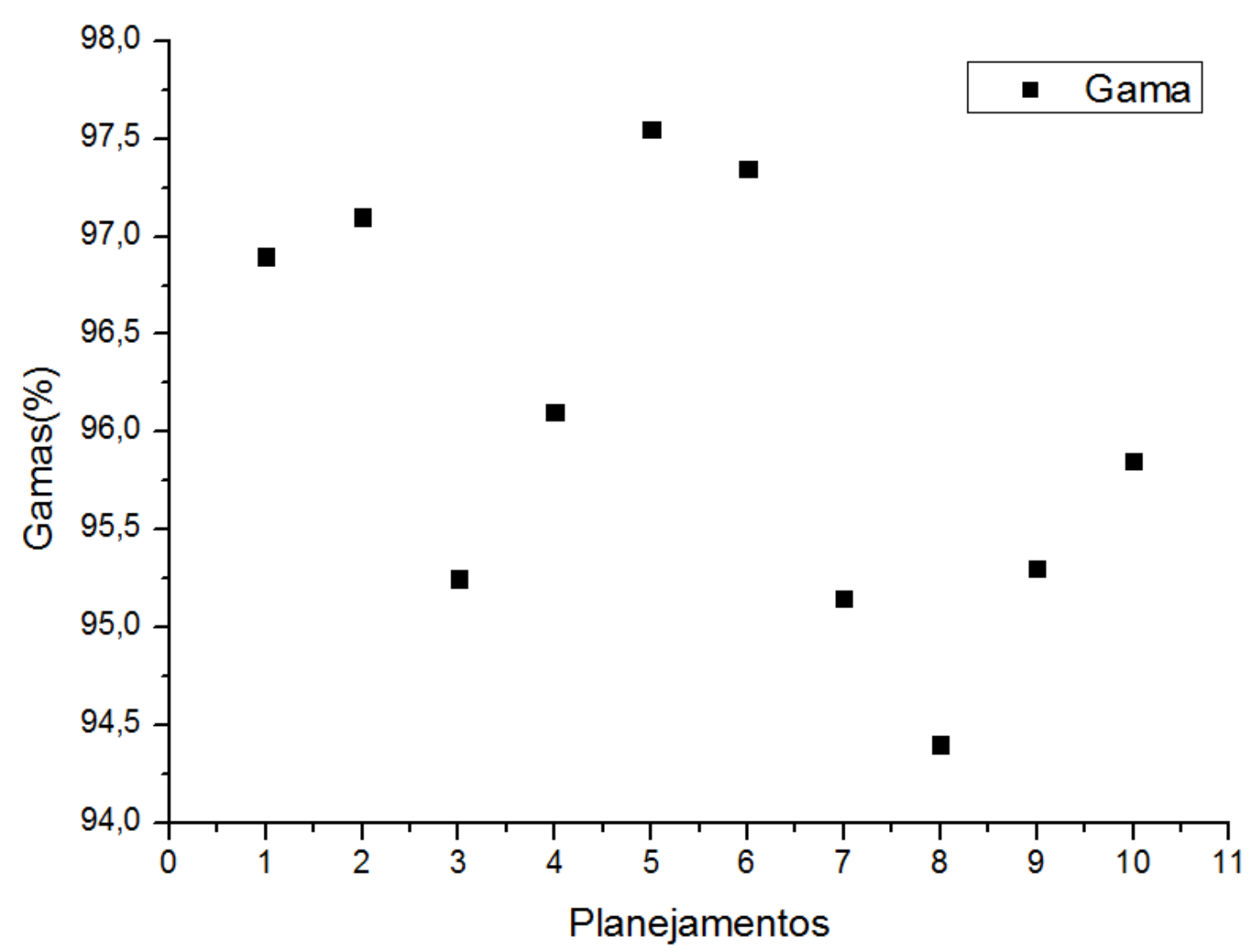

Figura 5.35: Médias da porcentagem de índices gama em cada paciente.

\subsection{2 - Análise dos resultados em cada paciente dos resultados}

Para o Paciente 1 os resultados apresentados foram de forma mais detalhada, mostrando as distribuições de dose em todos cortes obtidos. Na avaliação qualitativa em todos os cortes adquiridos ao longo do objeto simulador, há grande semelhança entre as distribuições planejadas e o medidas, verificada também pela sobreposição dos perfis de dose no isocentro. Os histogramas de pixels para o mapa de índices gama mostraram que apenas um corte não passa na aceitação de $90 \%$ e esse corte não possui o PTV. Os mapas de índices gama apresentados mostram que nas regiões de alto gradiente de dose, 95\%, sempre apresentam índices gama $\leq 1$.

Em todos os planejamentos os cortes que possuem o PTV apenas o paciente 8 possui dois cortes que falham com menos de 90\%. Para visualizar essa falha se considerar-se as médias de porcentagens de índices gama dos cortes com o PTV e considera-se como aceitação $95 \%$ com gama $\leq 1$ mostrado na figura 8.2. 


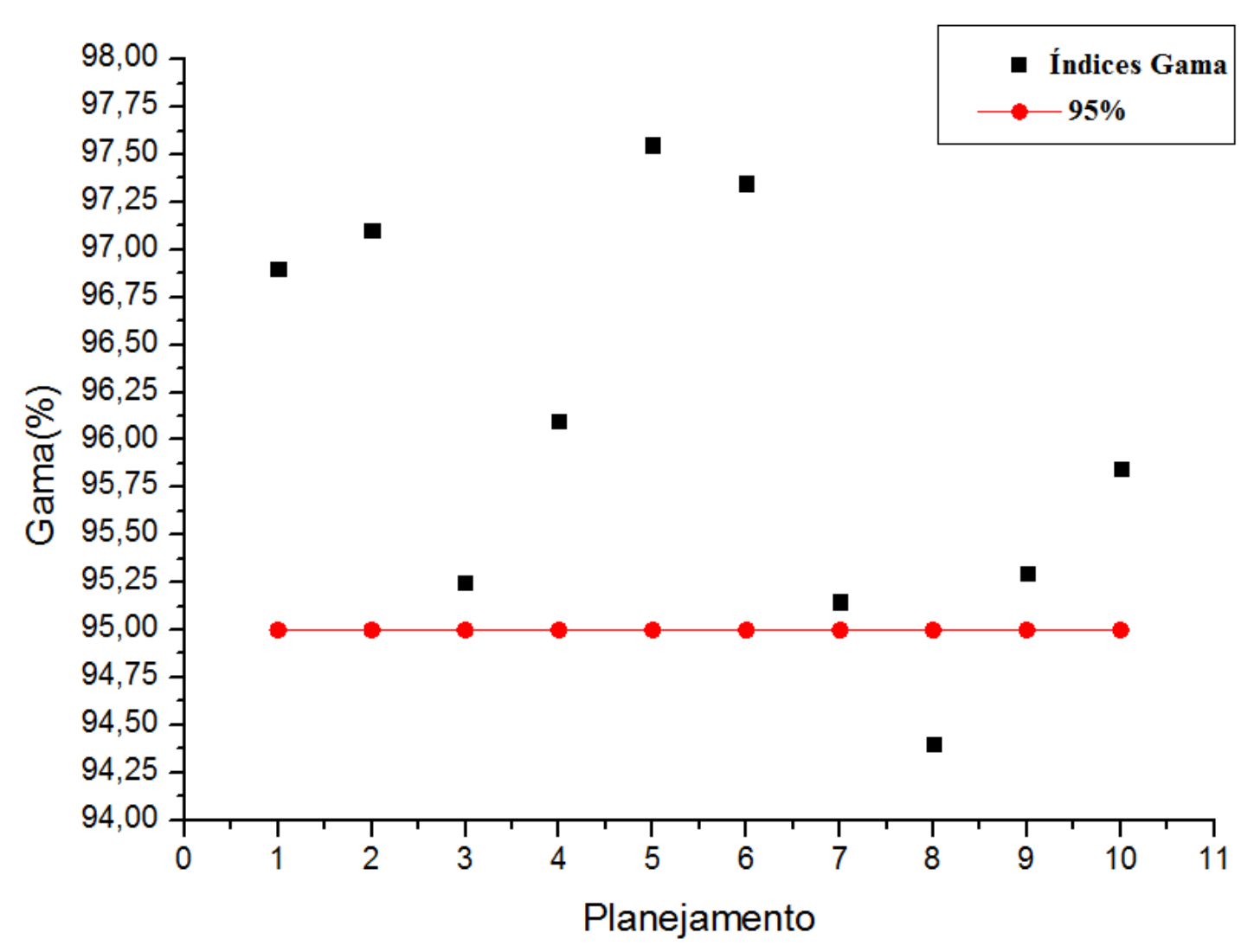

Figura 5.36: Média da porcentagem de índices gama índices gamas em relação a cada paciente.

O gráfico na figura 5.13.2 mostra que fazendo as médias das fatias com PTV apenas o paciente 8 fica abaixo dos $95 \%$ de aceitação. Enfim o paciente 8 falharia no teste tridimensional, mas passando nos testes pontual e bidimensional é liberado para o tratamento. Na literatura, De Deene et al, 2012 , sugere que quando a dosimetria 3D falha o controle de qualidade com gel deve-se se averiguar se o mesmo passa em outro controle de consolidado, como nesse trabalho se passa, caso contrário o planejamento para a região deveria ser refeito. Para esse paciente o controle de qualidade com a câmara de ionização avaliou na região homogenia de alto gradiente de dose, e o Mapcheck avalia a fluência de cada campo, o paciente passa om $100 \%$ dos pixels com gama $\leq 1$ e avaliando os cortes que falham na dosimetria gel, na região de alto gradiente de dose, os pixels não falham, o que leva a concluir que para esse paciente o planejamento do tratamento ainda seria aprovado. 


\subsection{3 - Considerações com os trabalhos apresentados na literatura}

$\mathrm{Na}$ literatura, os trabalho com géis encontrados (Ceberg et al, 2010), fez a verificação com dosimetria 3D usando gel PAG e simulação de Monte Carlo em tratamento de câncer de próstata usando Rapid Arc, há grande semelhança entre o calculado e o medido pelo gel, mas nessa comparação é usado um limiar de dose (threshold) em regiões de 50\% ou apenas a região de $90 \%$ de dose, além de se utilizar uma máscara na região de interesse. Os resultados das porcentagens de índices gamas nas regiões foram obtido com dois critérios, um de 3\% / 3mm e outro critério mais flexível de 5\%/5mm. As porcentagens de índices gama $\leq 1$ foram acima dos $95 \%$ nos critérios de $3 \%$ e $5 \% / 5 \mathrm{~mm}$.

Outro trabalho com gel feito por Zijtveld (Zijtveld et al, 2010) utilizando dosimetria 3D pelos feixes cônico de CT para planejamentos de câncer de próstatas em dez planejamentos obteve resultados de $98,5 \%$ do pixels com índice gama $\leq 1$ no isocentro mas usando threshold de na isodose de $50 \%$.

Em 2012 (Fernandes et al,2012) avaliou a um tratamento de próstata com tomoterapia e a análise gama com critérios $3 \% 3 \mathrm{~mm}$ e $4 \% / 4 \mathrm{~mm}$ utilizando sequencia spin eco para medir R2, os resultados ficaram passaram com o critério 4\%/4mm.

Comparando nosso trabalho com os trabalhos da literatura apresentados anteriormente os resultados estão bons, pois nesse mesmo não se usa nenhum limiar de dose,e ás médias das porcentagens com índices gama considerando todas as fatias ficam acima de $90 \%$ e considerando o PTV apresentam resultados acima de 95\% desconsiderando o paciente 8 que mostra $94,5 \%$ nas médias devia a falhar fatias com PTV.

Considerando as distribuições do paciente 1 utilizando thresholds de 20\%, 30\%, $40 \%, 50 \%$ e $85 \%$ apresentados na tabela 5.11.3, nenhum dos cortes apresenta porcentagens de índices menor que $90 \%$ dos pixel com gama $\leq 1$. 
Tabela 5.25: Índices Gama para o Paciente 1 com limiares de $20 \%$ a $85 \%$.

\begin{tabular}{|c|c|c|c|c|c|c|c|c|c|c|c|}
\hline \multicolumn{10}{|c|}{ Paciente 1- Limiar de doses } \\
\hline Z (cm) & -3 & -2 & -1 & 0 & 1 & 2 & 3 & 4 & 5 & 6 \\
\hline $\mathbf{2 0 \%}$ - Gama (\%) & 93,3 & 97,1 & 97,7 & 98,8 & 98,6 & 99,0 & 99,4 & 97,9 & 98,3 & 95,4 \\
\hline $\mathbf{3 0 \%}$ - Gama (\%) & 93,9 & 97,2 & 98,0 & 99,0 & 98,7 & 99,3 & 99,5 & 98,1 & 98,5 & 96,5 \\
\hline $\mathbf{4 0 \%}$ - Gama (\%) & 95,8 & 98,3 & 98,1 & 99,2 & 98,8 & 99,4 & 99,6 & 98,2 & 99,0 & 97,2 \\
\hline $\mathbf{5 0 \%}$ - Gama (\%) & 98,7 & 98,8 & 98,5 & 99,3 & 99,1 & 99,8 & 99,6 & 99,7 & 99,6 & 98,4 \\
\hline $\mathbf{8 5 \%}$ - Gama (\%) & 100,0 & 100,0 & 100,0 & 100,0 & 100,0 & 100,0 & 100,0 & 100,0 & 100,0 & 100,0 \\
\hline
\end{tabular}

Quando se aplica um limiar na isodose de $20 \%$ temos nenhum dos cortes falham em $90 \%$ de aceitação. Por exemplo, no paciente 1, na tabela 5.11.3, o corte na posição na posição $6,0 \mathrm{~cm}$ que falhava com $89,7 \%$ dos pixels passou a ser a 95,4\%. A média da porcentagem de índices gama de todos os corte passa a ser 98,1\% e considerando apenas os cortes onde há PTV tem-se 98,5\% de média. Apresentando nossos resultados utilizando limiar na isodose de 50\% temos resultados para a porcentagens de pixels com gama $\leq 1$ acima dos $95 \%$, A média dos das porcentagens de índices gama considerando todos os cortes passa de 96,7 para 99,2\% e apenas as fatias com PTV de $96,9 \%$ para $99,6 \%$. E usando um limiar maior como de $85 \%$, todos os cortes passam com $100 \%$ dos pixels aprovados, mostrando que na região de alta dose esta de acordo com o planejado. Essas porcentagens resultantes quando se usam limiares estão de acordo com o que se encontra na literatura nos artigos citados anteriormente. 


\section{Capítulo 6 - Conclusão e consideracões finais}

Nesse trabalho foi utilizada a dosimetria gel, como controle de qualidade tridimensional junto aos controles de qualidade convencionais: pontual e bidimensional, ou seja, câmara de ionização e o MapCHECK $2^{\circledR}$. Esses controles de qualidade foram feitos em dez planejamentos para tratamentos de câncer de próstata pertencentes a pacientes reais, que todos foram bem sucedidos.

Qualitativamente, os resultados encontrados com o controle de qualidade tridimensional, realizado com a dosimetria gel, indicaram grande semelhança entre as distribuições planejadas pelo sistema de planejamento $\left(\right.$ Eclipse $\left.^{\circledR}\right)$ e as distribuições de dose medidas pelas imagens por ressonância magnética (IRM).

Para determinar a aprovação ou reprovação de cada planejamento foi utilizado o cálculo do índice gama entre os cortes planejados e medidos com os critérios 3\%/3mm, o padrão em radioterapia. Para a aprovação foi considerado $90 \%$ dos pixels com gama $\leq$ 1, sendo assim, apenas o paciente 8 apresentou cortes com o PTV em que essa aceitação falhava, o que levaria ao replanejamento da região, ou a avaliação por outros controles de qualidade. Os cortes nos demais planejamentos em que se encontrava o PTV passaram no controle de qualidade tridimensional, o que era esperado já que os planejamentos passaram nos controle de qualidades convencionais. As médias dos índices gama dos cortes em que possui o PTV em cada planejamento, foram encontrados valores acima de $95 \%$ porcentagens de pixels com gama $\leq 1$ com exceção do paciente 8 , que possui regiões reprovadas com o PTV.

Quando comparados os resultados aqui encontrados com os resultados da literatura, verifica-se uma alta aprovação na porcentagem de índices gama sem usar limiar de dose (thresholds), avaliando assim toda a região do objeto simulador irradiado. Quando usado um limiar de dose é utilizado o resultado encontrado segue o mesmo padrão da literatura, acima dos $95 \%$ de aceite nas rotinas clínicas, por exemplo, no paciente 1 na isodose de $20 \%$, com média de $98,1 \%$ dos pixels com gama $\leq 1$.

Os resultados aqui apresentados nos levam a concluir que a dosimetria gel utilizando o gel Magic-f associado à leitura por imagem ressonância por magnética no controle de qualidade tridimensional complementa os controles de qualidade convencionais, devido à informação volumétrica apresentada. Além disso, podemos afirmar que a dosimetria gel, pode ser utilizada em clínicas como um método de 
dosimetria confiável para determinação das distribuições de dose tridimensionais e validação tridimensional dos sistemas de planejamento. 


\section{$\underline{\text { Referências Bibliográficas }}$}

ALVA M, MARQUES T, GONÇALVES L, PIANOSCHI T, BAFFA O, NICOLUCCI P. Caracterização da evolução temporal do sinal de RMN do gel MAGIC-f: Linearidade e estabilidade dosimétrica. Anais do XIV Congresso brasileiro de Física Médica, São Paulo, 2009.

BALDOCK C, BURFORD RP, BILLINGHAN, WAGNER GS, PATVAL S, BADAWI RD, KEEVIL SF. Experimental procedure for de manufacture of polyacrylamide ge(PAG) for magnetic resonance imaging(MRI) radiation dosimetry. Physics in Medicine and biology, v. 43, p. 695-702, 1998.

BALDOCK C, DE DEENE Y, DORAN S, IBBOTT G, JIRASEK A, LEPAGE M, MCAULEY KB, OLDHAM M, SCHREINER LJ. Polymer gel dosimetry. Physics in medicine and biology, v. 55, p. R1-R63, 2010.

CERBERG S, GAGNE I, GUSTAFSSON H, SHERMAN JB, KORREMAN SS,KJAER-KRISTOFFERSEN F, HILTS M, BACK S. RapidArc treatment verification in 3D using polymer gel dosimetry and Monte Carlo simulation. Physics in Medicine and Biology, v. 55, p. 4885-4898, 2010.

CHILDREES N., ROSON I., The Desingn ans testing of novel clinical parameters for dose comparison. Int. J. Radiation Oncology Phys. v. 56, p.1464-1479, 2003

DE DEENE Y, BALDOCK C. Optimization of multiple spin echo sequences for 3d polymer gel dosimetry. Physics in Medicine and Biology, v. 47, p. 3117-3141, 2002.

DE DEENE Y., VANDECASTEELE J. On the reability of 3D gel dosimetry. IC3DDose 2012 - 7 th International Conference on 3D Radiation Dosimetry, 2012.

FERNANDES,J., BAFFA,O.. An evaluation of dosimetric characteristics of MAGIC gel modified by adding formaldehyde (MAGIC-f). Radiation Measurements, v. 47. , p. 1074-1082, 2012.

FERNANDEs, J, ARAUJO D, PASTORELLO B, BAFFA O. Formoldehyde increases Magic gel dosimeter melting point an sensitivuty. Physics in medicine and Biology, v. 53, p. 53-58, 2008.

FERNANDEZ,J; PIKE,T; SNOW,J; DEWERD,L; BAFFA,O. Tomotherapy dose distribution verification using MAGIC-f polymer gel dosimetry. Medical Physics, v. 39, p. 2877-2844., 2012.

FONG PM, KEIL DC, DOES MD, GORE JC. Polymer gels for magnetic resonance imaging of orradiation dose distribuitions at normal room atmosphere. Medical physics, v. 46, p. 3105-3113, 2001.

GUSTAVSSON H, KARLSSON A, BACK SAJ, OLSSON LE, HARALDSSON P, ENGSTROM P, NYSTROM H. MAGIC-type polymer gel for three-dimentional 
dosimetry: Intesity-modulated radiation therapy verification. Medical Physics, v. 30, p. 1264-1271, 2003.

HARMS, WB; LOW,D;, MUTIC,S; PURDY,JA. A technique for the quantitative evaluation of the dose distribuitions. Medical Physics, v. 25, p. 6656-661, 1998.

LOW D, DEMPSEY J. Evaluation of the gamma dose distribution comparation method”. Medical Physics, v. 30, p. p2455-2464, 2003.

Marquez T

MANO E.,MENDES C. Introdução a polímeros. Edgad Bluncher Itda,1999.

MARYANSKY MJ, GORE JC,KENNAN RP, SCHULZ RJ.. NMR relaxation enhancement in gels polymerized and cross-linked by ionizing radiation: a new approach to 3d dosimeters by MRI. Magnetic resonance imaging, v. 39, p. 1437-1455, 1993.

MARYANSKY MJ, SCHULZ RJ,IBBOTT GS,XIE J, HORTON D,GORE JC. Magnetic resonance imaging of radiation dose distribuitions using a polymer-gel dosimeter. Physics in Medicine and Bioly, v. 39, p. 1437-1455, 1994.

PAVONI J,BAFFA O. Dosimetria tridimensional usando o Gel MAGIC com Formaldeído. Revista Brasileira de Física Médica, v. 4, p. 15-28, 2010.

TOFTS P.,Quantitative MRI of the Brain. Wiley1999

REDDY GG, NAGABHUSHANAM T, VENKATA RK, SANTAPPA M. polymerization of methylmethacrylate in the presence of moleular oxygen. Polymer, $v$. 22, p. 1692-1698, 1982.

STOCK M , KROUPA B, GEORGE D. Interpretation and evaluation of the $\gamma$ index and the gama index angle for verification of IMRT hybrids plans. Physics in medicine and Biology,v.50, p. 399-411,2005.

VENNING A, HEALY B, NITSCHKE K,KEALL PJ, BALDOC C. Radiological properties of the normoxid polymer gel dosimeters. Medical Physics, v. 32, p. 1047$1053,2005$.

VAN DYK J, BARNETT B.R. CYGLER E.J.,SHRAGGE P.C. Commissioning and quality assurance of treatment planning computers, Int. J. Radiat. Oncol biol Phys, v.26, 261-273, 1993

ZIJTVELD V.M.,DURKX M., BREUUERS M., KUIPERS R. HEIJMENB

B.,Evaluation of the 'dose of day' for IMRT prostate cancer patients derived from portal dose measurements and cone-beam CT. Radiotherapy and Oncology.v. 96,172177.2010. 